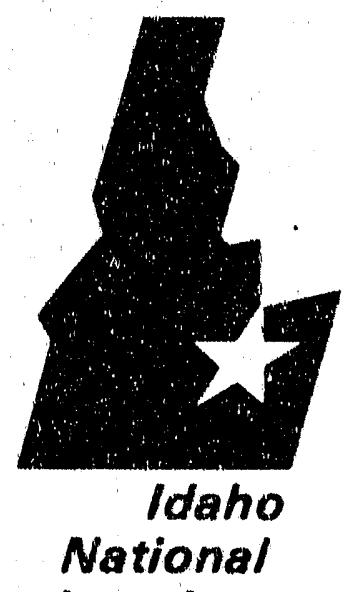

Engirneering

Laboratory

\section{Managed}

by the U.S.

Department

of Energy
EGG-NE-10289

July 1992

INFORMAL REPORT

Countercurrent Flow-limiting Characteristics of a Savannah River Plant Control Rod Septifoil

James L. Anderson

4.

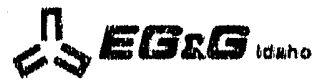

Wark performas under

DOE Contract

NO. DE.ACO7.761001570 


\title{
Countercurrent Flow-limiting Characteristics of a Savannah River Plant Control Rod Septifoil
}

\author{
James L. Anderson
}

July 1992

\author{
Idaho National Engineering Laboratory \\ EG\&G Idaho, Inc. \\ P. O. Box 1625 \\ Idaho Falls, Idaho 83415-2404
}

Prepared for the

U. S. Departmert of Energy

Assistant Secretary for Defense Programs

Under DOE Field Office, Idaho

Contrast DE-AC07-761D01570 
Countercurrent Flow-limiting Characteristics of a Savannah River Plant Control Rod Septifoil

Prepared by:

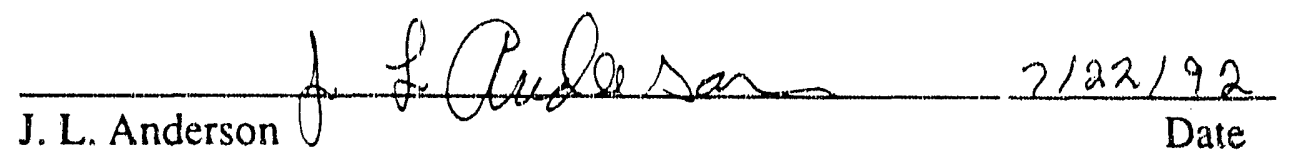

Reviewed by:

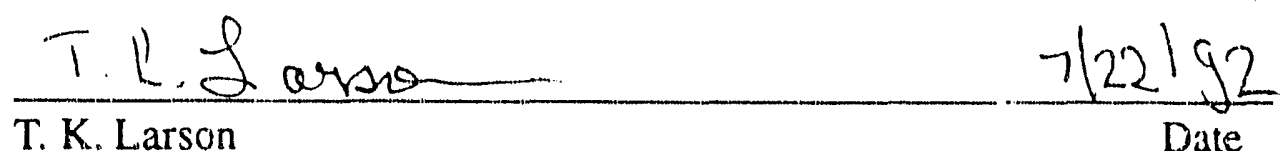

Approved by:
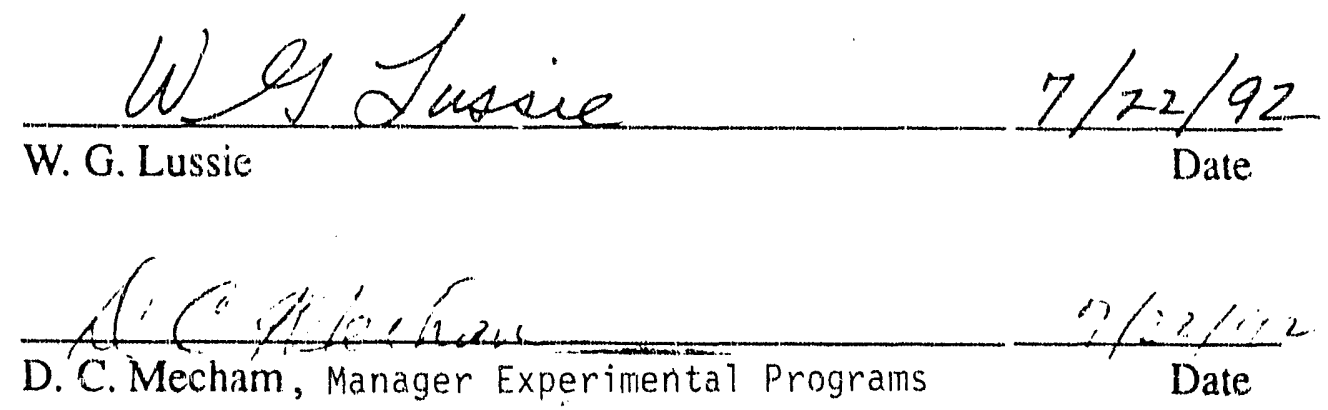

iii 


\section{ABSTRACT}

Experiments were performed at the Idaho National Engineering Laboratory to investigate the countercurrent flow limiting characteristics of a Savannah River Plant control rod septifoil assembly. These experiments were unheated, using air and water as the working fluids. Results are presented in terms of the Wallis flooding correlation for several different control rod configurations. Flooding was observed to occur in the vicinity of the inlet slots/holes of the septifoil, rather than within the rod bundle at the location of the minimum flow area. Nearly identical flooding characteristics of the septifoil were observed for configurations with zero, three, and four rods inserted, but significantly different results occurred with 5 rods inserted. 


\section{EXECUTIVE SUMMARY}

Experiments were performed at the Idaho National Engineering Laboratory (INEL) to investigate the countercurent flow-limiting (CCFL) characteristics of a type-Q control rod septifoil assembly at the Savannah River Plant (SRP). It has been postulated that a potential accident scenario is for a septifoil coolant line to become partially or totally blocked during normal reactor operation. In this scenario, the only cooling available for the control rods (being heated from the gamma and neutron flux in the reactor) would be by conductive heat transfer through the septifoil housing and water entering the septifoil from the moderator tank through the slots and holes at the top of the septifoil. The latter mechanism would be influenced by the CCFL characteristics of the septifoil. In order to predict the temperatures of the control rods resulting from this accident sce. nario, the amount of coolant entering the septifoil must be calculated. Becuase the coefficients used in the correlations for predicting the CCFL flowrates are geometry dependent, and could have a wide range of values, a set of experiments was performed to obtain the values of the correlation coefficients for several different control rod configurations. These experiments were performed using air and water as the working fluids.

The septifoil contains seven rods: two cadmium control rods that are completely withdrawn on reactor startup, and three full-length and two partial-length lithium-aluminum control rods that are at axial positions depending on reactor control requirements. The bottom of the fully withdrawn rods is at the elevation of the top of the slots in the septifoil housing. Flooding (or CCFL) was observed in the experiments to occur at the general elevation of the septifoil slots/holes. This observation was true for all configurations tested.
This is contrary to the generally accepted theory that flooding will occur at the location of the minimum flow area. It was expected that flooding would occur at the inlet in the septifoil (bottom), the location of the minimum flow area, and a two. phase pool would form above this location. Neither of these expectations occurred. At no time was a pool observed to occur within the septifoil housing. Flow through the 0.25 -inch holes was always observed to be liquid flow from the lank into the septifoil housing. Within the septifoil housing, air flow was predominatly up the empty channels (those in which the control rod would be fully withdrawn), with liquid flow down the channels with rods and film flow on the inner wall of the septifoil housing.

Results (in terms of the Wallis correlation) from the test series with zero, three, and four rods inserted were virtually identical when using a common flow area and hydraulic diameter the Wallis nondimensional superficial velocities use a flow area and hydraulic diameter to nondimensionalize the individual flowrates), and resulted in Wallis correlation coefficients within the generally excepted values $(m=0.88$ and $\mathrm{C}=0.88)$. However, the results from the series with five rods inserted are significantly different from the other configuration results, with much smaller values for the coefficients $(m=0.46$ and $C=0.64)$. Because flooding occurs in the general vicinity of the slots/holes, the liquid flow available for cooling of the control rods further down the septifoil is limited by conditions at this elevation. Analysis will require using the five-rod flooding results anytime that five rods are even partially inserted, leading to the most limiting liquid flow and cooling case. 


\section{ACKNOWLEDGEMENTS}

The work documented herein was supported by the U. S. Department of Energy, Assistant Secretary for Defense Programs, under the DOE Idaho Field Office, to whom we are grateful. We appreciate the guidance and interest of Dr. Fred E. Witmer and Sharon L. Zeigler, DOE, who helped as technical program monitors. Thomas K. Larson provided extensive help during the experimental proposal, also providing general advice and technical review. William H. Landman provided design and facility construction support. Blaine Merkley and Jody Boyce assisted in the installation and checkout of the instrumentation, and provided support during testing and configuration changes. Dr. M. G. McKellar helped checking the calculations. We are also grateful to Dr. Greg Flach and George Richardson of Savannah River Laboratory for technical information and providing the septifoil spider. 


\section{CONTENTS}

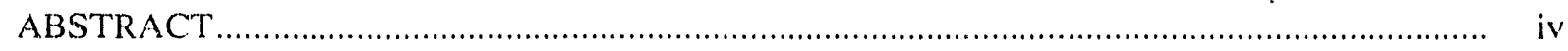

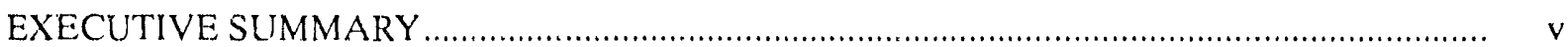

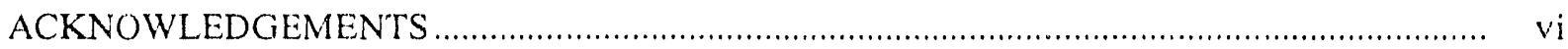

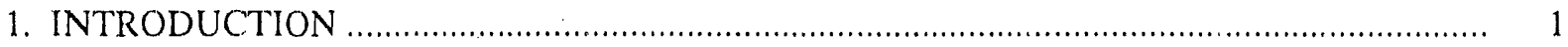

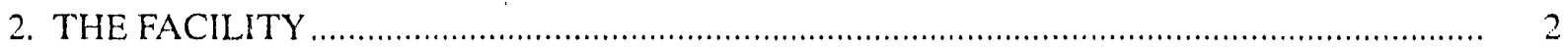

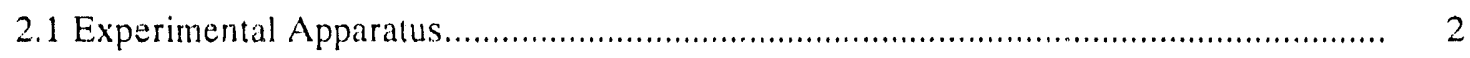

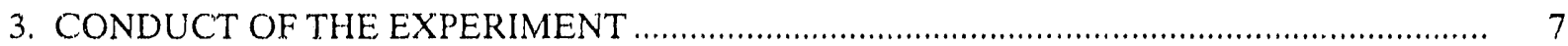

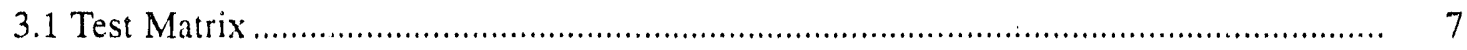

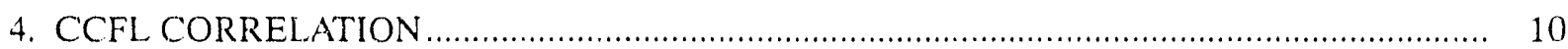

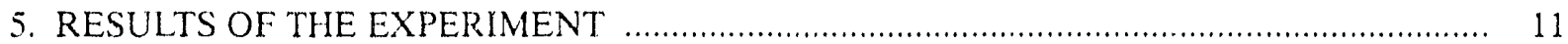

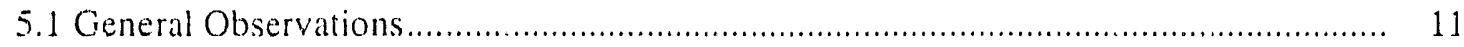

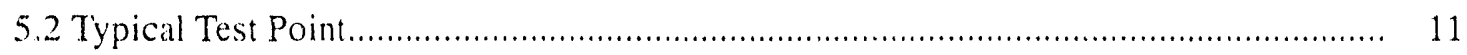

5.3 Wallis Correlation Results .............................................................................. 15

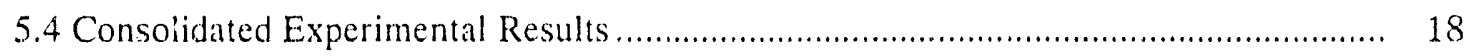

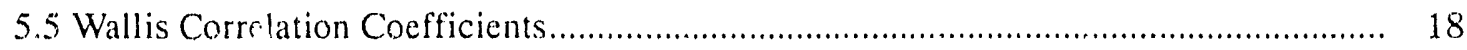

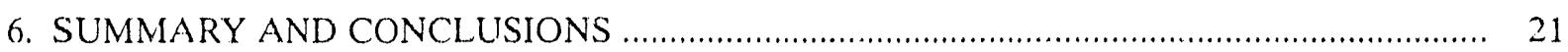

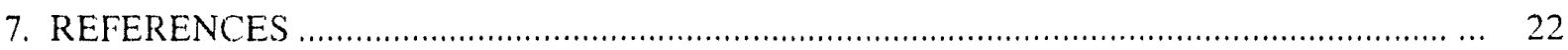

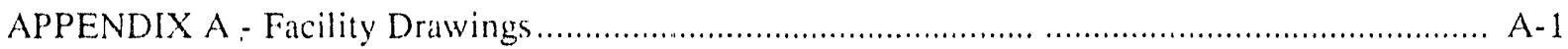

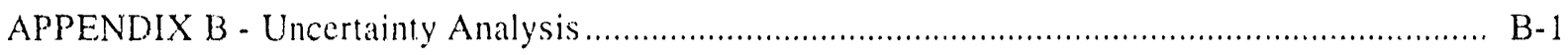

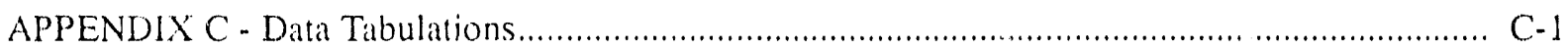




\title{
Countercurrent Flow-limiting Characteristics of a Savannah River Plant Control Rod Septifoil
}

\author{
1. INTRODUCTION
}

One postulated accident scenario for a Savannah River Plant (SRP) reactor is plugging of a septifoil coolant flow supply line, resulting in either partial or complete termination of coolant to the control rods. It is further postulated that this occurs under normal power operations and remains undetected such that reactor scram does not occur. In this scenario; liquid in the septifoil would reach saturation temperature and would begin to boil. The only water available for cooling of a type-Q septifoil would need to flow into the septifoil through the slots and holes near the top of the septifoil. It has been postulated that liquid flow from the tank through the septifoil slots into the septifoil may be limited owing to the courtercurrent flow of steam from the holes or within the rod bundle of the septifoil (CCFL). In fact, if the rate of steam generation within the septifoil is sufficient, no liquid would be able to flow into and down the septifoil, possibly leading 10 melting of the control rods. Because the coefficients used in the most common CCFL correlation, [the Wallis correlation (1969) ${ }^{\mathrm{a}}$ are geometry dependent, and because the range of values these coefficients take is broad, an rccurate prediction of

a. Seferencing is by author-date. See the Reference section for full citations. the liquid flowrate into the septifoil is not possible without experimental confirmation of the values of the correlation constants. This report documents the results from experiments performed at the Idaho National Engineering Laboratory (INEL) to determine the CCFL characteristics of the septifoil assembly under various configurations using air and water as the working fluids.

The purpose of these experiments was to determine the slope and intercept coefficients of the Wallis CCFL correlation as applied to the SRP Type-Q septifoil. Of particular interest, are the CCFL characteristics within the rod bundle for various rod configurations, and at the slots and holes in the vicinity of the deflector plate. The results will be used for analysis of the septifoil response (particularly the control rods thermal response) during the postulated accident of interrupted coolant flow to the septifoil.

This document describes the experiment facility, conduct of the experiment, and the test results. Appendix A presents drawings of the facility and various components. Appendix B presents an uncertainty analysis of calculated parameters. Appendix $\mathrm{C}$ tabulates selected data. 


\section{THE FACILITY}

\subsection{Experimental Apparatus}

Figure 1 shows the test section used for the experiments. The test section consisted of an upper section fabricated with a segment of $36-\mathrm{cm}$ (14-inch) OD acrylic pipe for the moderator tank simulator. A 2-m- (6-foot-) long seplifoil simulator with the holes/slots near the top was also fabricated from acrylic pipe, which permitted visual observation of the flooding characteristics. The septifoil included a 2-m (6-foot) segment of an actual septifoil spider. Figure 2 is a cross-sectional view of the septifoil and rod configuration.

The septifoil was terminated approximately 6 inches above the holes/slots. For flooding to occur at the holes/slots or within the control rod bundle, all liquid within the septifoil above the holes/slots would have drained down to the level at which CCFL occurs, so it was not necessary to simulate the upper standpipe section of the guide tube structure. The septifori simulator ended in a 20-cm (8-inch) diameter tank for air injection and separation of the water and entrained air. Air was injected into the separator tank above the level of the septifoil bottom, flowed down the tank and up into and through the septifoil, exited into the moderator tank simulator, and finally vented to the atmosphere from the top of the tank. Injected licuid was measured and controlled using the steamair-water (SAW) loop. The liquid was injected into the top of the moderator tank simulator. The level was maintained at $114 \mathrm{~cm}$ ( 45 inches) above the top of the septifoil slots by controlling the liquid injection rate. Liquid from the tank flowed into the septifoil slots and holes, down through the septifoil, and into the separator tank where a level was established based on the naturally occurring pressure drops that resulted from the test conditions. Liquid exited the separator tank, flowed through the appropriate flow measurement devices, and flowed back into the SAW loop water supply tank for recirculation. Table 1 tabulates pertinent dimensions.

Figure 3 is a piping and instrumentation diagram (P\&ID) for the facility. The experiments were performed using the SAW loop in Building TAN-645 at the INEL. The SAW loop comprised pump, piping, and measurement systems for delivering air and water to the experimental apparatus, measuring the individual flows, separating the air and water, venting the air to the atmosphere, and recirculating the water. Individual component flowrates were measured over multiple ranges, permitting a wide range of flows to be controlled and measured. Liquid flowrate was measured using turbine flow meters. Air flowrate was measured using venturi and thermal flow meters. The P\&ID in Figure 3 differentiates between the existing SAW loop components and those components of the experimental rig. The primary experimental measurements were the flowrates of the air injected into the apparatus and the flowrate of the liquid draining into and down through the septifoil, upon which the nondimensional superficial velocities are based. Secondary measurements include temperatures, pressures, and differential pressure measurements for determining level and pressure drops in the septifoil Table 2 lists all measurements and individual uncertainties. Uncertainties are based on manufacturers specifications and calibration results from the INEL Standards and Calibration Lat tory. Appendix A presents drawings of the facil-ty and various components. Appendix P presents an uncertainty analysis of calculated parameters. 


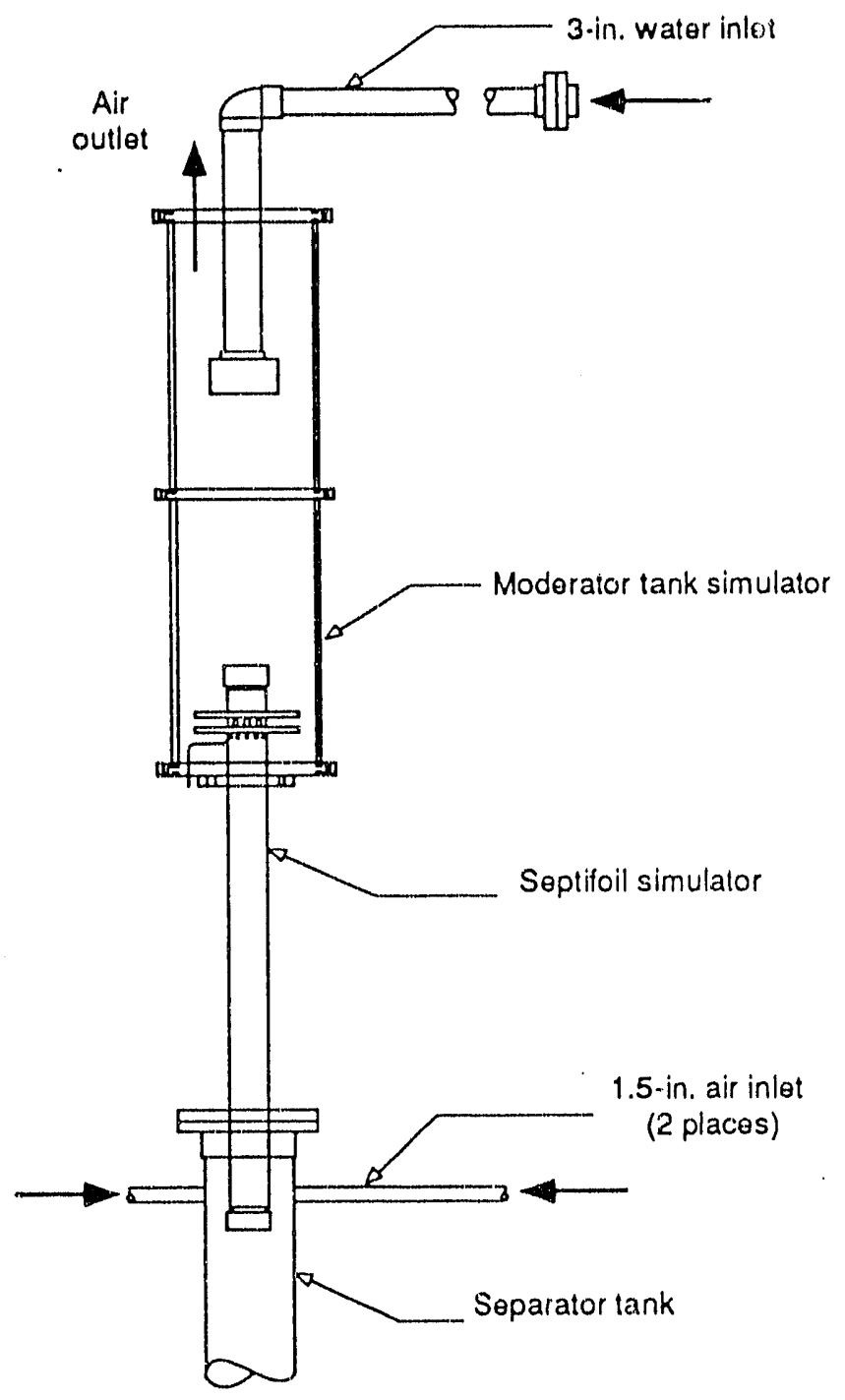

Figure 1. Septifoil CCFL test apparatus.

Full-length rods: $B, C, E, G$, and $F$ Partial-length rods: $A$ and $D$

Note: $E$ and $G$ are stainless steel clad cadmium control rods.

$A, B, C, D$, and $F$ are aluminum clad lithiumaluminum control rods.

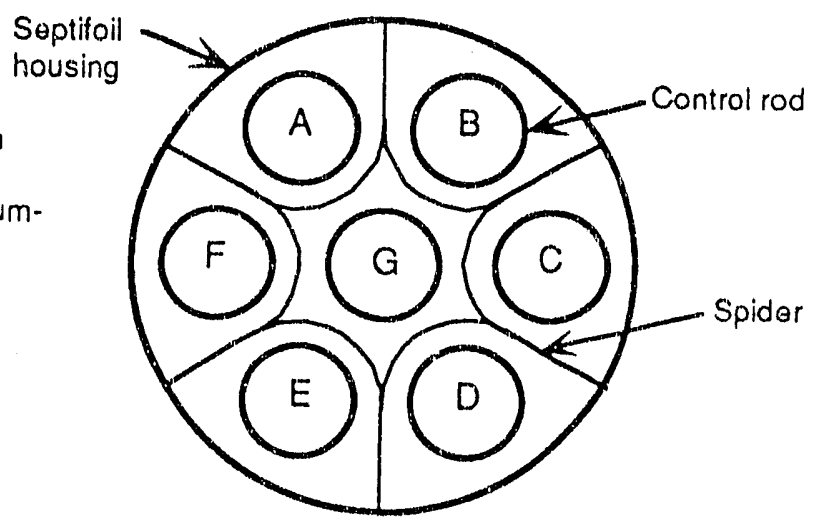

Figure 2. Cross-section of septifoil, showing rod positions. 
Table 1. Pertinent dimensions of the CCFL apparatus.

\begin{tabular}{|c|c|c|c|}
\hline Component & $\begin{array}{l}\text { Wetted } \\
\text { Perimeter } \\
\quad(m)\end{array}$ & $\begin{array}{l}\text { Flow Area } \\
\qquad\left(\mathrm{m}^{2}\right)\end{array}$ & $\begin{array}{l}\text { Hydraulic } \\
\text { Diameter } \\
\quad(\mathrm{m})\end{array}$ \\
\hline $\begin{array}{l}\text { Slot } \\
(0.436 \text { in. } x 1.1 .55 \text { in. })\end{array}$ & 0.0713 & $2.985 \times 10^{-4}$ & 0.016 \\
\hline Hole $(0.25 \mathrm{in})$. & 0.020 & $3.167 \times 10^{-5}$ & 0.0064 \\
\hline Slots/Holes (12) & 1.095 & $3.963 \times 10^{-3}$ & 0.0145 \\
\hline Spider $^{b}$ & 0.458 & $3.490 \times 10^{-4}$ & 0.0030 \\
\hline Rod & 0.075 & $4.535 \times 10^{-4}$ & 0.0240 \\
\hline Housing, Lucite & 0.261 & $5.418 \times 10^{-3}$ & 0.0831 \\
\hline \multicolumn{4}{|l|}{ Septifoil with } \\
\hline 0 Rods Inserted ${ }^{c}$ & 1.095 & $3.963 \times 10^{-3}$ & 0.0145 \\
\hline 3 Rods Inserted & 0.946 & $3.709 \times 10^{-3}$ & 0.0157 \\
\hline 4 Rods Inserted & 1.021 & $3.255 \times 10^{-3}$ & 0.0128 \\
\hline 5 Rods Inserted & 1.096 & $2.802 \times 10^{-3}$ & 0.010 \\
\hline \multicolumn{4}{|c|}{$\begin{array}{l}\text { a. Wetted perimeter, flow area, and hydraulic diameter are based on location of minimum flow } \\
\text { area. } \\
\text { b. Spider dimensions are from Vreeland } 1991 \text {. } \\
\text { c. Minimum flow area is located at the slots/holes. }\end{array}$} \\
\hline
\end{tabular}




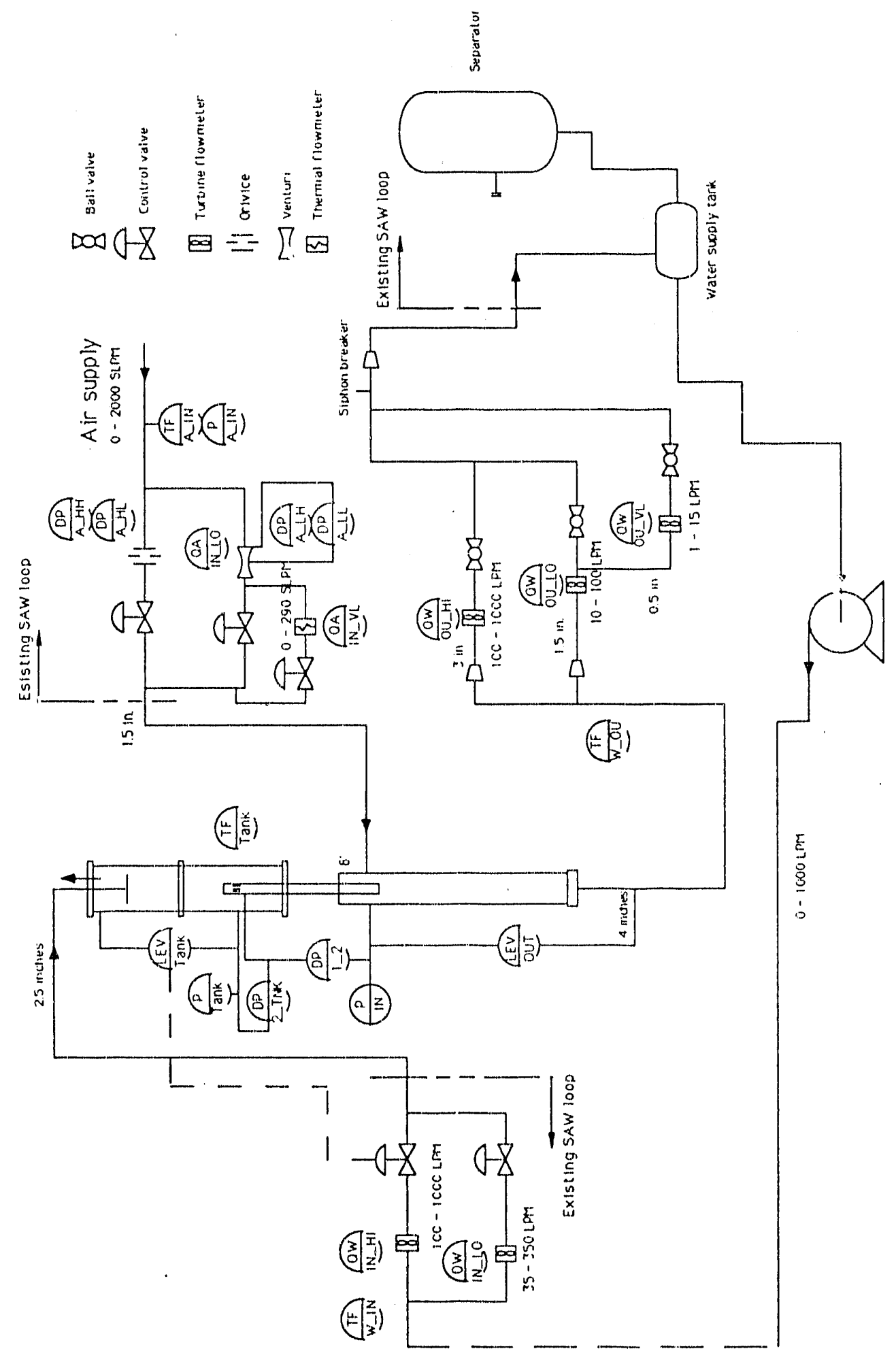

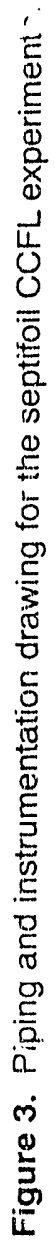


Table 2. Measurements list.

\begin{tabular}{|c|c|c|c|c|}
\hline $\begin{array}{l}\text { Measurement } \\
\text { ID }\end{array}$ & Description & Type & Rarige & Uncertainly \\
\hline QW_IN_HI & Liquid injection rate - high range & Turbine & $100.10001 . . \mathrm{pm}$ & $\pm 3 \mathrm{Lpm}$ \\
\hline QW_IN_LO & Liquid injection rate - low range & Turbine & 10-35 Lpm & $\pm 1 \mathrm{Lpm}$ \\
\hline OW_OU_HI & Liquid draining rate - high range & Turbine & $100.1000 \mathrm{Lpm}$ & $\pm 3 \mathrm{Lpm}$ \\
\hline QW_OU_LO & Liquid draining rate - low range & Turbine & 10.100 Lpm & $\pm 0.2 \mathrm{Lpm}$ \\
\hline QW_OU_VL & Liquid training rate - very low zange & Turbine & $1.15 \mathrm{Lpm}$ & $\pm 0.03 \mathrm{Lpm}$ \\
\hline QA_IN_VL & Air injection rate - very low range & Thermal flow meter & $6-300 \mathrm{sLFm}$ & $\pm 6 \mathrm{sLpm}$ \\
\hline$D P A_{-} L H$ & Low-range venturi - high.p ange DP & Differential pressure & $0.125 \mathrm{kPa}$ & : $1.6 \mathrm{kPa}$ \\
\hline$D P \_A_{-} L L$ & Low-range venturi - low-Range DP & Differential pressure & $0.12 .5 \mathrm{kP}$ & $\pm 0.12 \mathrm{kPa}$ \\
\hline L_TANK & Liquid level in moderator tank & Differential pressure & $0.1 .72 \mathrm{~m}$ & $\pm 0.013 \mathrm{~m}$ \\
\hline L_OUT & Liquid level in outlet tank & Differential pressure & $0.2 .975 \mathrm{~m}$ & $\pm 0.038 \mathrm{~m}$ \\
\hline DP_1_2 & DP from bottom of rods to holes & Differential pressute & $0.25 \mathrm{kPa}$ & $=0.25 \mathrm{kPa}$ \\
\hline DP_2_TNK & DP from holes to moderator tank & Differential pressure & $0.25 \mathrm{kPa}$ & $:=0.25 \mathrm{kPa}$ \\
\hline P_TANK & Pressure in tank at level of slots & Absolute pressure & $0.170 \mathrm{kPa}$ & $\therefore 0.35 \mathrm{kPa}$ \\
\hline P_IN & Pressure at inlet to septifoil & Absolute pressure & $0.170 \mathrm{kPs}$ & $\pm 0.35 \mathrm{kPa}$ \\
\hline$P_{-} A_{-} I N$ & $\begin{array}{l}\text { Pressure at inlet to venturi } \\
\text { air measurement }\end{array}$ & Absolute pressure & $0.800 \mathrm{kPa}$ & $\pm 1.6 \mathrm{kPa}$ \\
\hline$T F^{*}, W \ldots I N$ & $\begin{array}{l}\text { Fluid temperature at inlet } \\
\text { measurement }\end{array}$ & Fluid temperature & $273.82 \mathrm{dK}$ & $\pm 2 \mathrm{~K}$ \\
\hline TF_W_OU & $\begin{array}{l}\text { Fluid temperature at outlet } \\
\text { measurement }\end{array}$ & Fluid temperature & $273.821 \mathrm{~K}$ & $\pm 2 \mathrm{~K}$ \\
\hline$T F \_A_{-} I N$ & Fluid temperature at air inlet & Fluid temperati" & $273.821 \mathrm{~K}$ & $\pm 2 \mathrm{~K}$ \\
\hline TF_TANK & Fluid temperaturs in tank & Fluid temperature & $273.821 \mathrm{~K}$ & $\pm 2 \mathrm{~K}$ \\
\hline
\end{tabular}




\section{CONDUCT OF THE EXPERIMENT}

The experiments were steady-state and performed to the following procedural steps.

1. Insert the control rod simulators into the septifoil for the desired configuration. Perform the daily measurement systems checks, including backfill of the differential pressure sense lines. Record averaged data for an initial drained noflow cundition.

2. Adjust the water injection rate into ihe moderator tank simulator to a $114 \mathrm{~cm}$ (45-inch) licuid level. Set the level control system to autoriatic.

3. Establish the air injection rate according to the test matrix.

4. Allow the system to stabilize and reach steady-state.

5. Siart the data acquisition system, and record data for 5 minutes.

6. Repeat Steps 3 through 5 until complete flooding occurs, or maximum air flowrate is reached.

7. Terminate air and water injection.

8. Record averaged data for a post-test drained no-flow condition.

For analysis. all data were acquired at the rate of 2 samples per second and averaged over the 5 . minute recording period. The original time series data were converted into the HDF format ${ }^{b}$ and archived.

b. HDF (hierarchical data format) is a machineindependent file format developed and supported by the National Center for Supercomputer Applications (NCSA) in Urbana, Illinois.

\subsection{Test Matrix}

Table 3 tabulates ire test configurations and designates the test points. Six different iod configurations, with .5 different air injection rates for each configuration, were tested. The first two configurations, each with five rods, represent maximum power generation. The intent was to obtain the flooding characteristics within the rod bundle in a segment with five control rods inserted (presumably near the top of the sepiifoil, just below the slots/holes). ${ }^{\mathrm{c}}$ The next threc configurations represent four and three rods inserted (two different three-rod ccifigurations to determine sensitivity to rod location) to obtain the flooding characteristics in Iegions in which three and four rods exist (presumably, these configurations would occur in the middle and lower reaches of the septifoil). The final two configurations were with all rods totally withdrawn to obtain the flooding characteristics of the slots/holes in the septifoil housing (the last configuration was with the upper tube sheet and deflector plate simulators installed to determine the sensitivity of the results to the plates). It is recognized that these final two configurations are nel realistic for actual reactor conditions; however, it was desired to obtain the flooding characteristics of the slots/holes for compteteness in modeling, which can only be obtained with all rods withdrawn, thus resulting in the fiow area equivalent to the flow area through the slotsholes.

c. S5Ab was a repeat of S5A, with the same rod configuration. However, the poison/deflector plate simulators were installed. This test was repeated to verify the non-typical response observed in the original scries. 
Table 3. Matix of tests performed.

\begin{tabular}{|c|c|c|}
\hline $\begin{array}{l}\text { Test } \\
\text { Point } \\
\text { Designation }\end{array}$ & $\begin{array}{l}\text { Control } \\
\text { Rod } \\
\text { Configuration }\end{array}$ & $\begin{array}{l}\text { Air } \\
\text { Injection } \\
\text { Rate }(\mathrm{m} / \mathrm{s})\end{array}$ \\
\hline$(0-15)$ & 5 rods $(A, B, C, D, E)$ & $0-7$ \\
\hline $\mathrm{S} 5 \mathrm{Ab} \mathrm{b}_{-}(0-15)$ & 5 rods $(A, B, C, D, E)$ & $0-7$ \\
\hline$S 4 A_{-}-(0-15)$ & 4 rods $(A, B, C, D)$ & 0.7 \\
\hline $\mathrm{S} 3 \mathrm{a} \bar{A}_{-} \quad(0-15)$ & 3 rods $(A, C, D)$ & $0-7$ \\
\hline $\mathrm{S}_{3} \mathrm{bA} \mathrm{A}_{-}^{-}(0-15)$ & 3 rods $(C, D, E)$ & $0-7$ \\
\hline $\mathrm{SOaA}-(0.15)$ & 0 rods & 0.7 \\
\hline SObA_ $(0-15)$ & 0 rods & $0-7$ \\
\hline
\end{tabular}




\section{COUNTERCURRENT FLOW-LIMITING CORRELATION}

There are two major correlations used for predicting CCFL, the Wallis and Kutateladze correlations. For comparing air/water and steam/water systems, there is no significant technical reason for choosing one above the other. Because the Wallis correlation is more frequently used, this is the correlation that will be discussed. The Wallis correlation (Wallis 1969) is given by

$\sqrt{j_{g}^{*}}+m \sqrt{j_{f}^{*}}=C$

where

$j_{g}=j_{g} \sqrt{\left(\rho_{g} /\left(g d_{h}\left(\rho_{F}-\rho_{g}\right)\right.\right.}$

$\mathrm{m}=$ slope constant in the Wallis correlation

$j_{f}=j_{f}^{*}=j_{f} \sqrt{\left(\rho_{f} /\left(g_{h}\left(\rho_{\Gamma}-\rho_{g}\right)\right.\right.}$

$\mathrm{C}=$ intercept constant in the Wallis correlation

$j_{g}=$ vapor upflow superficial velocity $(\mathrm{m} / \mathrm{s})$

$\rho_{\mathrm{g}}=$ vapor density $\left(\mathrm{kg} / \mathrm{m}^{3}\right)$

$\mathrm{j}_{\mathfrak{f}}=$ liquid downflow superficial velocity $(\mathrm{m} / \mathrm{s})$

$\mathrm{d}_{\mathrm{h}}=$ hydraulic diameter $\left(=1.447 * 10^{-2} \mathrm{~m}\right)$

$\mathrm{g}=$ gravitational acceleration $\left(=9.8 \mathrm{~m} / \mathrm{s}^{2}\right)$

$\rho_{f}=$ liquid density $\left(\mathrm{kg} / \mathrm{m}^{3}\right)$

The superficial velocities in Equation (1) are defined using the minimum flow area through the septifoil. Depending on the number of rods inserted into the septifoil, the minimum flow area, and the location that flooding would be expected to occur is below the slots and inside the septifoil. The SRP reactors use steam rather than air as the working fluid. This raises a question regarding the outsome of the results. This can be answered by considering the fluid material properties in Equation (1). Define parameters $\beta_{\mathrm{g}}$ and $\beta_{\mathrm{f}}$ as $\beta_{\mathrm{g}}=\left[\rho_{\mathrm{g}} /\left(\mathrm{gd}_{\mathrm{h}}\left(\rho_{\mathrm{f}}-\rho_{\mathrm{g}}\right)\right]^{\frac{1}{4}}\right.$

$\beta_{\mathrm{f}}=\left[\rho_{\mathrm{f}} /\left(\mathrm{gd}_{\mathrm{h}}\left(\rho_{\mathrm{f}}-\rho_{\mathrm{g}}\right)\right]^{\frac{1}{4}}\right.$

These parameters are functions only of fluid properties and the hydraulic diameter. Equation (1) can be rewritten as

$\beta_{g} \sqrt{j_{g}}+m \beta_{f} \sqrt{j_{f}}=C$

The parameters $\beta_{\mathrm{g}}$ and $\beta_{\mathrm{f}}$ can be used for comparing the expected results when using air/water with the expected behavior of heavy steam/water in the reactor. Assuming local atmospheric conditions with a $1.14-\mathrm{m}$ liquid head ( 98 $\mathrm{kPa}$ and $290 \mathrm{~K}$ ), the values for these functions using air/water are ${ }^{\mathrm{d}}$

$$
\begin{aligned}
& \beta_{\mathrm{g}}=0.3022 \\
& \beta_{\mathrm{f}}=1.6301 .
\end{aligned}
$$

These compare to the values calculated for heavy water under full-power reactor conditions $\left(158 \mathrm{kPa}\right.$ and $\left.340^{\circ} \mathrm{K}\right)$, assuming saturation tempera'ture at a local pressure $\left(387^{\circ} \mathrm{K}\right)$ of

$$
\begin{aligned}
& \beta_{g}=0.2864 \\
& \beta_{f}=1.6300 .
\end{aligned}
$$

Use of air/water at local conditions results in a $\beta_{\mathrm{g}}$ value $5.5 \%$ larger than for $\mathrm{D}_{2} \mathrm{O}$ and $\beta_{\mathrm{f}}$ equal to that for $\mathrm{D}_{2} \mathrm{O}$.

Because the slope and intercept constants in the Wallis correlation are predominantly functions of geometry, and the property constants $\beta_{\mathrm{g}}$ and $\beta_{\mathrm{f}}$ for air/water are within $5.5 \%$ of those for the actual $\mathrm{D}_{2} \mathrm{O}$ system, performing these experiments with air/water rather than steam/water appears technically justified. Additionally, performing the experiments with air is much more economic (no

d. Using a hydraulic diameter of $1.447 \mathrm{~cm}$, calculated for both the 12 slots and the 120.25 -inch holes. 
heated system for safety considerations and no need for obtaining a steam supply system) and easier in terms of operation and measurement (no need to account for condensation and moisture content of the steam). However, condensation effects at the slots/holes resulting from steam mixing with the subcooled water will not be accounted for in these experiments. The magnitude of this effect on the septifoil flooding characteristics is unknown. 


\section{RESULTS OF THE EXPERIMENT}

\subsection{General Observations}

Flooding (or CCFL) was observed to occur at the general elevation of the slots/holes, or slightly below, an observation true for all configurations tested. This is contrary to the generally accepted theory that flooding will occur at the location of minirnum flow area. Figure 4 is an example of the flooding location, being a photograph of a low air flow injection point with four rods inserted (S4A_3b). For these tests, it was cxpected that flooding would occur at the inlet to the septifoil (bottom of the control rods), and a two-phase pool would form above this location. Neither of these expectations occurred. At no time was a pool observed to occur within the septifoil housing. Flow through the $1 / 4$-inch holes was always observed to be liquid flow from the tank into the septifoil housing. Within the septifoil housing, air flow was predominatly up the empty channels, liquid flow was down the channels with rods, and film flow occurred on the inner wall of the septifoil housing. Surging in the test section was observed at low air flowrates, resulting from an insufficient gravity head in the separator tank for the liquid flowrate (the level in the scparator tank was oscillating at the bottom entrance to the septifoil housing). These test points were not used in determining the correlation coefficients.

\subsection{Typical Test Point}

CCFL phenomena are typically time varying, but stationary over a sufficiently long period. The 5-minute data acquisition period used during these experiments is sufficiently long that the averages approach the stationary (or steady-state) value. The time series data for selected measurements and parameters are presented in this section, to support this assertion.

The first parameter that determines the liquid flowrate through the septifoil is the level of the liquid pool in the moderator tank simulator. This level was controlled in the experiments using a proportional-integral-differential (PID) controller, controlling the liquid injection rate into the moderator tank simulator. This level, calculated using a differential pressure transducer to measure the hydrostatic head, is shown in Figure 5 for an all liquid test point (S3bA_0). The liquid level varied $13 \mathrm{~cm}$ over the two cycles exhibited during the 5 minute period (a standard deviation of $3.5 \%$ ), with an average value of $114.8-\mathrm{cm}$. Because the parameter of most interest is the nondimensional liquid flowrate $\left(j^{*} f\right.$ ) through the septifoil, the square root of this parameter is shown in Figure 6. In this case, the standard deviation is $0.6 \%$, significantly less than the level variation. ${ }^{\mathrm{e}}$ Thus, the variation in the moderator tank simulator liquid level is a secondary effect on the nondimensional superficial liquid velocity used in the Wallis correlation.

e. This is to be expected since the draining rate depends on the square root of the liquid level; thus, the square root of the nondimensional liquid superficial velocity depends only on the 4th root of the liquid level in the moderator tank simulator. 


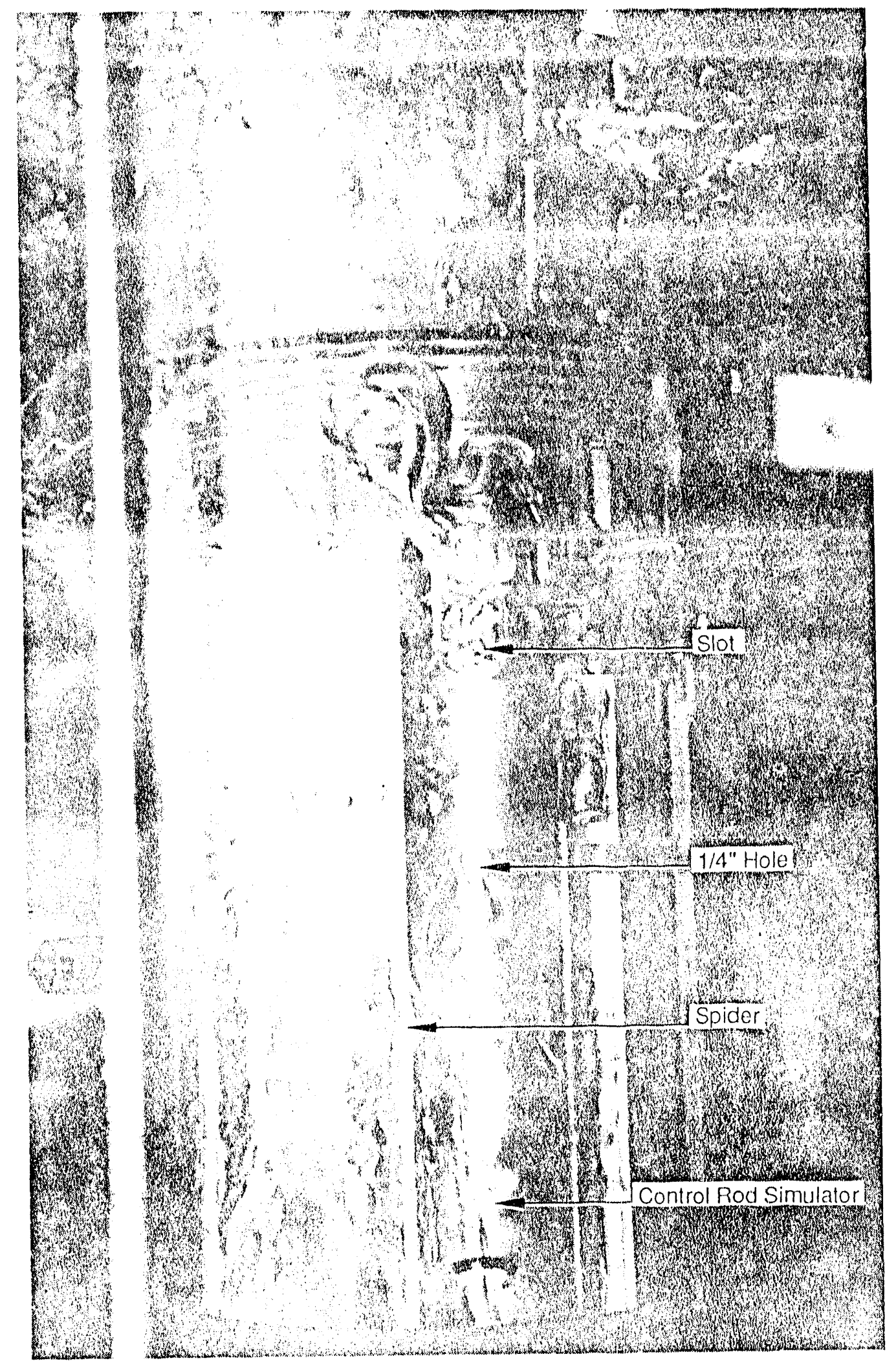

Figure 4. Photograph of the upper septifoil housing, showing flow patterns for test point S4A_3b. 


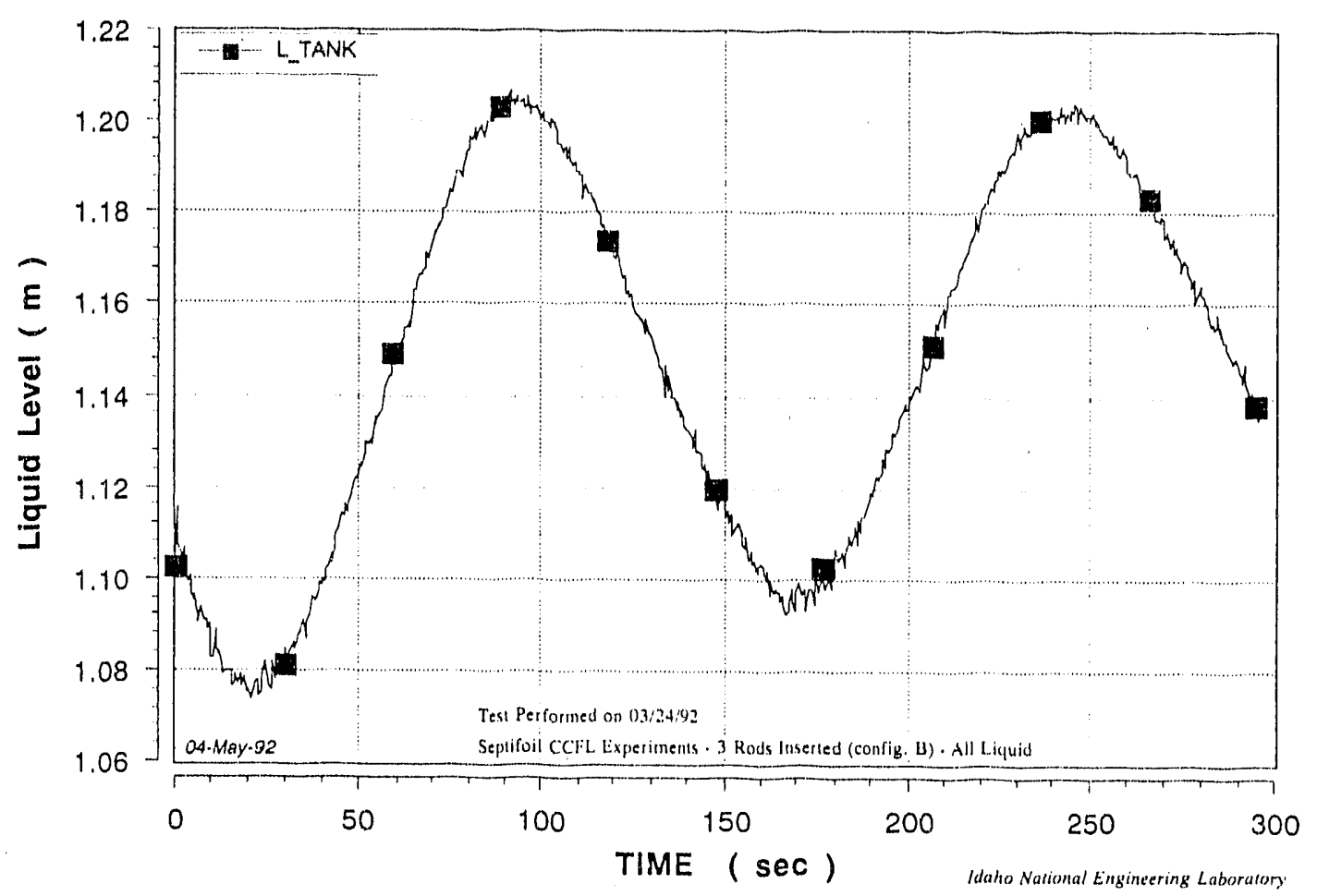

Figure 5. Moderator tank simulator liquid level for all liquid flow point S3bA_0.

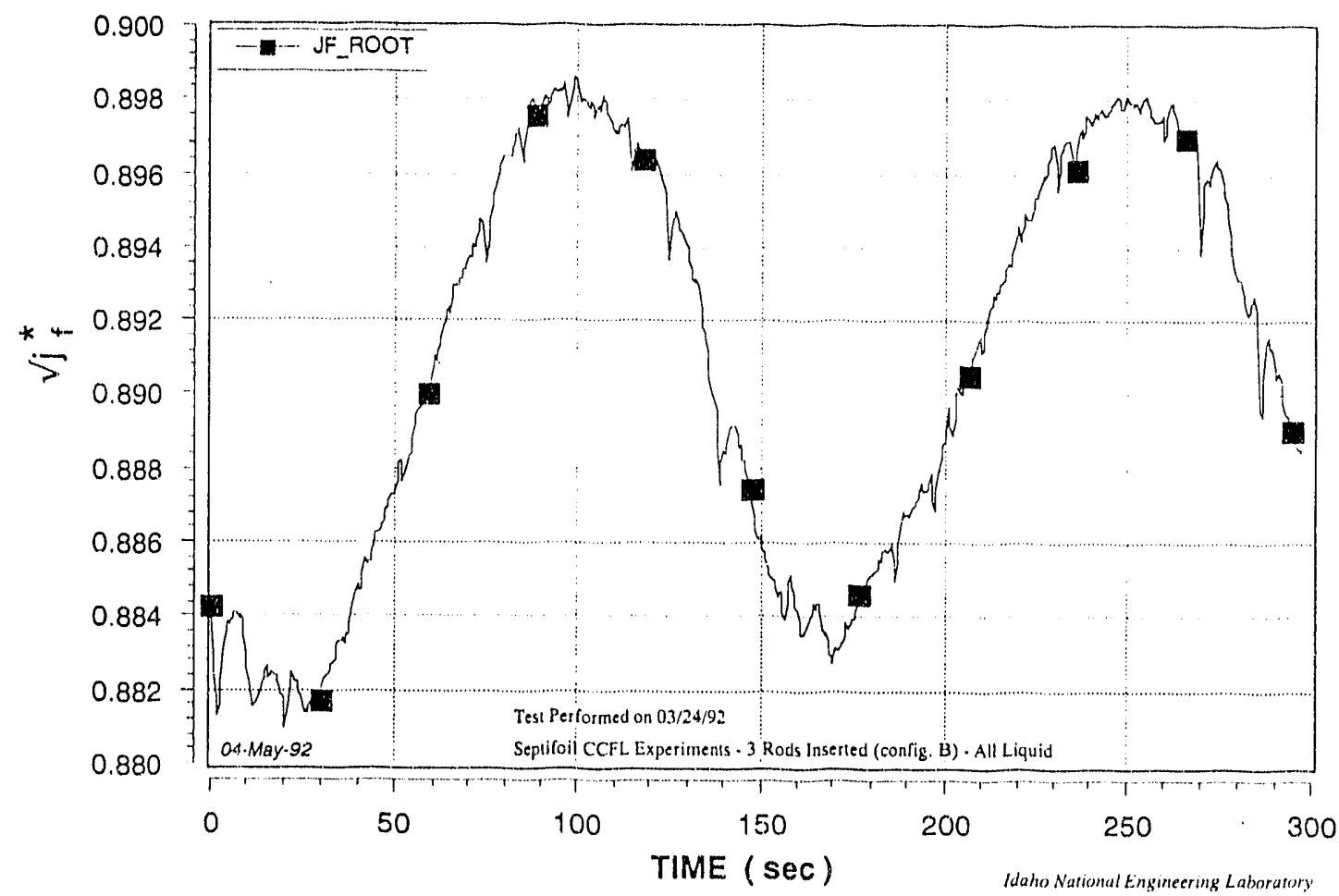

Figure 6. Square root of nondimensional superficial liquid velocity $j^{*}{ }_{f}$ for all liquid flow point S3bA_0. 
The same variation was observed fo:" a typical two-phase test point. Figure 7 shows the level variation for test point S3bA_5 (a 3-rod configuration with an inlet air superficial velocity of $0.86 \mathrm{~m} / \mathrm{s}$ ); Figure 8 shows the nondimensional liquid superficial velocity. The variation

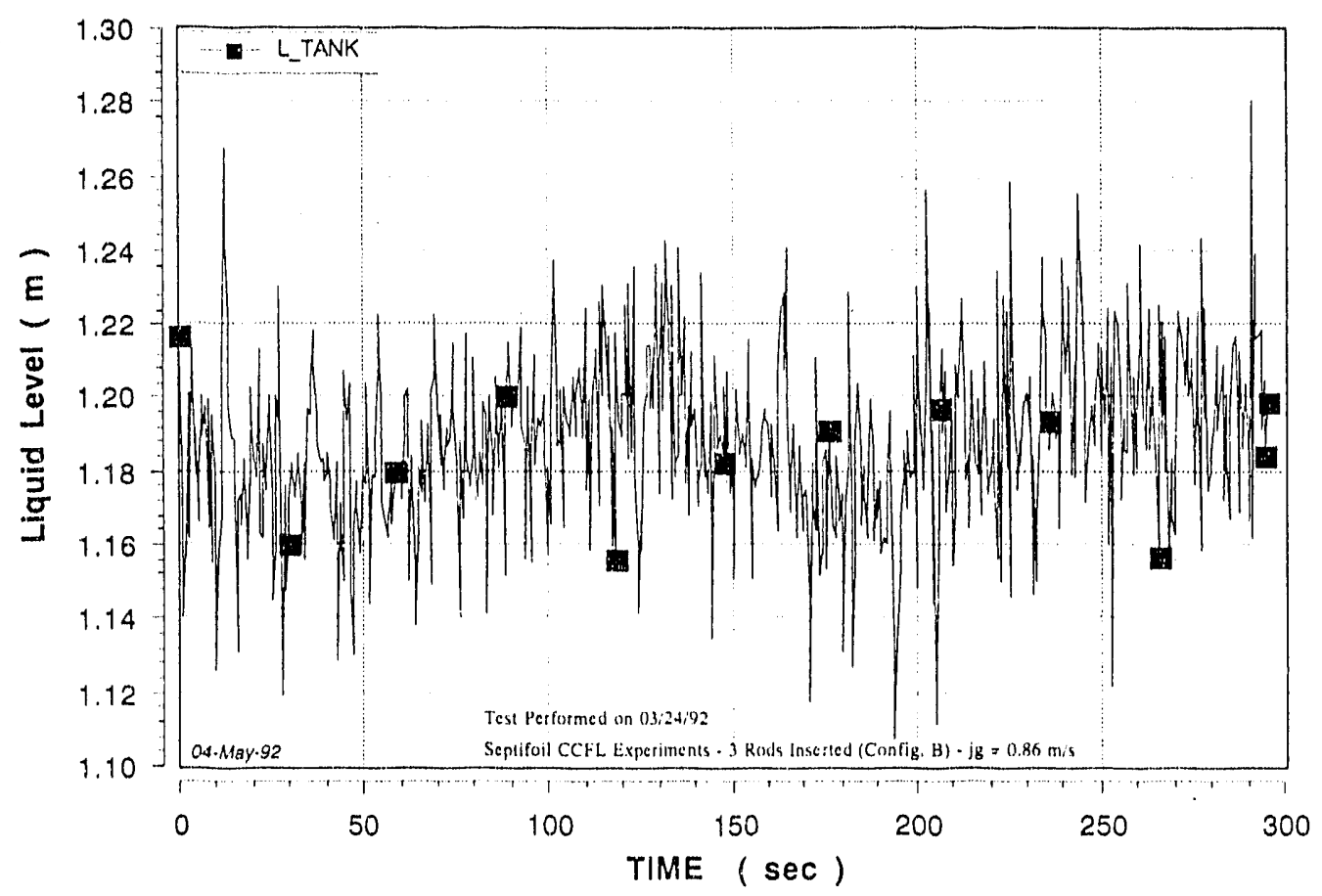

Figure 7. Moderator tank simulator liquid level for two-phase flow point $S 3 b \mathrm{~b}_{-} 5\left(\mathrm{j}_{\mathrm{g}}=0.86 \mathrm{~m} / \mathrm{s}\right)$.

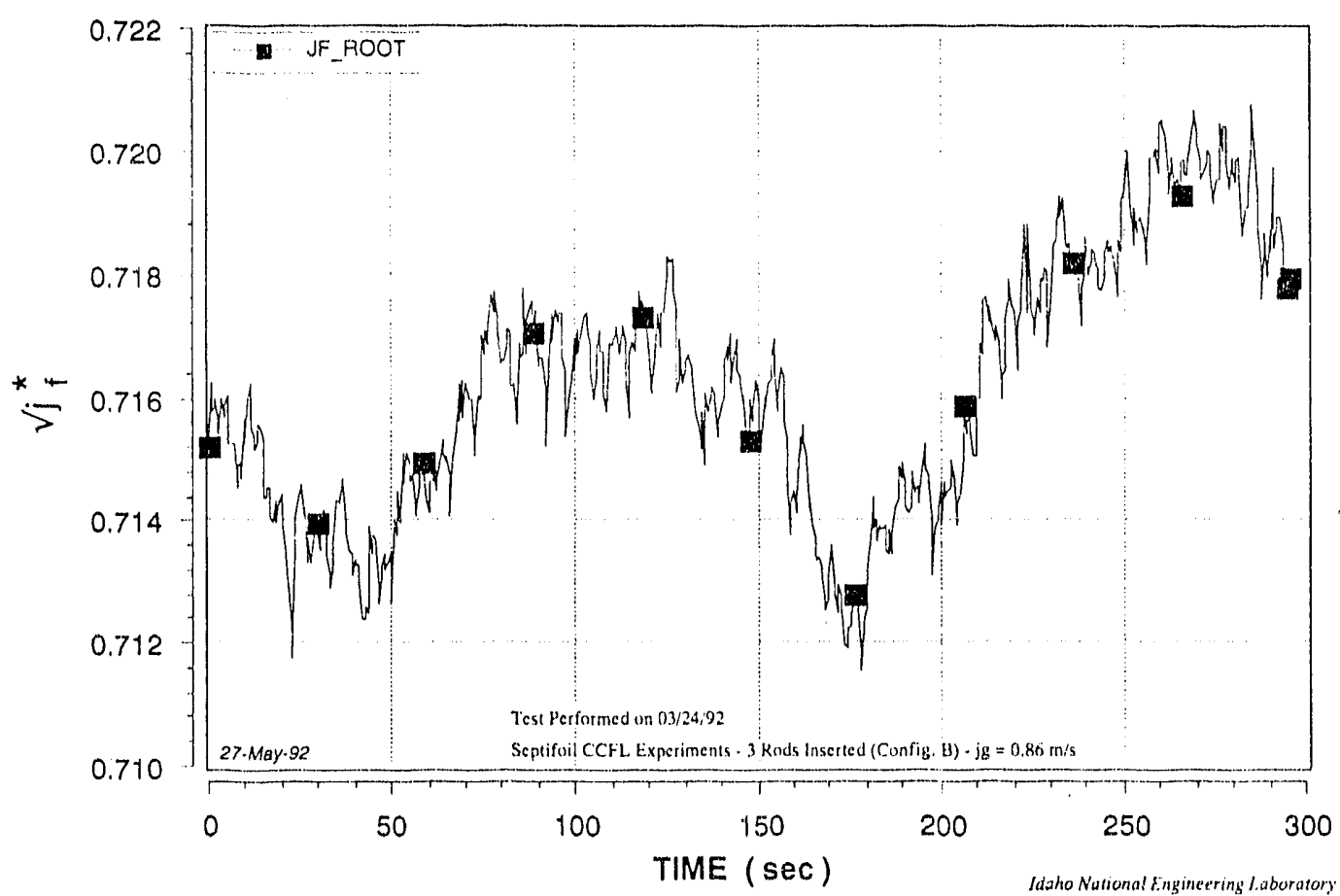

Figure 8. Square root of nondimensional superficial liquid velocity $j^{*} f$ for two-phase flow point S3bA_5 $\left(\mathrm{j}_{\mathrm{g}}=0.86 \mathrm{~m} / \mathrm{s}\right)$. 
in the liquid level was only $2.0 \%$ with a variation in $V \mathrm{j}_{\mathrm{f}}^{* t}$ of $0.3 \%$. This reduced variation in the liquid level oscillation was frequently observed (but not always) for the two-phase test points. However, the control point (the average liquid level about which the automatic controller controlled) frequently increased with an increasing air injection rate, the reason for which was never determined.

\subsection{Wallis Correlation Results}

Two different test series were performed with no rods inserted, SOaA and SObA, to investigate the effect of adding the mockups of the deflector and poison plates to the assembly. Series SOaA was conducted without the plates, and series SObA was conducted with the plates. Installation of the plates had no effect on the septifoil flow area. Figure 9 presents the results from the two series in terms of the liquid and air nondimensional superficial velocities. With the exception of some scatter in the SOaA data at low air injection rates, the data from these two series is statistically indistinguishable. The Wallis correlation coeffi- cients for these two series are SOaA: $m=0.80$, $\mathrm{C}=0.85$, and S0bA: $\mathrm{m}=0.76, \mathrm{C}=0.80$.

The conclusion drawn is that the deflector and poison plate mockups had no effect on the flooding characteristics of the septifoil with no rods inserted. Because this configuration is expected to have the most sensitivity to these plates, it can be concluded that the flooding characteristics of the septifoil in general do not depend on the plates, but rather that the flooding characteristics of the septifoil probably depend only on the internal geometry of the septifoil (including the internal characteristics of the slots/holes).

Another sensitivity to geometry investigated was the effect of rod location within the septifoil for two cases with the same number of rods inserted (i.e., three rods). This was investigated in test series S3aA (rods in positions $A, C$, and $D$ ) and S3bA (rods in adjacent positions C, D, and E). Figure 10 presents the results from these two series. The data from the two series are virtually identical. It can, therefore, be concluded that the rod positions (at least for the three-rod case) have no effect on the flooding characteristics of the septifoil. The Wallis

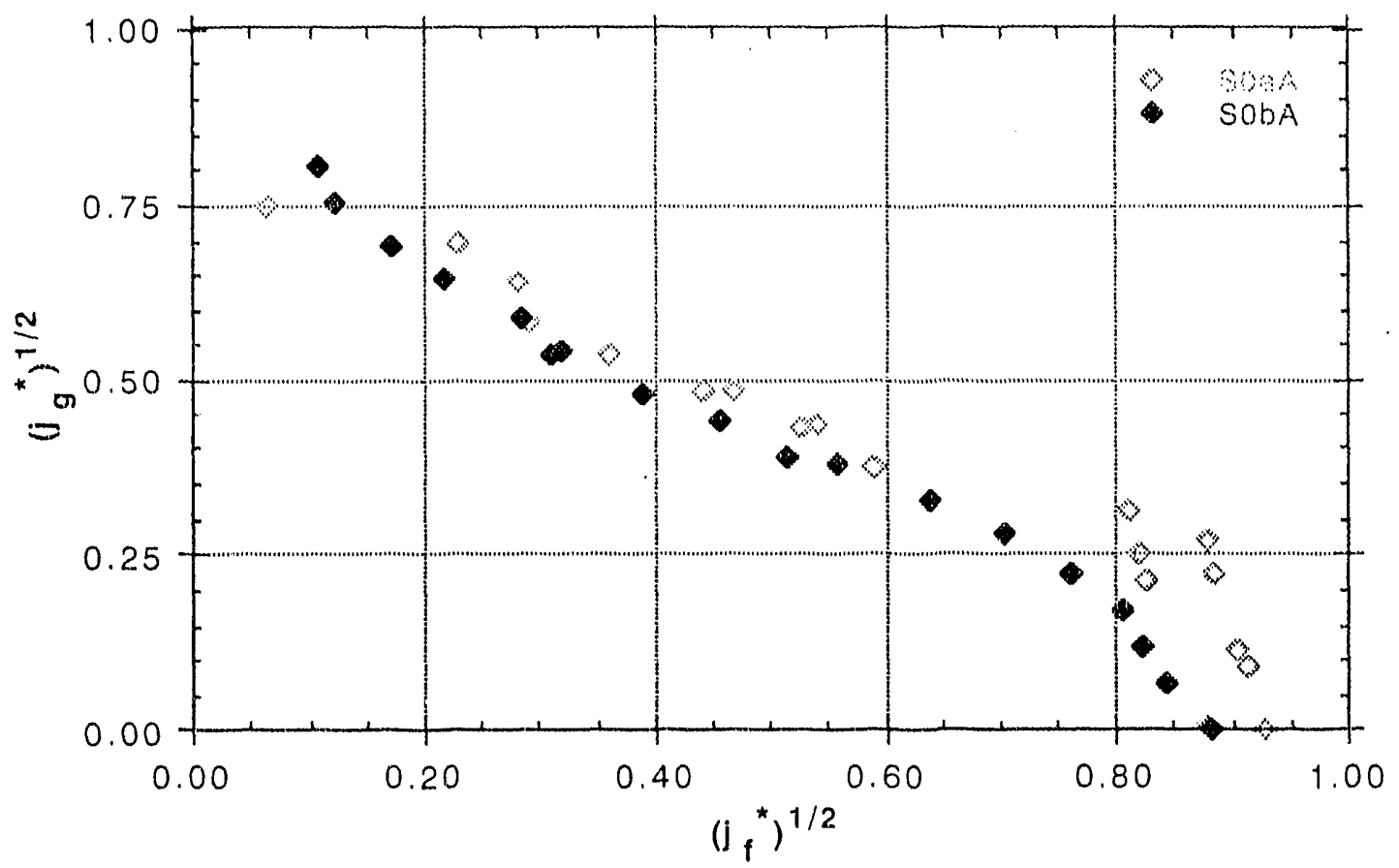

Figure 9. Square root of liquid and air nondimensional superficial velocities for series SOaA and SObA. No control rods. 


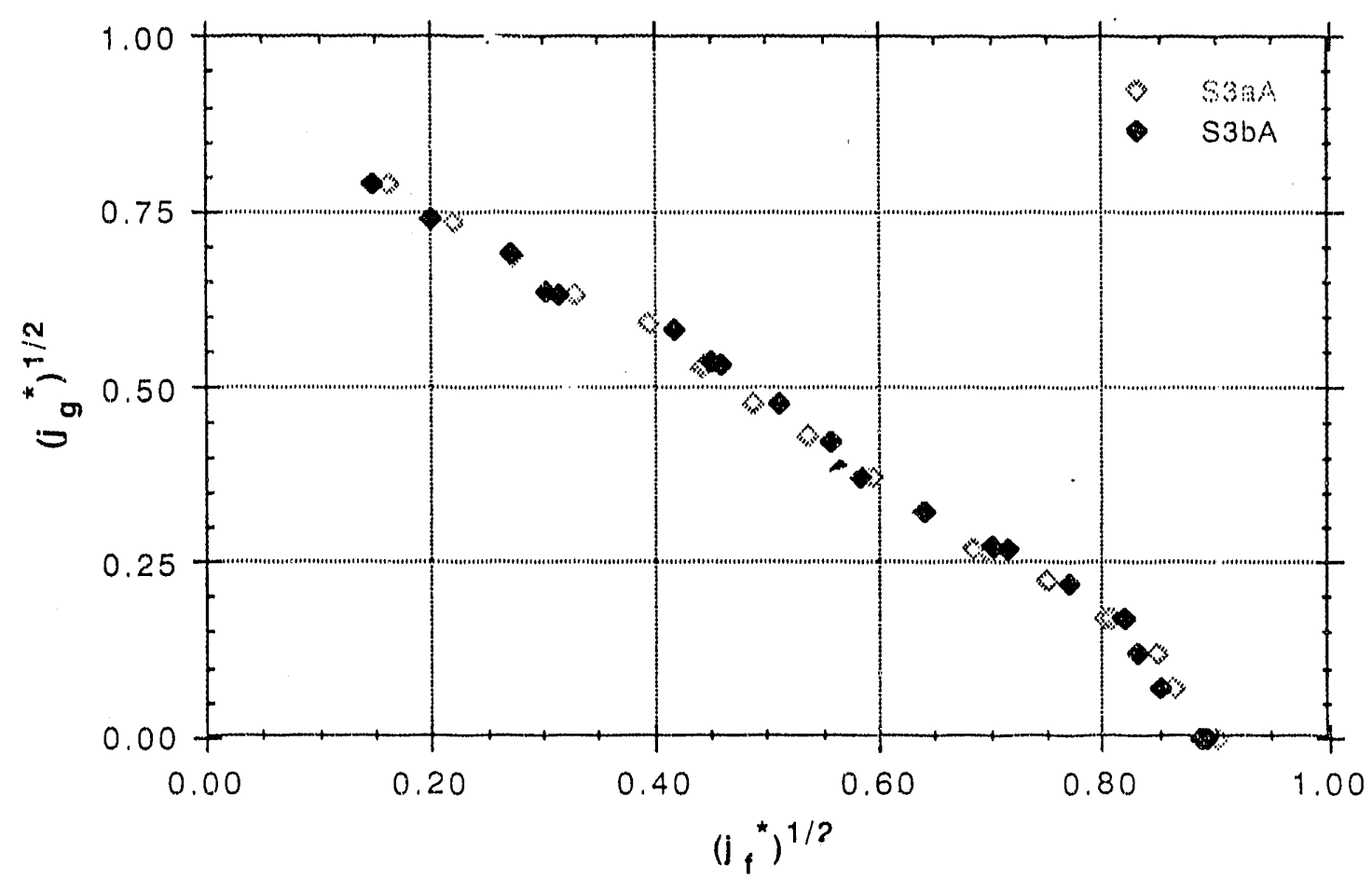

Figure 10. Square root of liquid and air nondimensional superficial velocities for series S3aA and S3bA. Three control rods inserted.

correlation coefficients are $\mathrm{S} 3 \mathrm{aA}: \mathrm{m}=0.98, \mathrm{C}=0.96$ and S3bA: $\mathrm{m}=0.93, \mathrm{C}=0.94$.

Figure 11 presents the results from the configuration with four rods inserted. The results are different from the three-rod configuration results, with Wallis correlation coefficients of $m=1.08$ and $\mathrm{C}=1.16$.

Figure 12 presents results from the configuration with five rods inserted. The S5Ab series was a repeat of the S5A series (same rod configuration, that is, with the poison/deflector plates installed following the SObA series). This series was performed to verify the results obtained from the original series, because the five-rod configuration results were somewhat different from the other configuration results. As shown in Figure 12, the S5A results were duplicated in the repeat series.
Basically, there is a very large slope change in the results at approximately $\sqrt{j}_{\mathrm{f}}^{*}=0.9$. Although this phenomena had been observed in the other configuration results, the $S 5 \mathrm{~A}$ slope change is larger and extends over a larger range. Several mechanisms for this slope change were investigated. The tests were performed using two different low-air-flow measurements (both thermal flow meters) to see if perhaps the original measurement was in error. This change had no effect. The tests were repeated using the 3-inc'n discharge line, rather than the 1.5inch discharge line normally used, with no appreciable effect on the results. It is concluded that in the region of $\mathrm{Vj}_{\mathrm{f}}^{\prime \prime}>0.9$ there is an interaction between the CCFL phenomena occurring near the slots/holes and pressure drops occurring within the much smaller flow area of the septifoil region with five-rods inserted. The Wallis correlation coefficients for these two series are S5A: $m=0.45$, $\mathrm{C}=0.82$; and S5Ab: $m=0.43, \mathrm{C}=0.83$. 


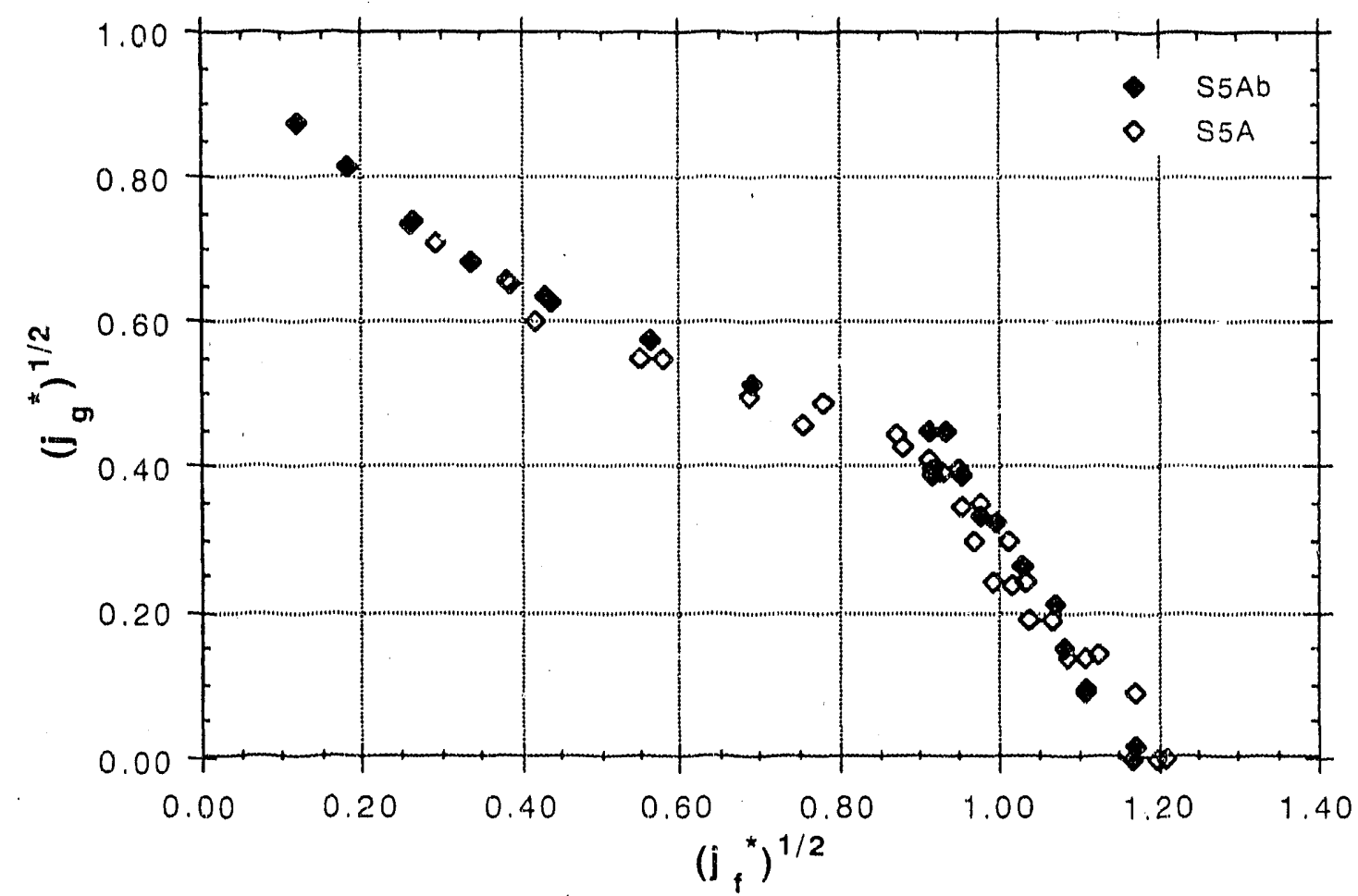

Figure 11. Square root of liquid and air nondimensional superficial velocities for series S4A. Four control rods inserted.

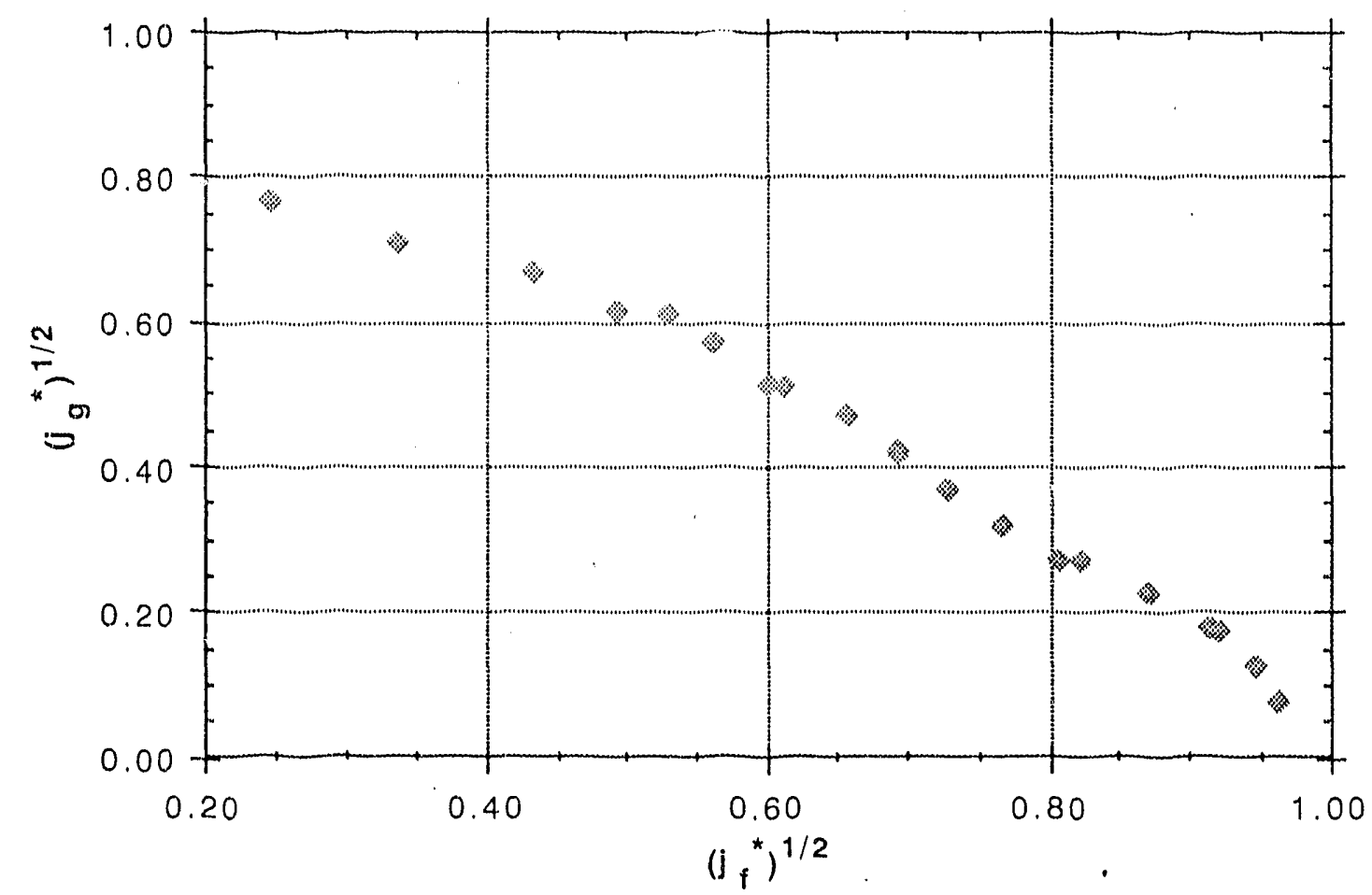

Figure 12. Square root of liquid and air nondimensional superficial velocities for series S5A and S5Ab. Five control rods inserted. 


\subsection{Consolidated Experimental Results}

Figure 13 presents the results from all of the test series in terms of $\sqrt{j}^{*}$ te versus $\sqrt{j}^{*} \mathrm{~g}$. Every configuration has its own unique characteristics, including the slope and intercept values. In an attempt to consolidate the results, all of the nondimensional superficial velocities were converted by using a common flow area and hydraulic diameter in equation (1). The values used were those for the slots/holes used in series SOaA and SObA, with no rods incerted (Wallis 1969) $\left(A_{\mathrm{f}}=3.963 \times 10^{-3} \mathrm{~m}^{2}\right.$, $\mathrm{dh}=1.447 \mathrm{~cm}) \cdot 4$

Figure 14 presents the results from these calculations. With the exception of the five-rod configuration results, series S5A and S5Ab, this modif:cation collapsed all of the results into a single curve. Excepting the five-rod configuration resulti, the data can be fit with a single equation, as shown in Figure 15. The resulting slope and intercept values $(\mathrm{m}=0.877$ and $\dot{\mathrm{C}}=(0.885)$ are well within the typical values for these coefficients (usually on the order of 0.8-1.2 for both coefficients). What is different is the large change in the flow area between the zero-, three-, and fourrod configurations, with no discernible effect o. the flooding characteristics of the septifoil.

Figure 16 presents the results from the fiverod configuration, series S5A and S5Ab, along with the curve fit to the data. The resulting values of the coefficients are significantly smaller $(m=0.462$ and $C=0.642)$ than the generally accepted values and the coefficient values from the other series $n$ the septifoil CCFL experiments.

\subsection{Wallis Correlation Coefficients}

Table 4 tabulates the slope and intercept coefficients, $m$ and $C$ in equation (1), for all test series.

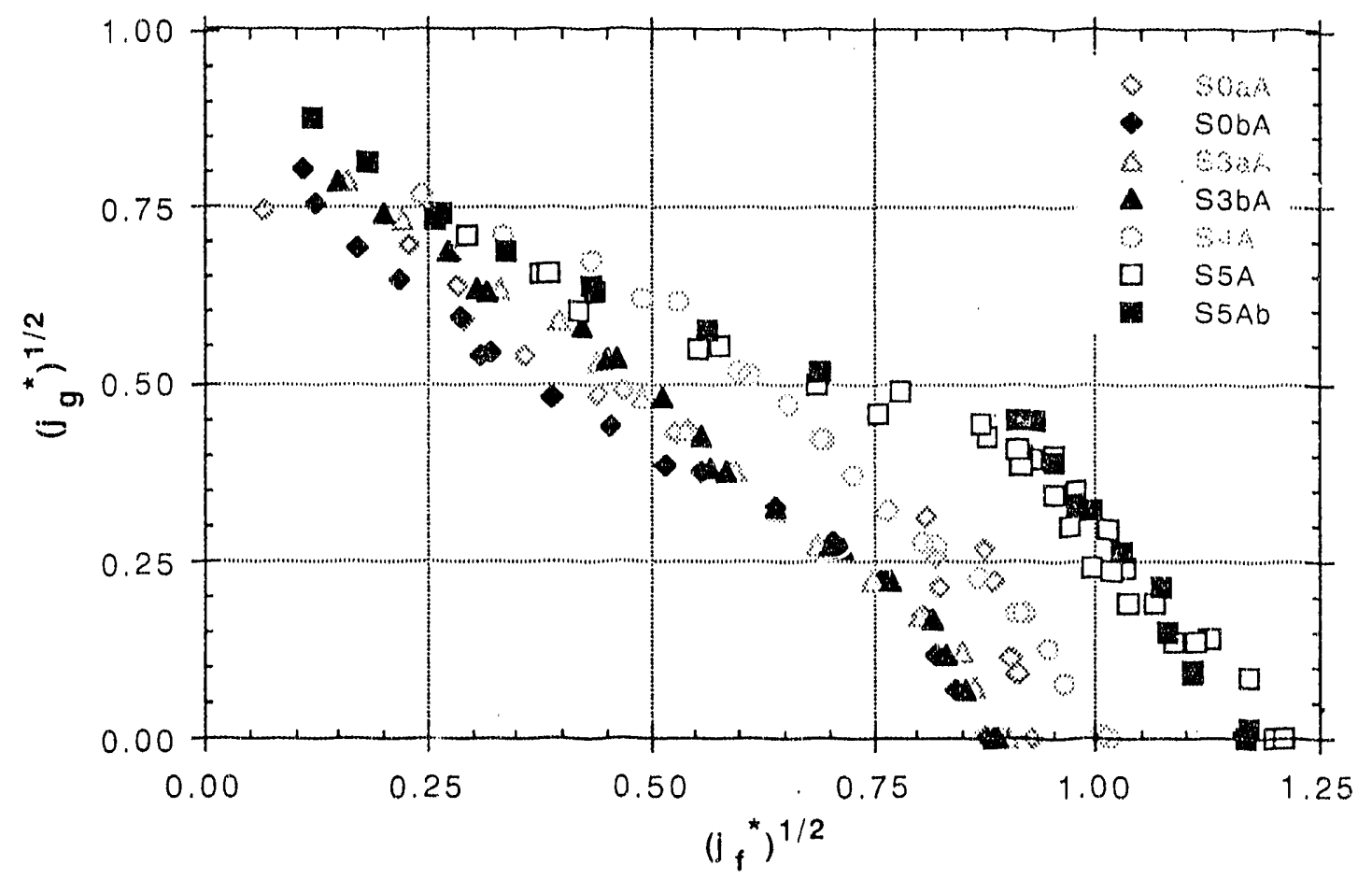

Figure 13. Square root of liquid and air nondimensional superficial velocities for all septifoil CCFL. test series. 


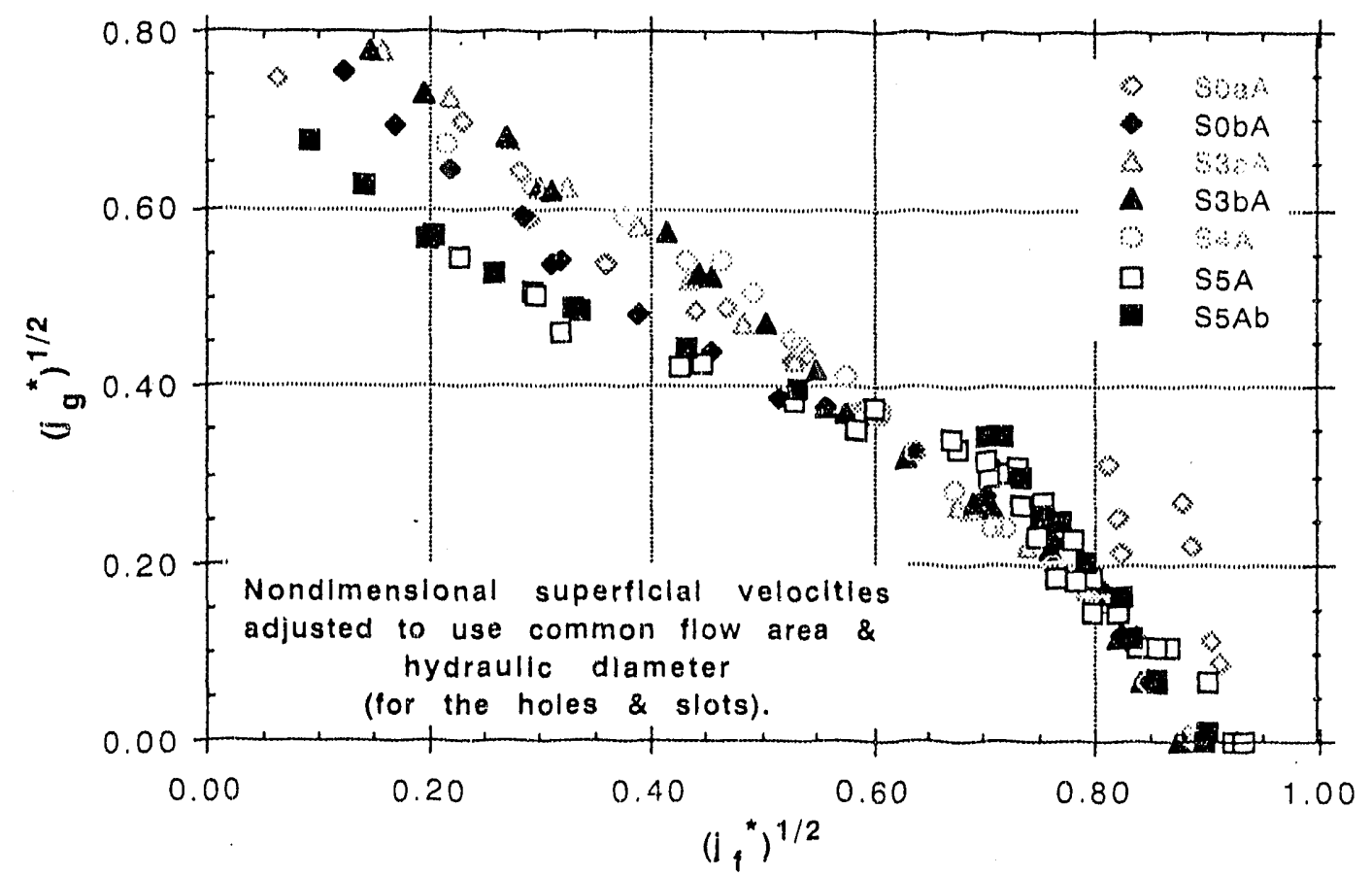

Figure 14. Square root of liquid and air nondimensional superficial velocities for all septifoil CCFL test series, based on slots/holes flow area and hydraulic diameter.

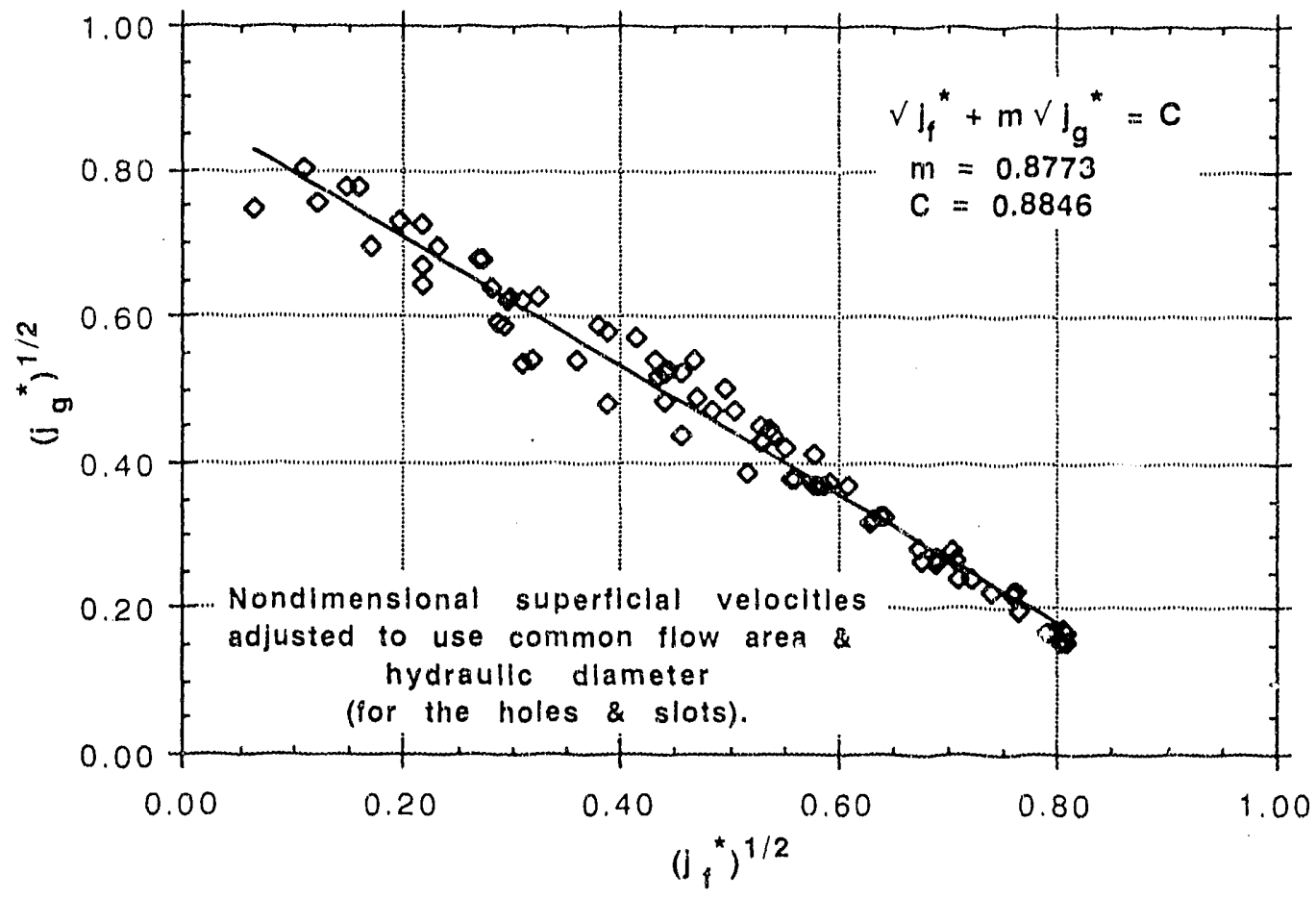

Figure 15. Square root of liquid and air nondimensional superficial velocities for series SOaA, SObA, $S 3 a A, S 3 b A$, and $S 4 A$, based on slots/holes flow area and hydraulic diameter. Five-rod data are excludP.d. 


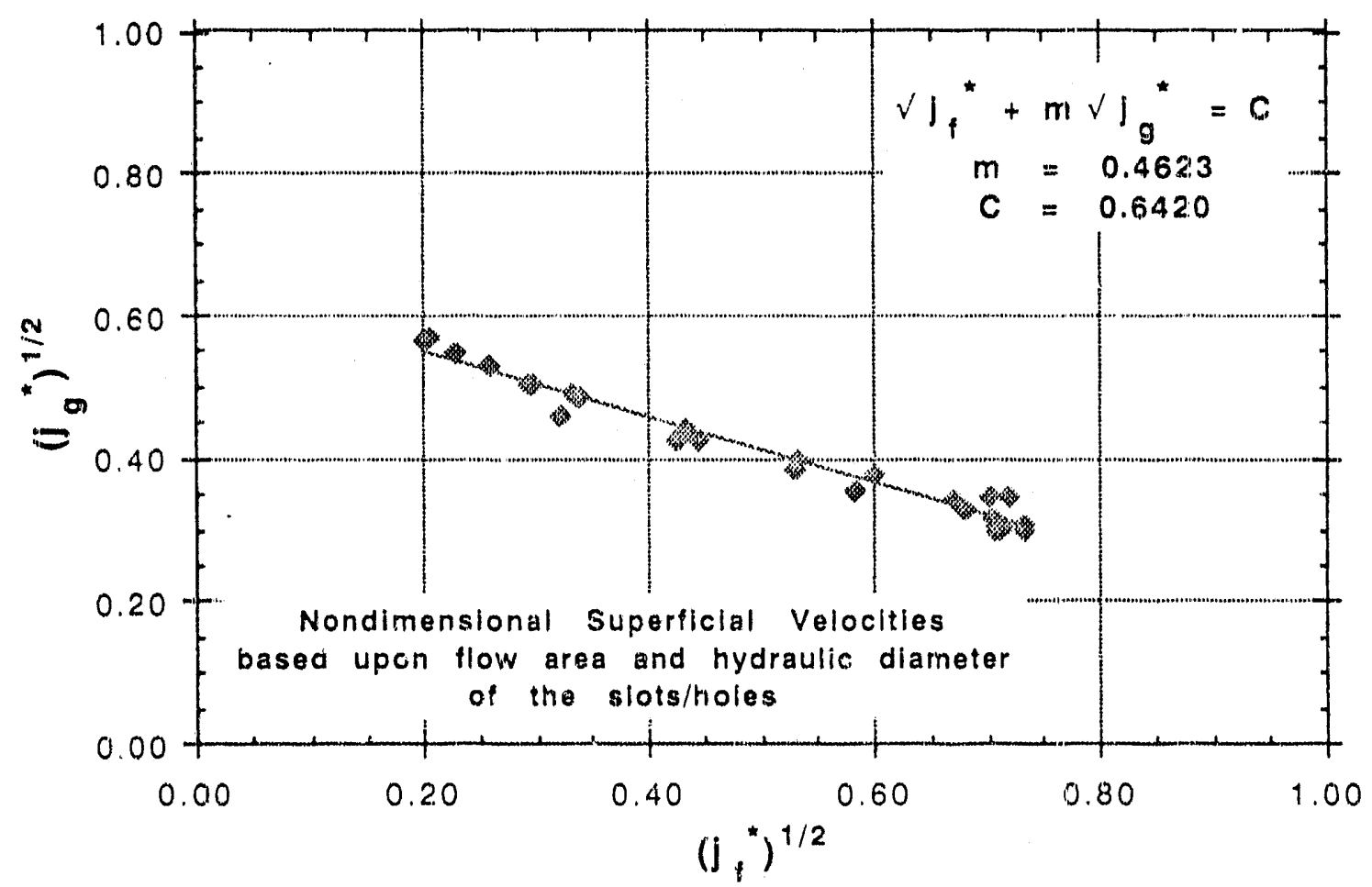

Figure 16. Square root of liquid and air nondimensional superficial velocities for series S5A and $S 5 \mathrm{Ab}$, based on slots/holes flow area and hydraulic diameter. Data only for five-rod config-

Table 4. Correlation coefficients of the septifoil CCFL experiments.

Configuration Slone, $m \quad$ Intercept, $C \quad \mathrm{r}^{\mathrm{z}^{\mathrm{a}}}$

Based on slots/holes flow area and hydraulic diameter.
$0,3, \& 4$ rods
0.8773
0.8846
0.972
5 rods
0.4623
0.6420
0.972

Based on each configurations minimum flow area and hydraulic diameter

$\begin{array}{llll}\text { SOaA } & 0.8003 & 0.8514 & 0.964 \\ \text { SObA } & 0.7622 & 0.7978 & 0.991 \\ \text { S3aA } & 0.9790 & 0.9559 & 0.998 \\ \text { S3bA } & 0.9316 & 0.9351 & 0.991 \\ \text { S4A } & 1.0837 & 1.1649 & 0.990 \\ \text { S5A } & 0.4489 & 0.8150 & 0.974 \\ \text { S5Ab } & 0.4299 & 0.8321 & 0.981\end{array}$

a. Goodness of fit parameter. Perfect fit, $\mathrm{r}^{2}=1$. 


\section{SUMMARY AND CONCLUSIONS}

Flooding (or CCFL) was observed to occur at the general elevation of the septifoil slots/holes, an observation true for all configurations tested. This is contrary to the generally accepted theory that flooding would occur at the location of minimum flow area. It was expected that flooding would occur at the inlet to the septifoil (bottom of the control rods), and that a two-phase pool would form above this location. Neither of these expectations occurred. At no time was a pool observed 10 occur within the septifoil housing. Flow through the 0.25 -inch holes was always observed to be liquid flow from the tank into the septifoil housing. Within the septifoil housing, air flow was predominatly up the empty channels, liquid flow was down the channels, with rods and film flow occurring on the inner wall of the septifoil housing.
Results (in terms of the square root of the Wallis non-dimensional superficial velocities) from the test series with zero, three, and four rods inserted were virtually identical when using a common flow area and hydraulic diameter in Equation (1) and resulted in correlation coefficients within the generally excepted values $(m=0.38$ and $C=0.88)$. However, the results from the series with five rods inserted are significantly different from the other configuration results, with much smaller values for the coefficients $(m=0.46$ and $C=0.64$ ). Because flooding occurs in the general vicinity of the slots/holes, the liquid flow available for cooling of the control rods further down the septifoil is limited at this elevation. Analysis will require using the five-rod flooding results anytime that five rods are even partially inserted, leading to the most limited liquid flow and cooling. 


\section{REFERENCES}

1. G. B. Wallis, One Dimensional Two-Phase Flow, McGraw Hill, Inc., 1969.

2. Vreeland, D. G. 1991. Control rod power and flow levels based on fiow instability limits, SRLSAG-91-9057, Appendix A, pp. 23-27. 
APPENDIX A

Facility Drawings 


\section{APPENDIX A}

\section{Facility Drawings}

This Appendix presents the facility drawings for the components of the Septifoil CCFL experiments. The following special purpose drawings are included in this Appendix:

CCf11 CCFL Test Facility - Piping and Instrumentation Diagram

CCFL2 CCFL Test Facility - Septifoil Housing Details

CCFL3 CCFL Test Facility - Septifoil Housing Details

CCFL4 CCFL Test Facility - Septifoil Housing Asse mbly

CCFL5 CCFL Test Facility - Simulated Control Rod Assembly and Details

CCFL9 CCFL Test Facility - Test Rig Installation

CCFL10 CCFL Test Facility - Test Rig Lower Flange Assembly

CCFL11 CCFL Test Facility - Tubesheet \& Deflector Simulator 


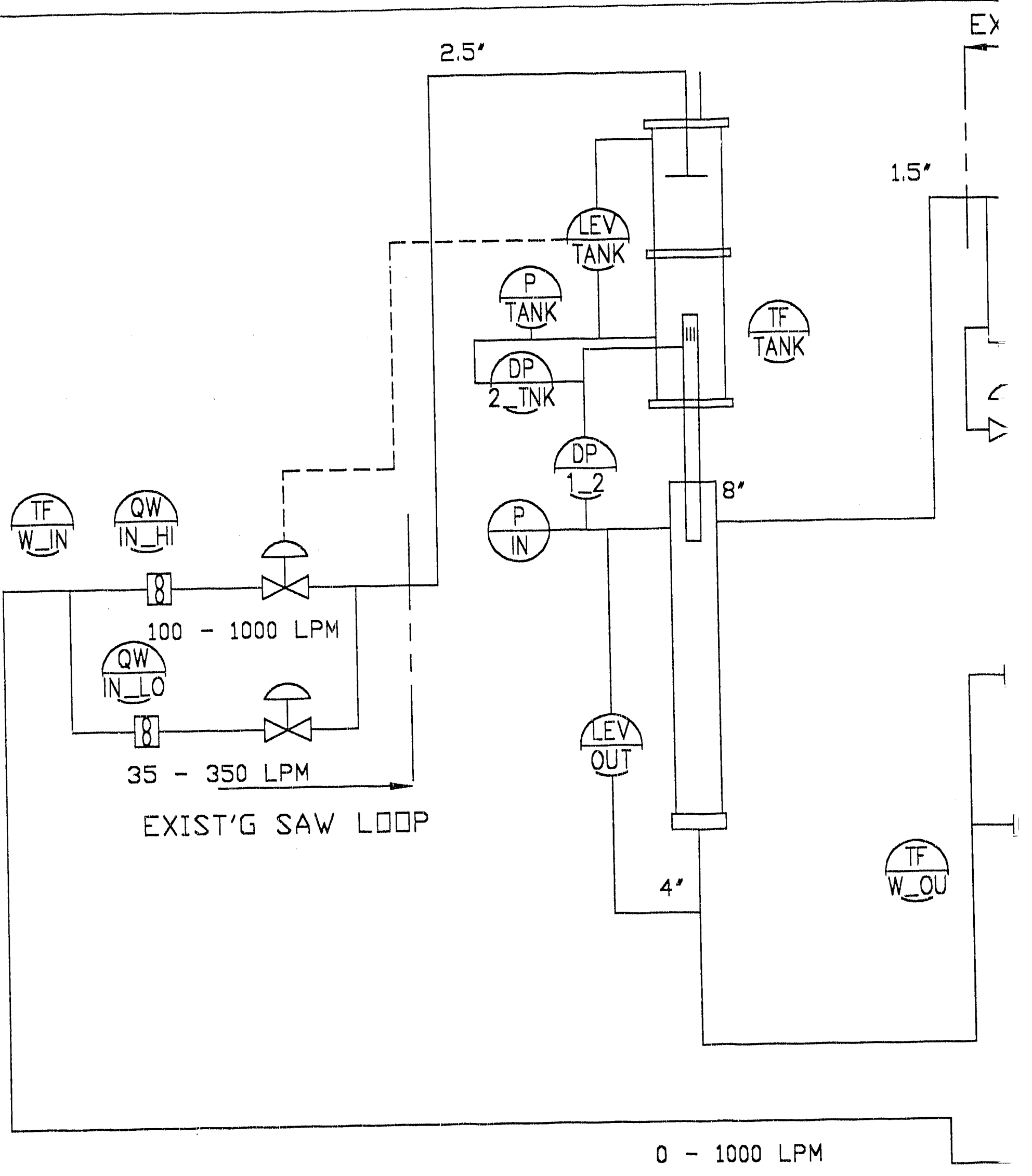


IST'G SAW LUDP

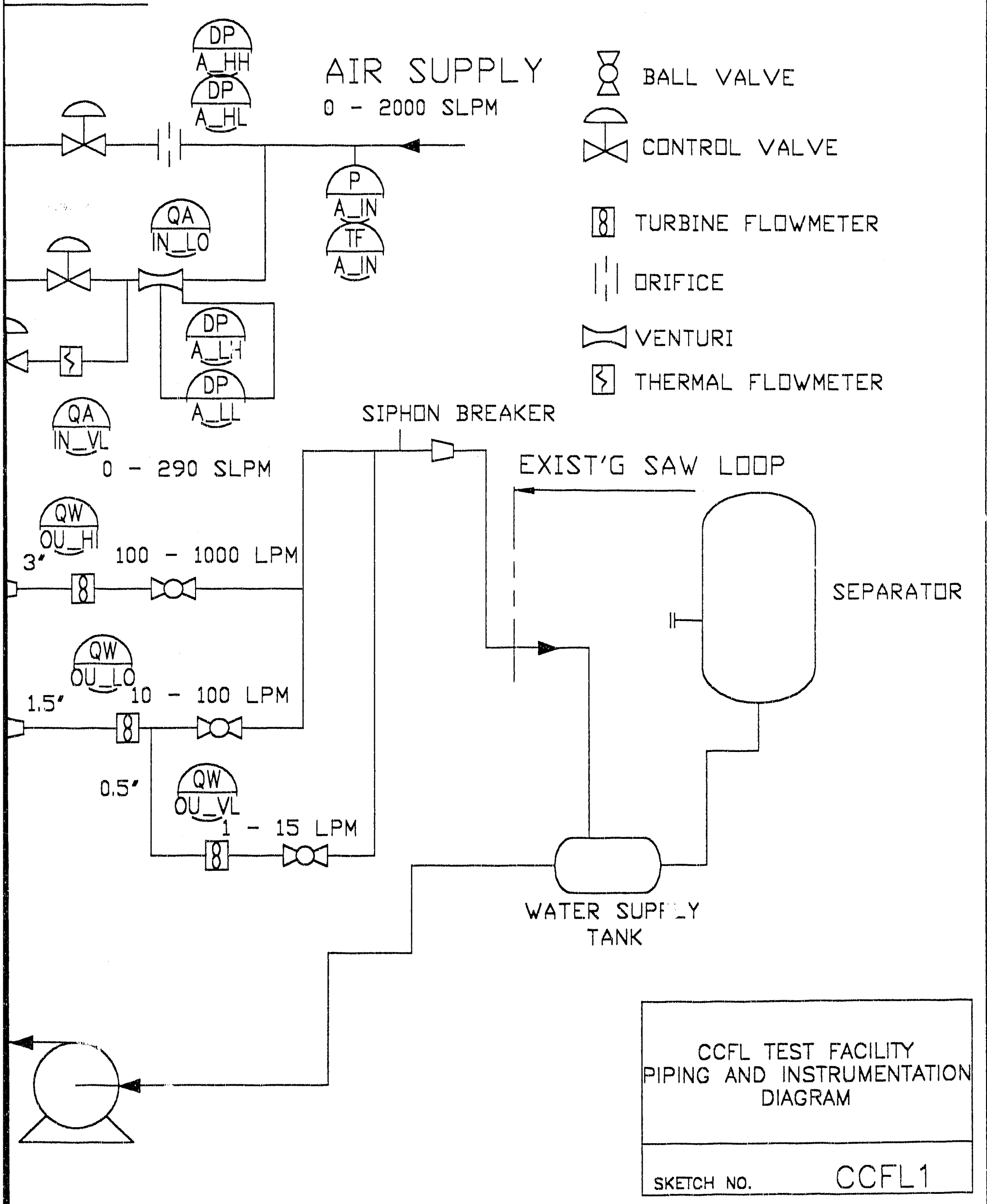




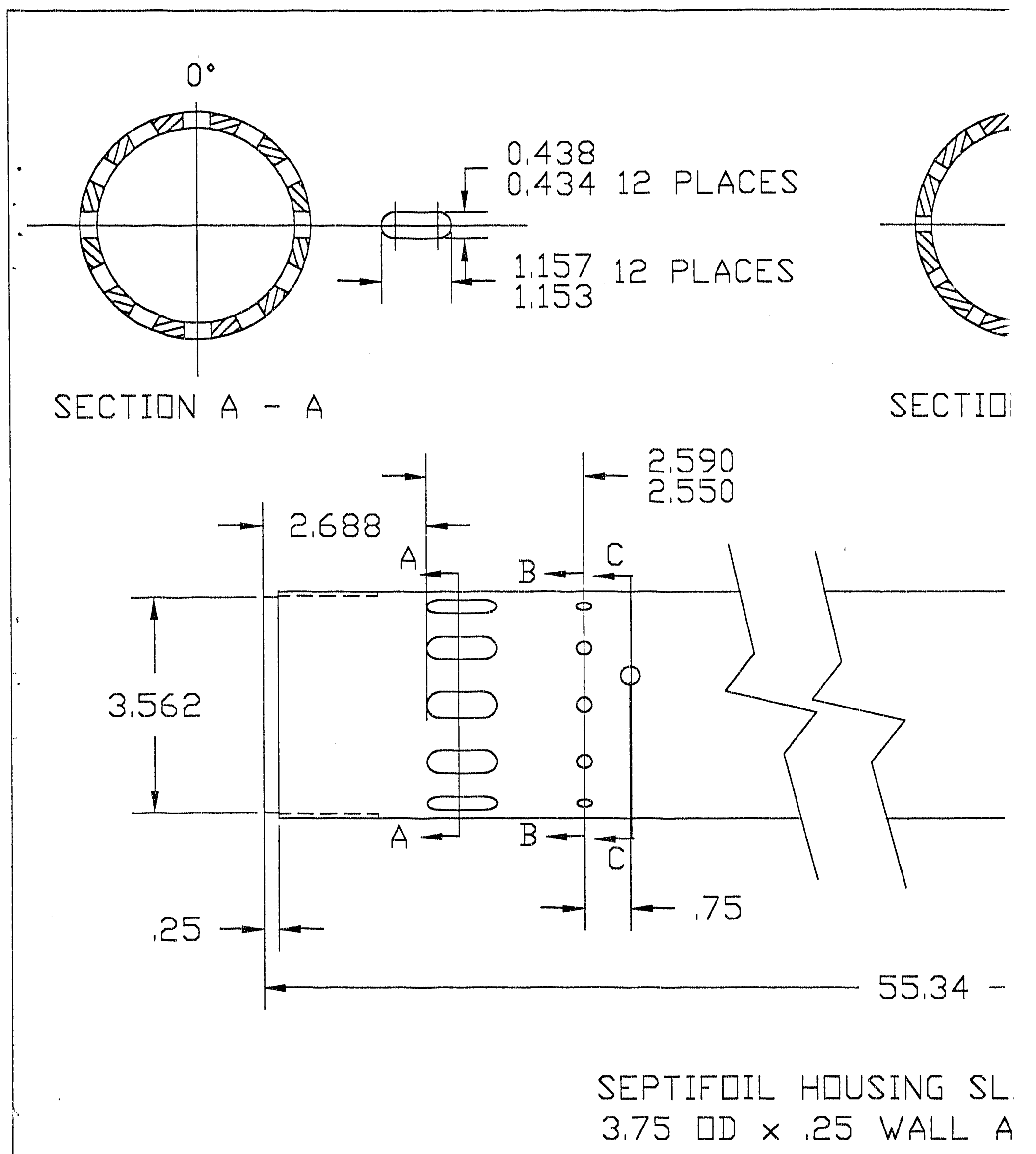


1. ALL MATERIAL 6061-T6 ALUMINUM

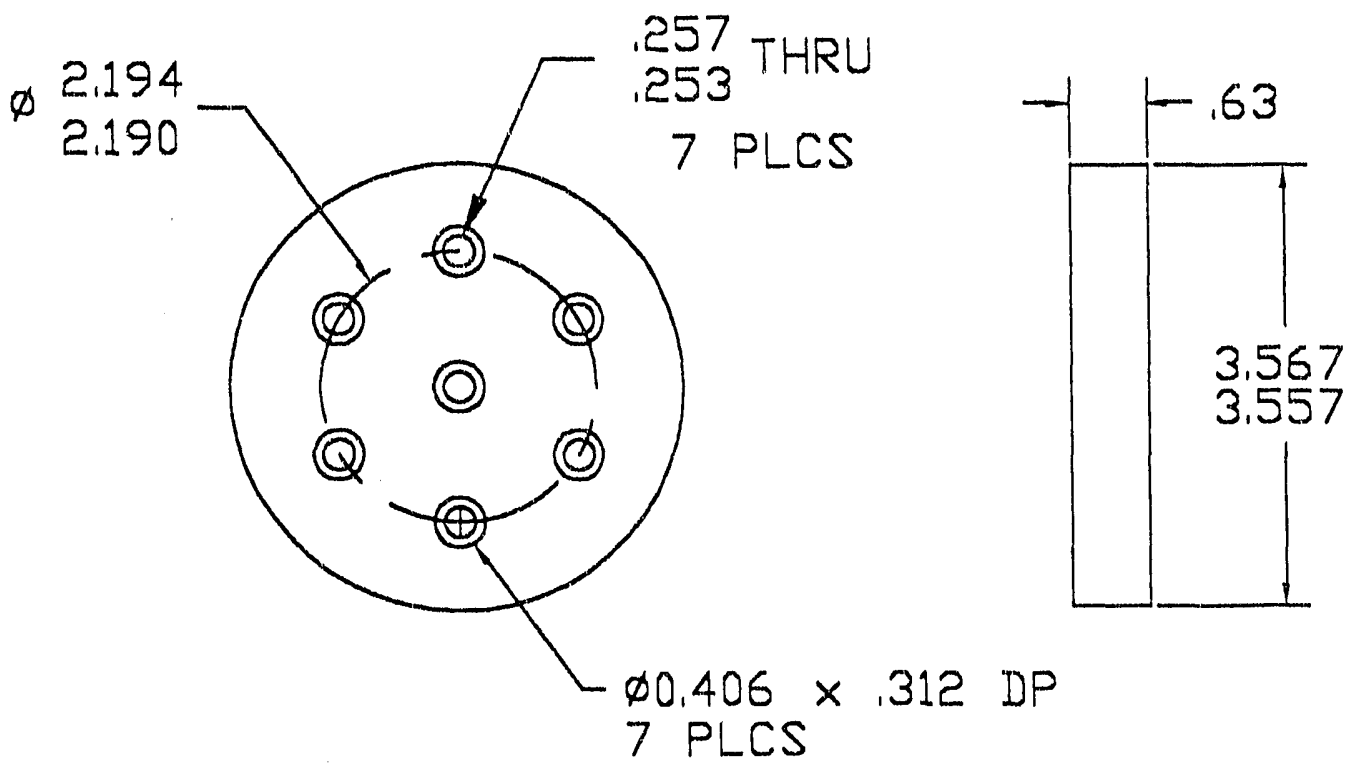

HIUSING PLUG DETAIL
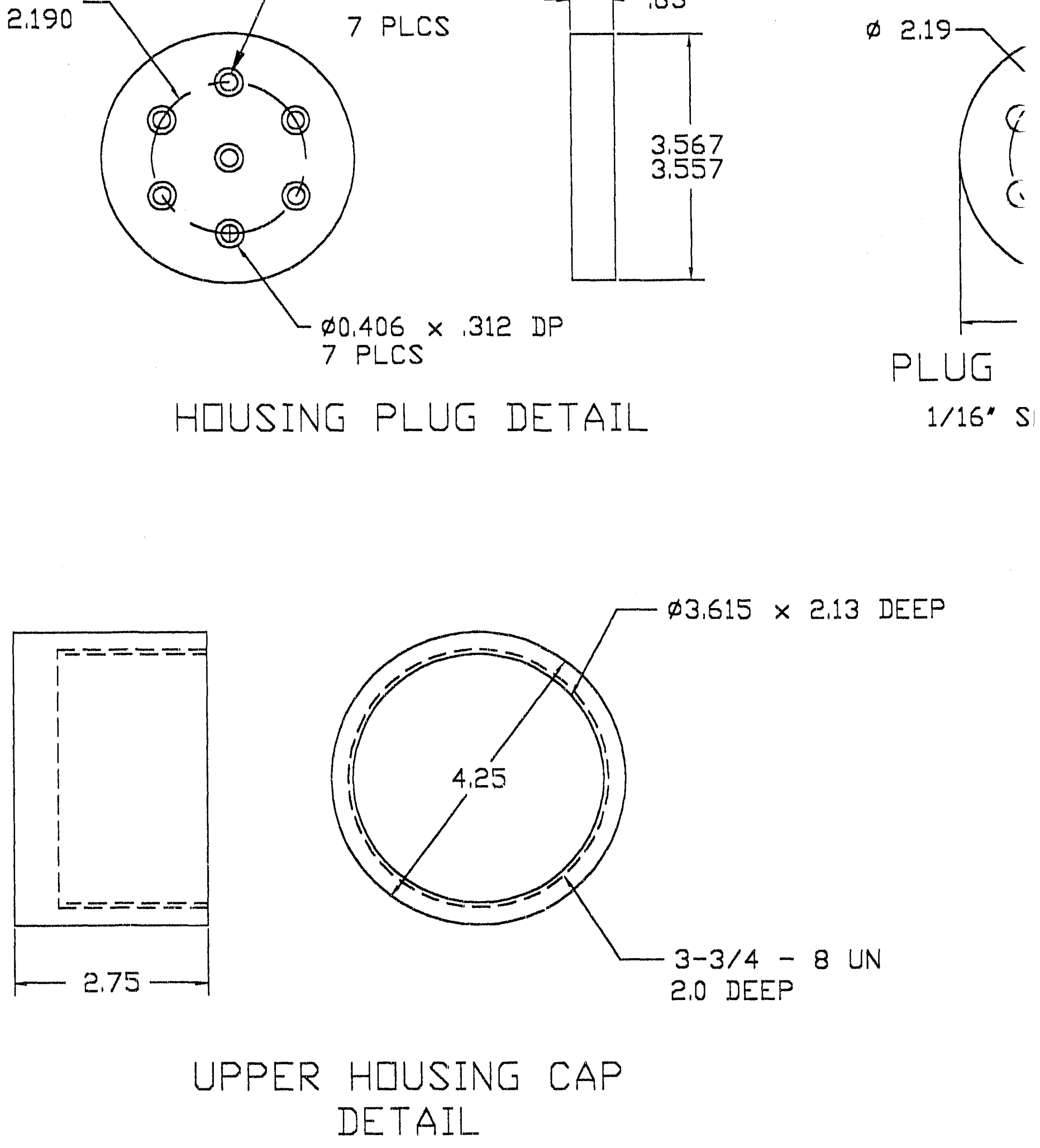

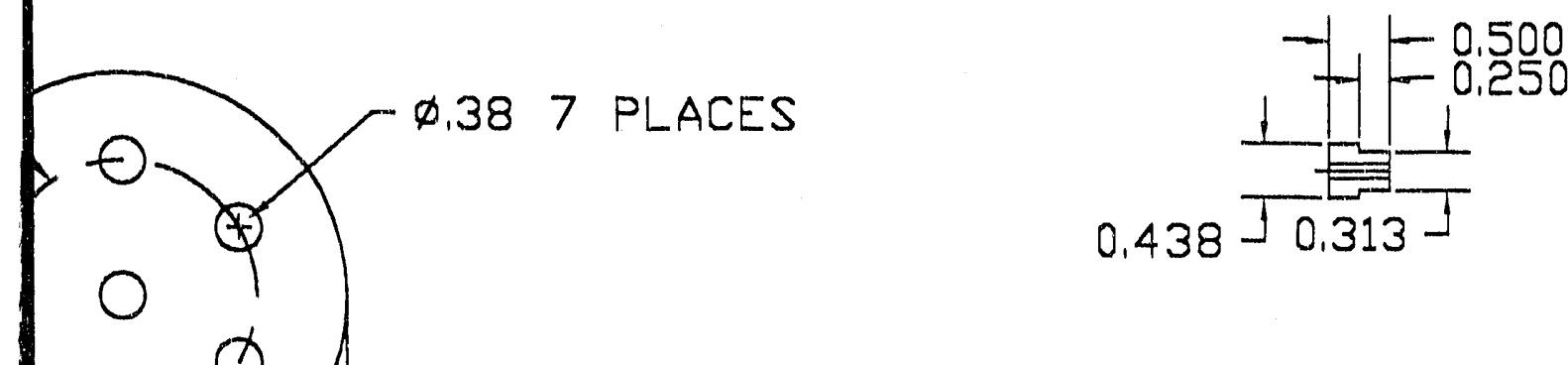

(ब)

PRESSURE TAP PLUG DETAIL

3.625

-ASKET DETAIL

LICDNE RUBBER
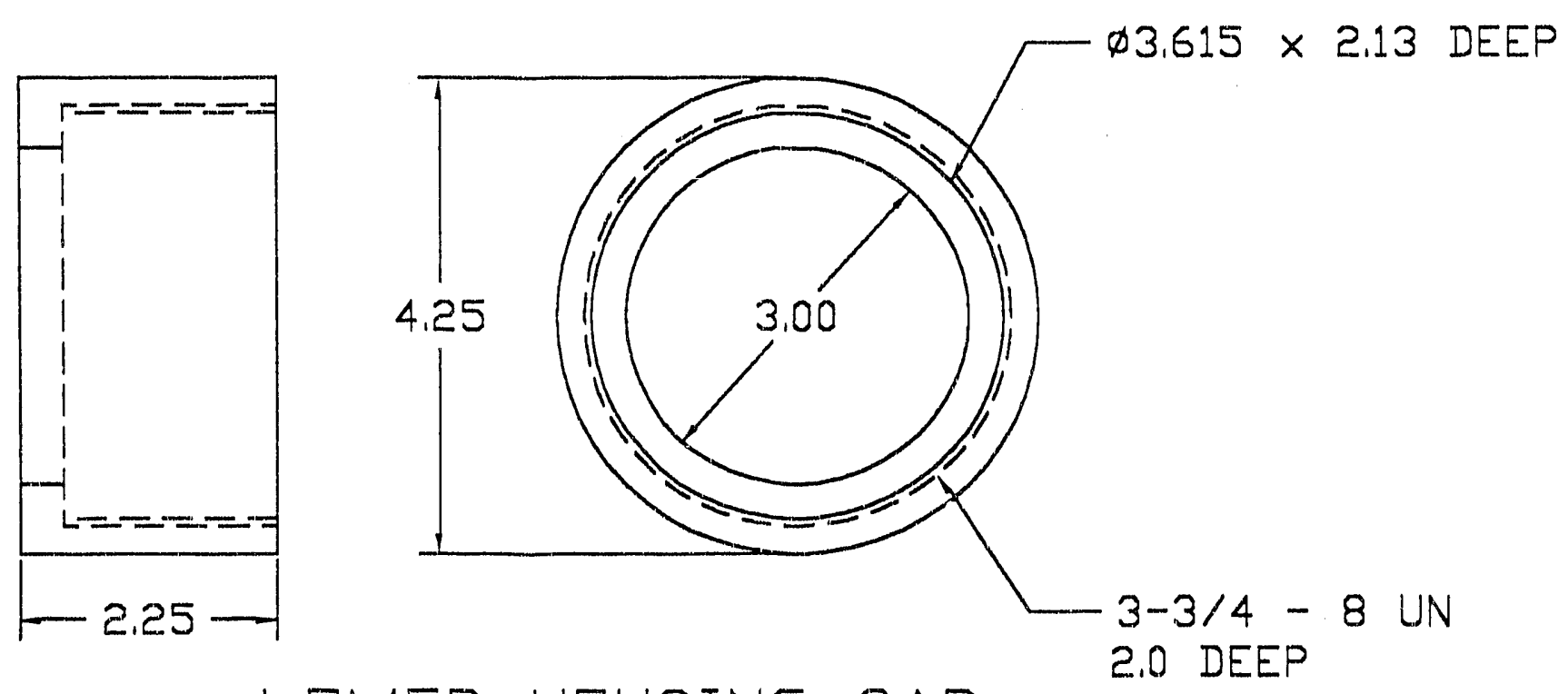

LIWER HIUSING CAP DETAIL

CCFL TEST FACILITY SEPTIFOIL HOUSING DETAILS 
1. GLUE ITEMS USING WELD-DN 40

2. ASSEMBLE SPIDER IN HOUSING TUBE WITH SILID END TOWARDS UPPER HUUSING PLUG.

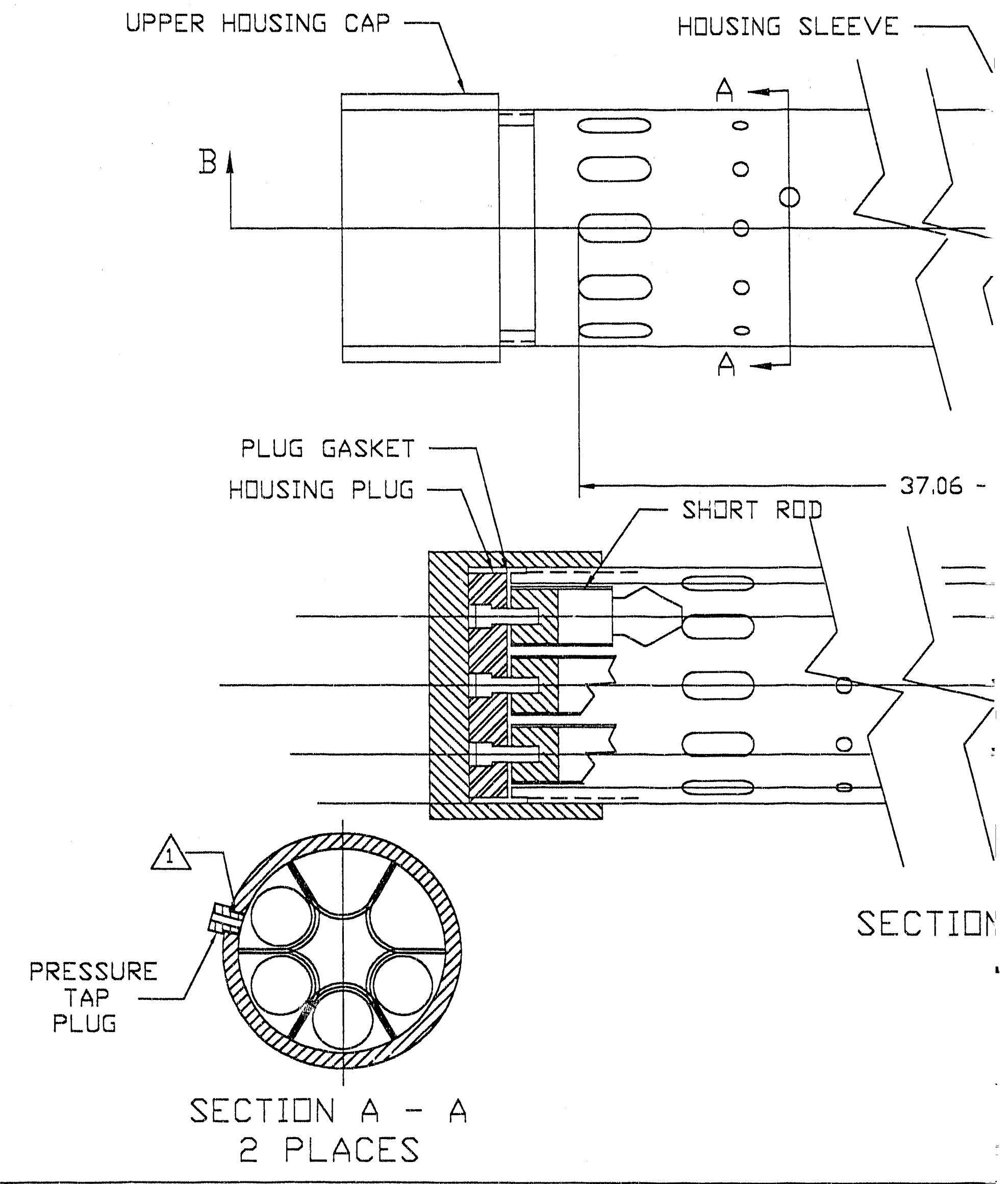




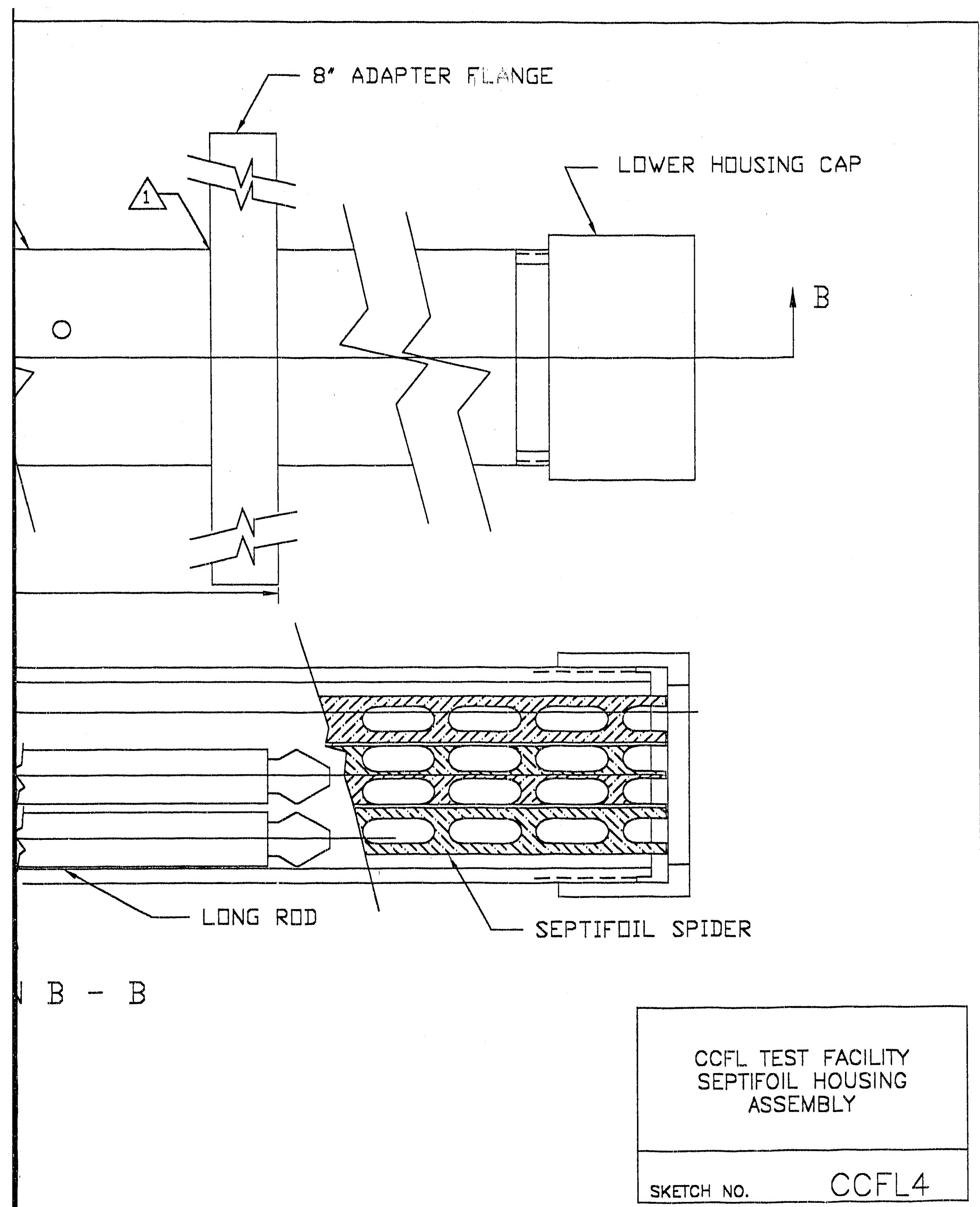


1. ALL MATERIALS 300 SERIES SS

A) WELD PER $S$ 2.0. WELD HEIGHT NDT TD EXCEED .03" WELD BUILD-UP QN D.D, NUT TO EXCEED .004",
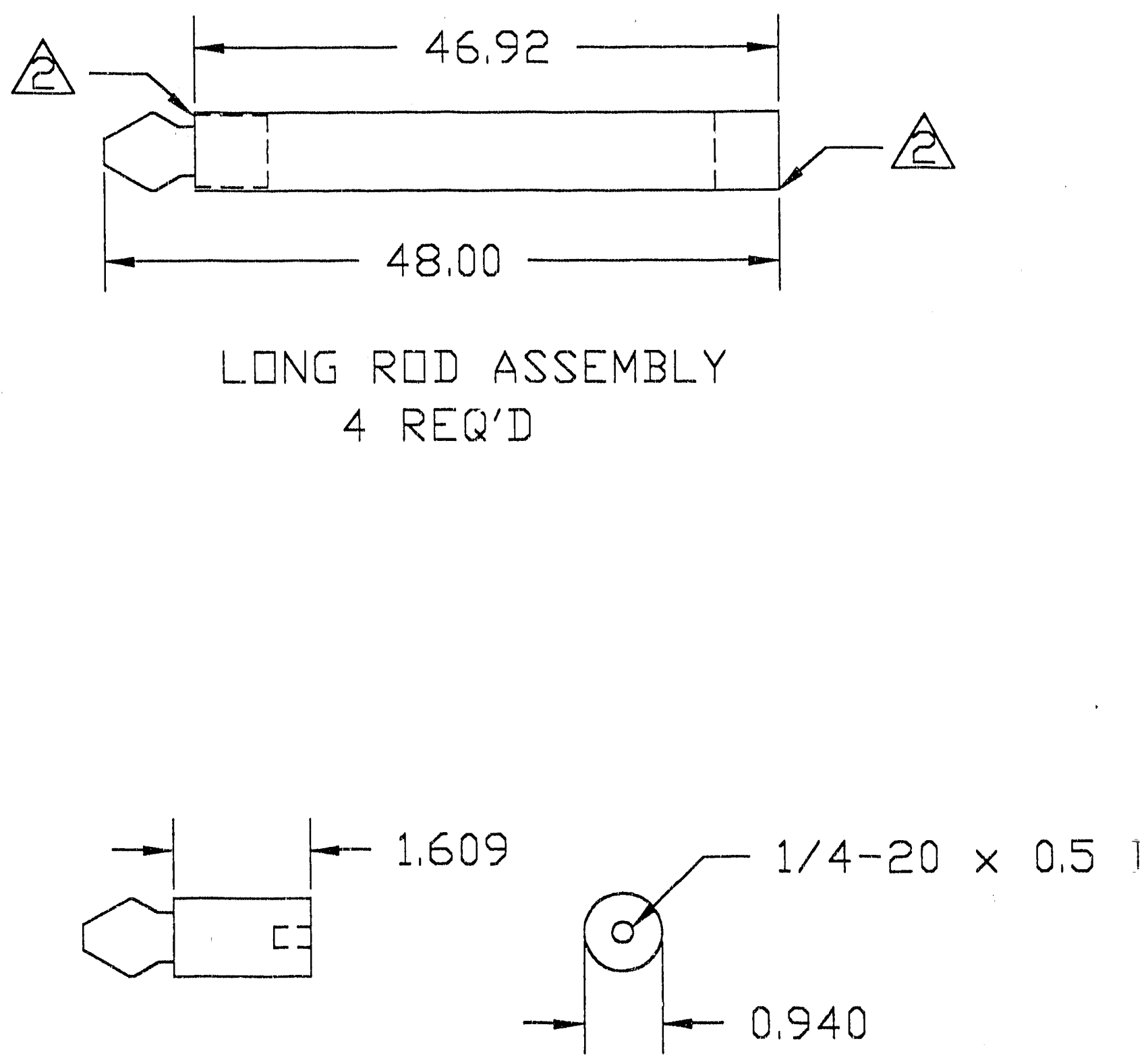

SHORT ROD

DETAIL

7 REQ'D 


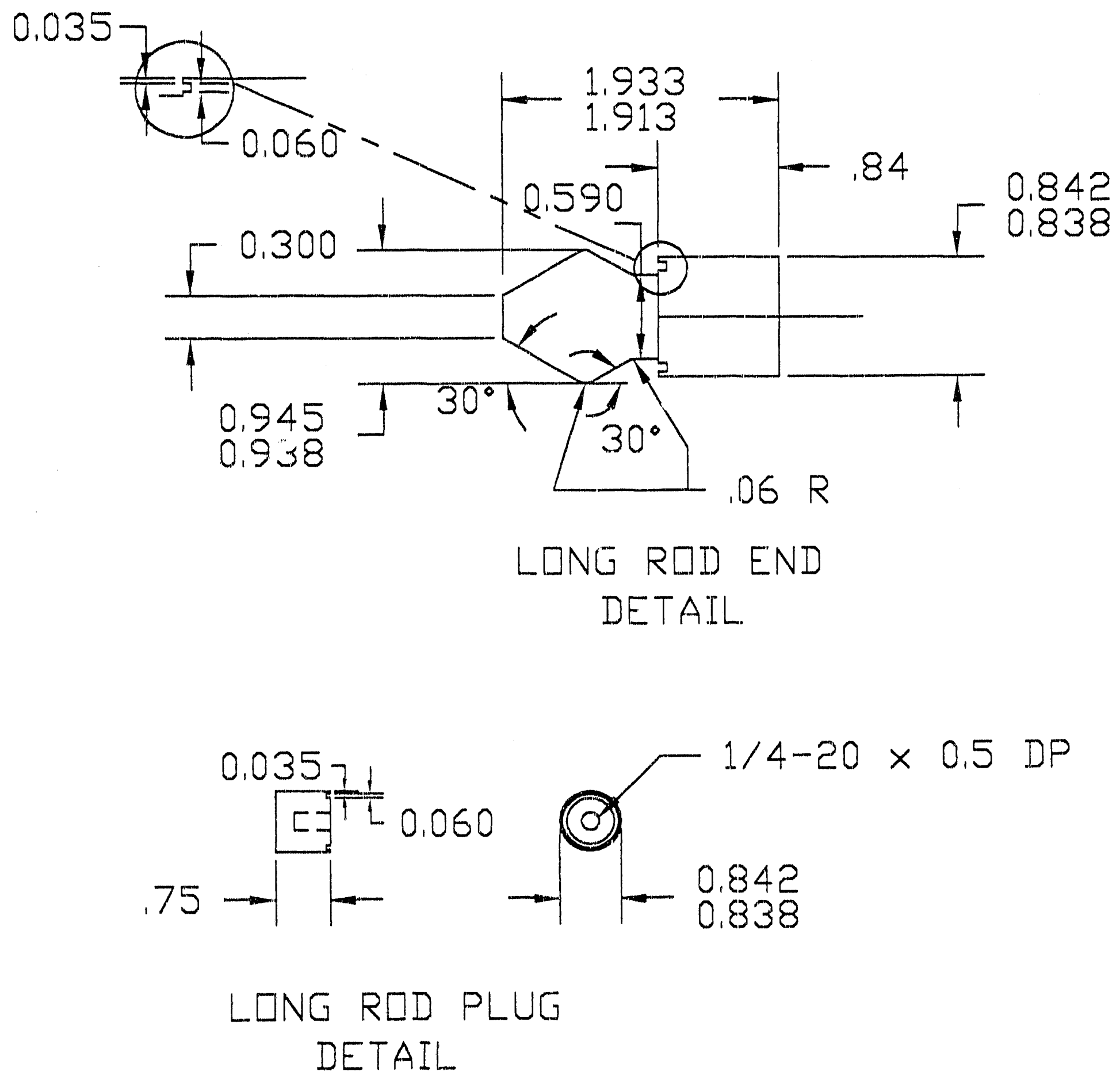




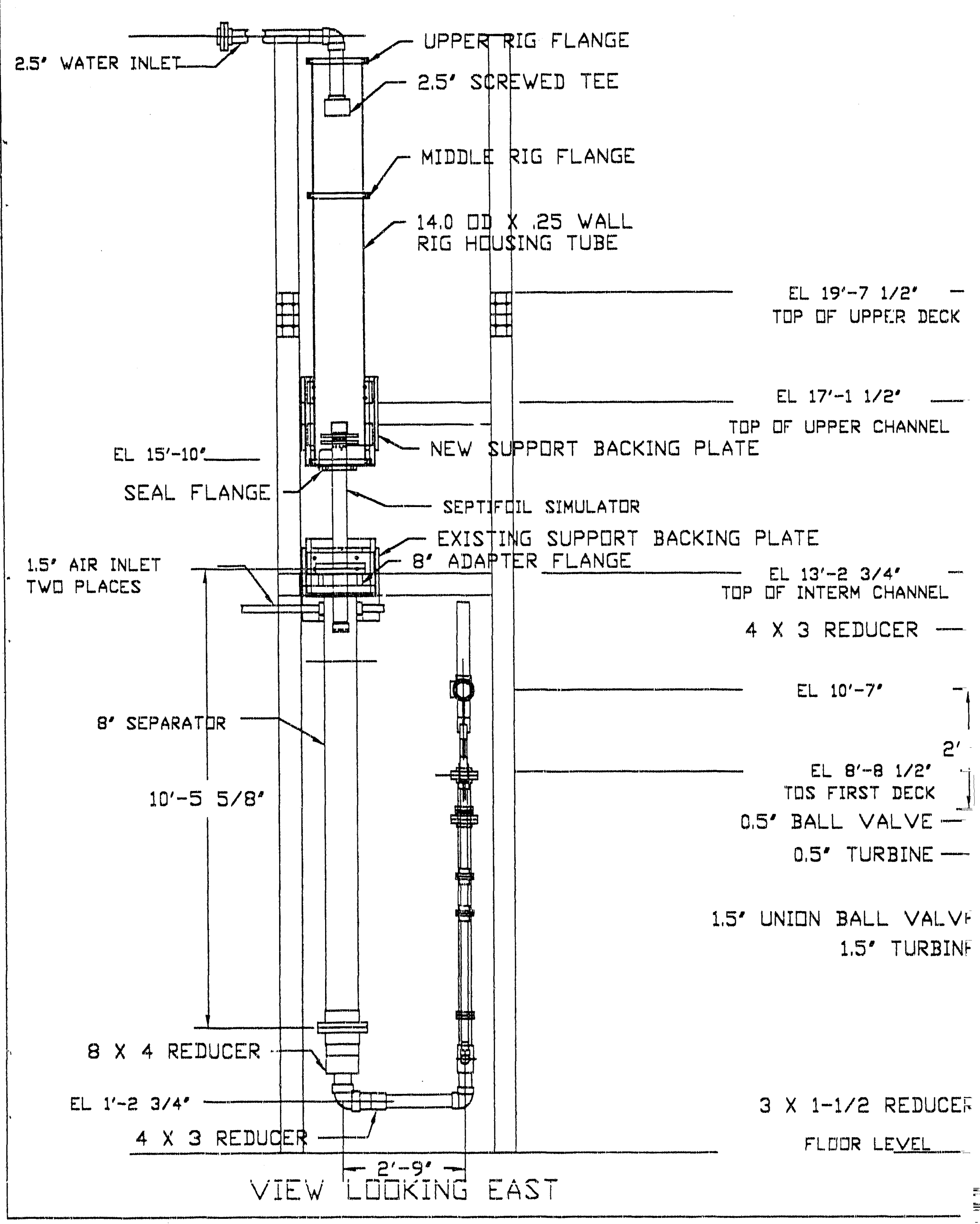




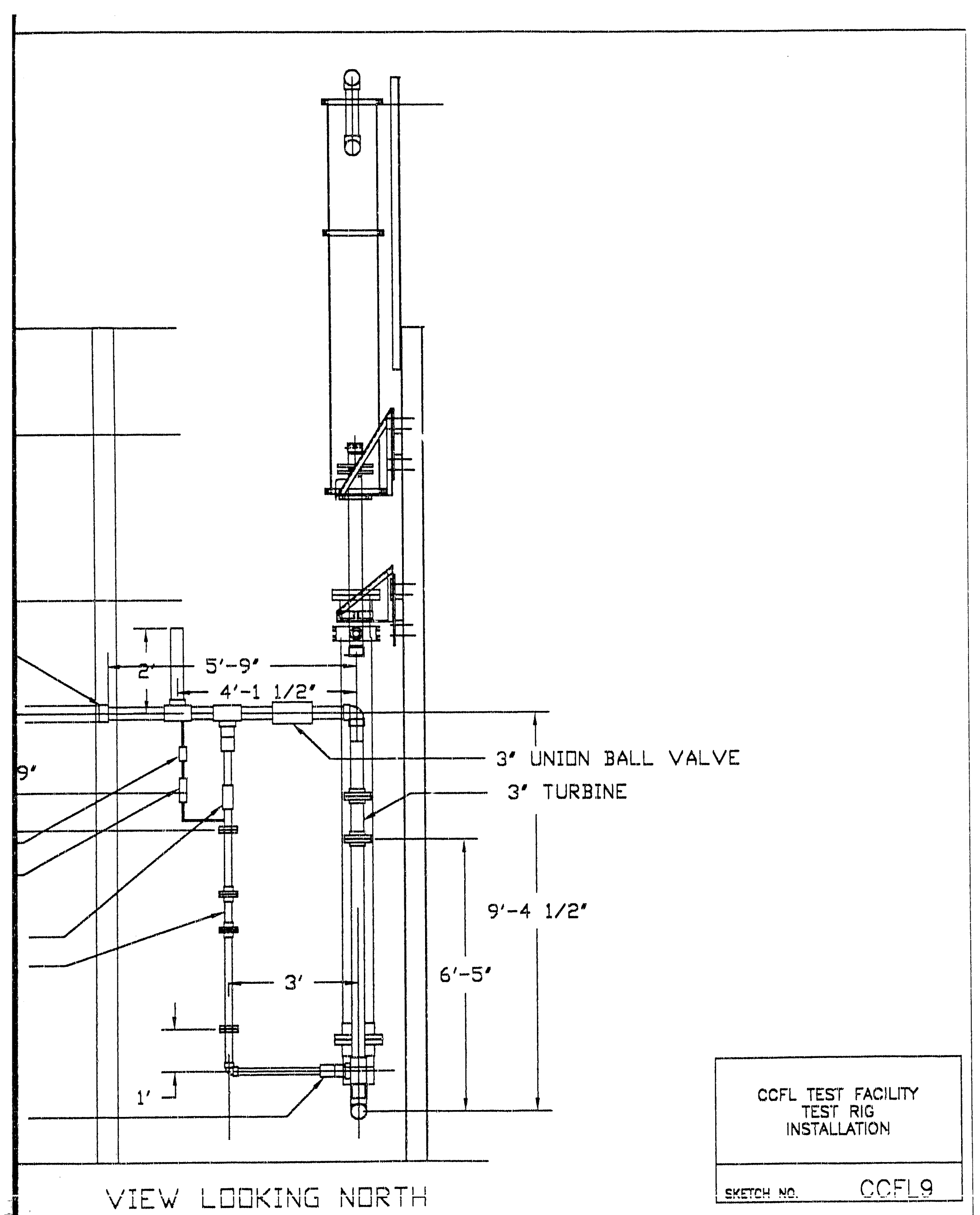




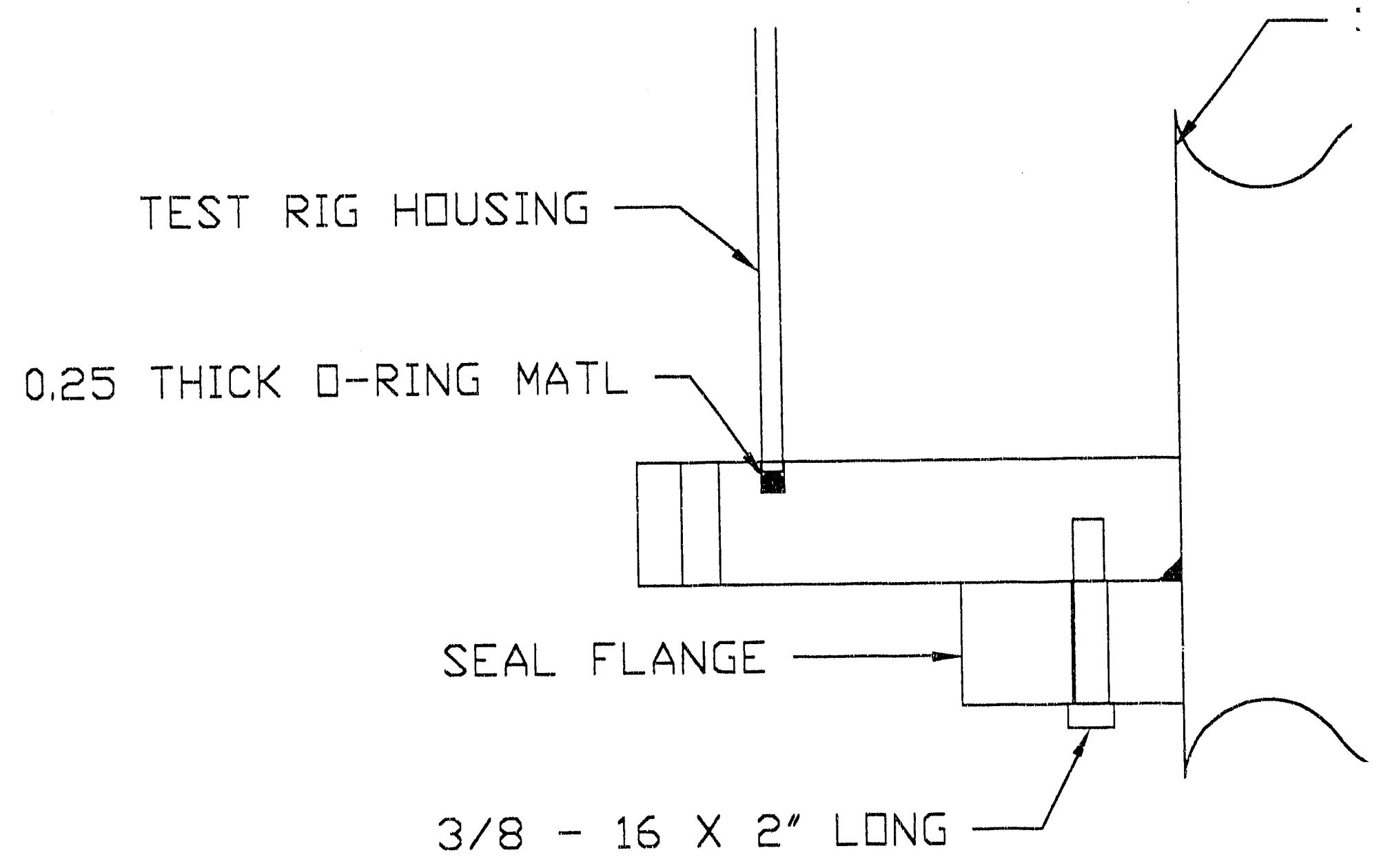


PEPTIFUIL HOUSING

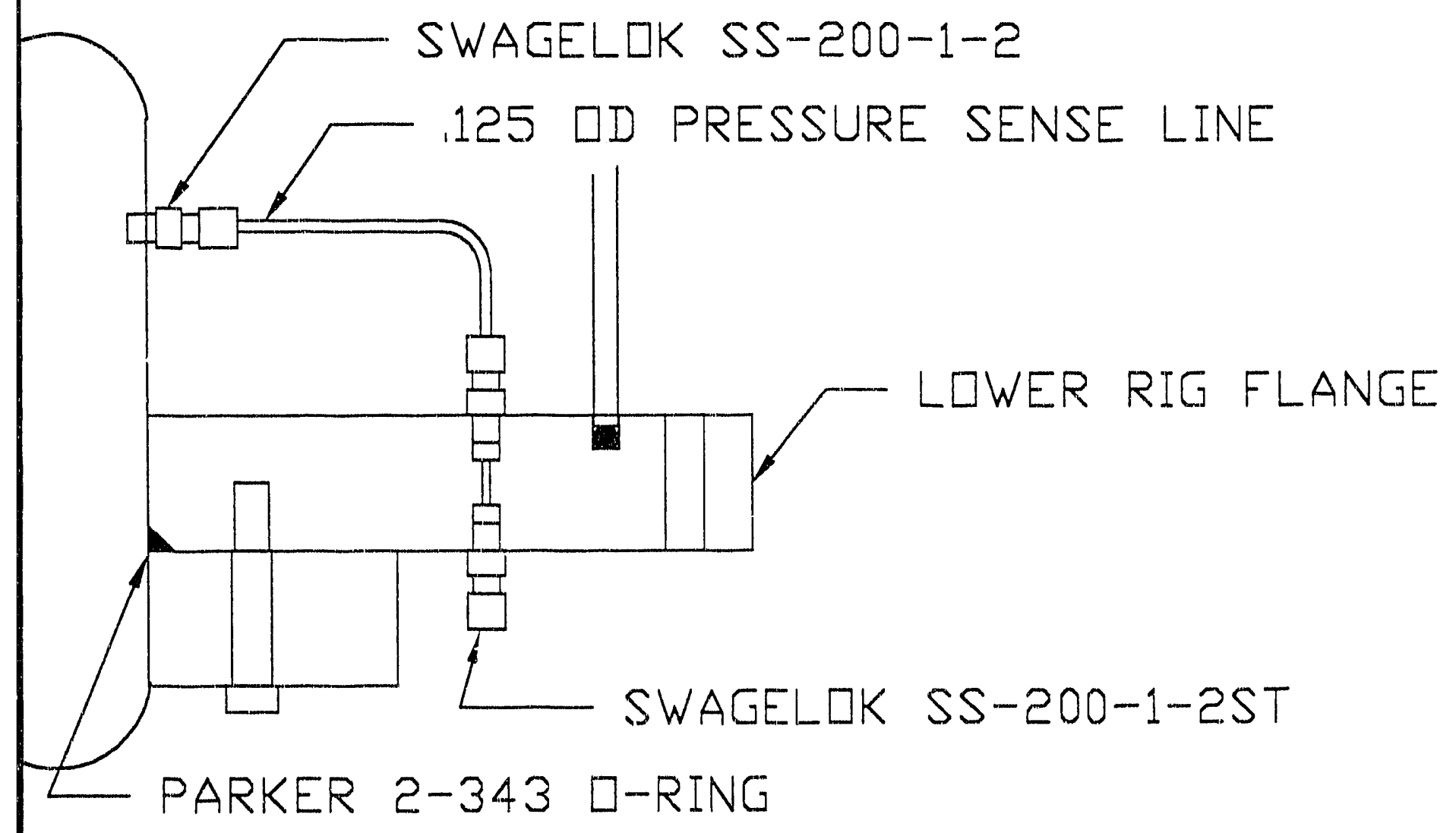

CCFL TEST FACILITY

TEST RIG LOWER FLANGE ASSEMBLY 


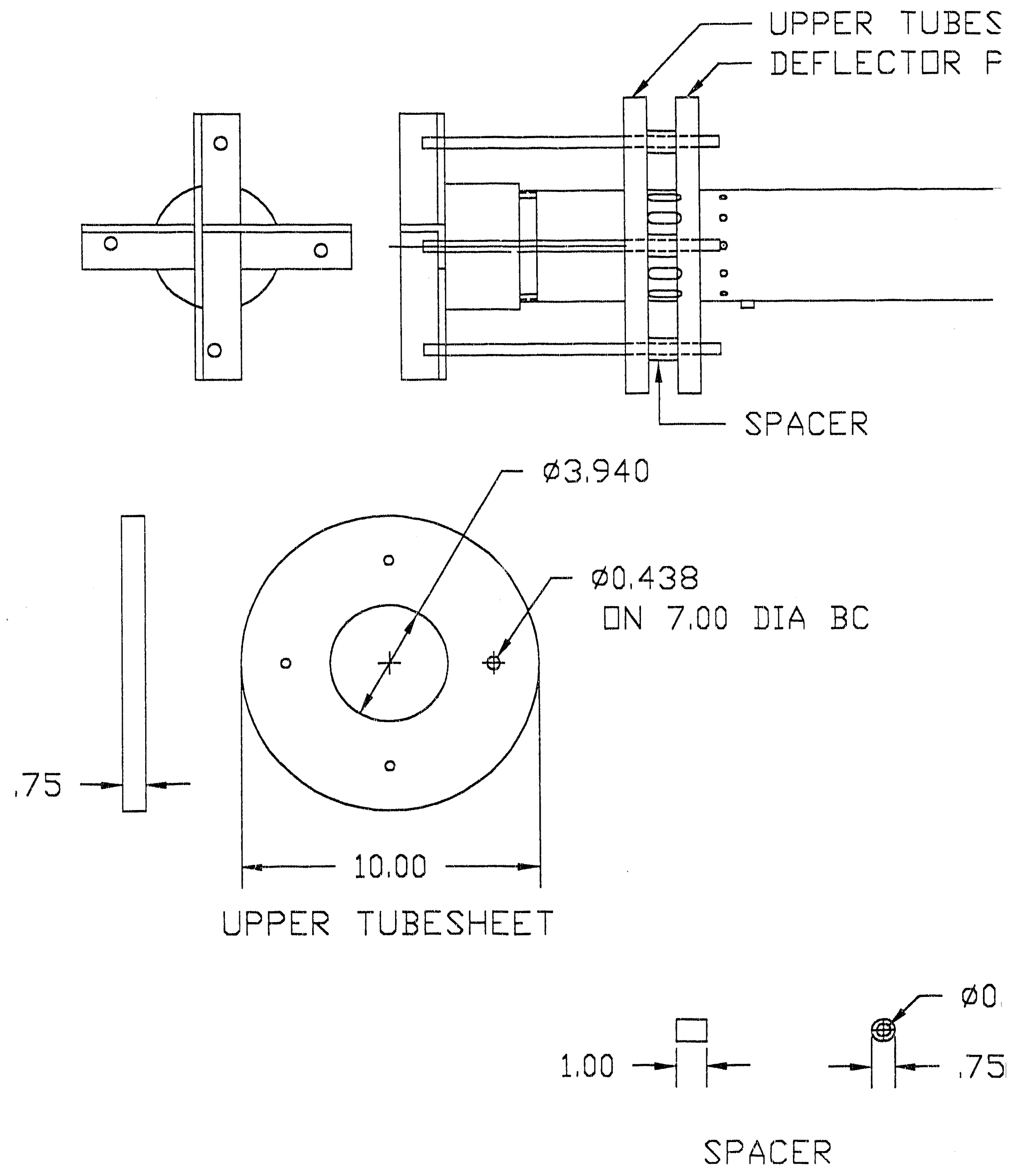


HEET SIMULATUR

LATE SIMULATIR

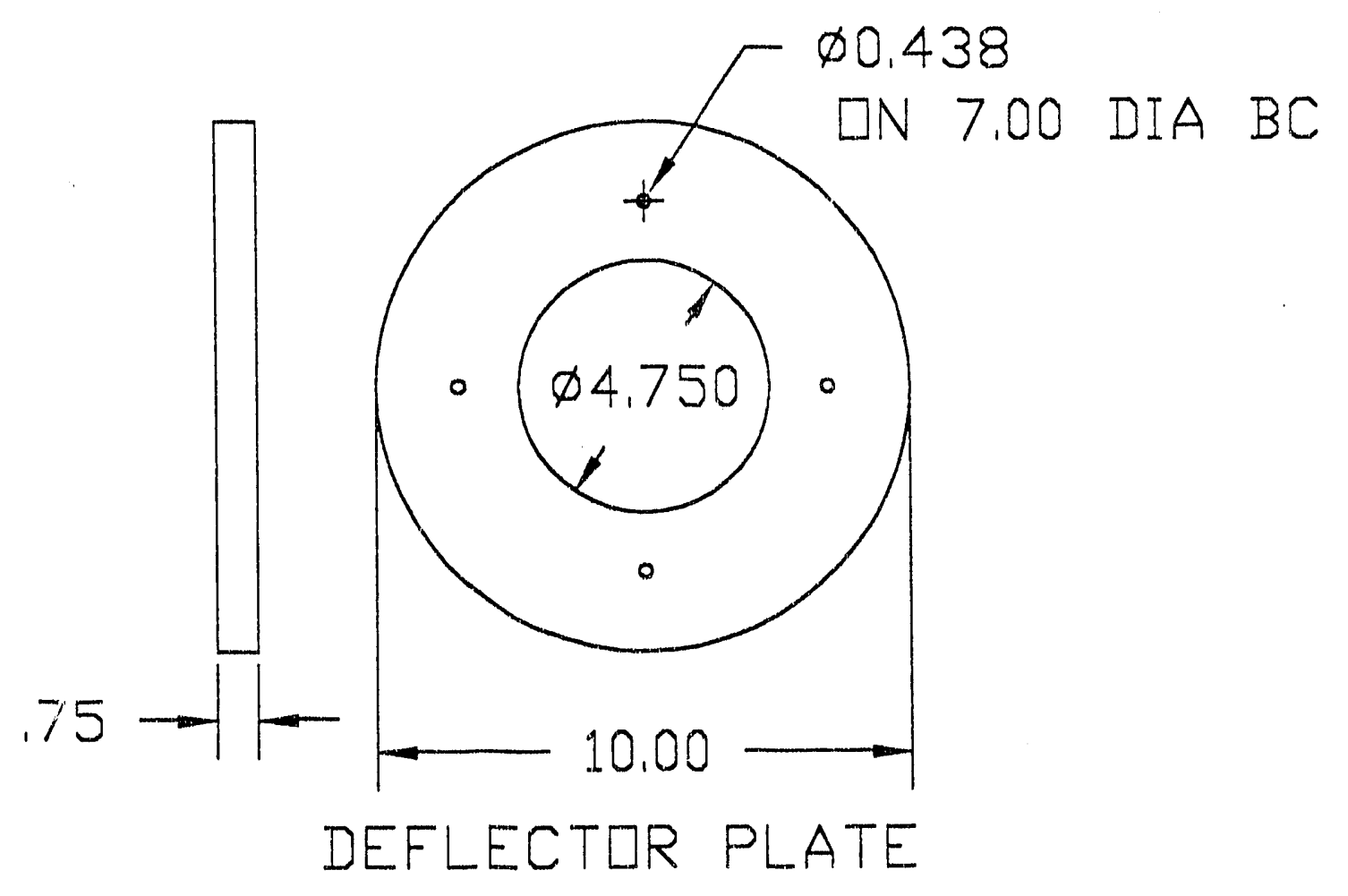

438

CCFL TEST FACILITY TUBESHEET \& DEFLECTOR SIMULATOR

SKETCH NO. CCFL11 


\section{APPENDIX B}

Uncertainty Analysis For CCFL Calculated Parameters 


\section{APPENDIX B \\ Uncertainty Analysis For CCFL Calculated Parameters}

The following analysis of the uncertainties in the calculated parameters is based upon the method presented by S. J. Kline and F. A. McClintock ${ }^{\mathrm{B}-1}$ for uncertainties in the single sample experiments and accepted by the ASME ${ }^{\mathrm{B}}-2$. The analysis is primarily to provide the uncertainty for the root of the Wallis nondimensional mass fluxes $\mathrm{jg}^{*}$ and $\mathrm{jf}^{*}$. However, the uncertainty in the individual phase densities and mass flow rates are also derived, since the uncertainties in the nondimensional mass fluxes require these.

In this appendix the derivation of the basic uncertainty equations will be presented first. Next the results of the uncertainty analysis for five test cases will be presented.

\section{Method for Uncertainty Analysis}

The method for uncertainty analysis of a computed result presented by Kline and McClintock ${ }^{B-1}$ may be summarized by

$$
\Delta R=\left[\sum_{i=1}^{N}\left(\frac{\partial R}{\partial V_{i}} \Delta V_{i}\right)^{2}\right]^{1 / 2}
$$

where

$$
\begin{array}{ll}
R= & \text { result } \\
V_{i}= & i^{\text {th }} \text { independent variable } \\
\Delta R_{i}, \Delta V_{i}= & \begin{array}{l}
\text { absolute uncertainty in the result and the independent } i^{\text {th }} \text { variable, } \\
\text { respectively. }
\end{array}
\end{array}
$$

\section{Uncertainty in Mass Flow Measurements}

The mass flow rate of the gas and liquid were measured by two different methods. The injection gas was measured by a venturi using two differential pressure transducers of 10:1 ranges, to provide a total 10:1 range of the flow rate measurement, and a thermal mass flow meter with a 20:1 range. This provided a total air mass flow rate range of 7$3400 \mathrm{~g} / \mathrm{min}$. The liquid draining measurement (upon which the $\mathrm{jf}^{*}$ number is based) was made using turbines (10:1 range) of sizes 0.5 -inch, 1-inch, and 3-inch, providing a total measurement range of 1-1000 LPM. The uncertainty analysis of each measurement type will be presented separately. 
Liquid Mass Flow Rate Uncertainty. The liquid mass flow rate, using a turbine, is calculated using

$$
\dot{m}_{F}=Q_{F} \rho_{F}
$$

where

$$
\begin{array}{ll}
\dot{m}_{F}= & \text { liquid mass flow rate }(\mathrm{kg} / \mathrm{s}) \\
\mathrm{QF} & =\text { volumetric flow rate measured by the turbine }\left(\mathrm{m}^{3} / \mathrm{s}\right) \\
\rho \mathrm{FF} & =\text { liquid density }\left(\mathrm{kg} / \mathrm{m}^{3}\right)
\end{array}
$$

Applying Equation (B-1) upon Equation (B-2) the measurement uncertainty in the liquid mass flow rate can be given by

$$
\delta \dot{m}_{F}=\frac{\Delta \dot{m}_{F}}{\dot{m}_{F}}=\sqrt{\left(\frac{\Delta Q_{F}}{Q_{F}}\right)^{2}+\left(\frac{\Delta \rho_{F}}{\rho_{F}}\right)^{2}}
$$

where the absolute uncertainties in the independent variables are represented by $\Delta$ 's. The uncertainty in the volumetric flow rate measured by the turbine, $\Delta Q_{F}$, is given in Table 2 of the main report as $\pm 0.5 \%$ of the full scale. The liquid density, $\rho_{F}$, is obtained from a curve fit to the steam tables using the measured temperature. Using the uncertainty in the temperature measurement as input to the curve fit results in an uncertainty for the liquid density of $\pm 0.4 \mathrm{~kg} / \mathrm{m}^{3}$. This includes the uncertainty due to the curve fit and the difference between subcooled and saturated liquid densities for the temperature range of interest. Therefore, the uncertainty in the liquid mass flow rate is a constant for a particular flow rate measurement.

Venturi Gas Mass Flow Rate Uncertainty, The mass flow rate of the gas measured using a venturi can be given by

$$
\dot{m}_{G}=\frac{\beta^{2}}{\sqrt{1-\beta^{4}}} Y A C \sqrt{\rho_{G} D P}
$$

where

$$
\begin{aligned}
& \dot{m}_{G}=\text { mass flow rate of the gas }(\mathrm{kg} / \mathrm{s}) \\
& \beta=\text { diameter ratio (= throat diameter/pipe diameter) (nondimensional) } \\
& A=\text { pipe flow area }\left(\mathrm{m}^{2}\right) \\
& \mathrm{C}=\text { venturi discharge coefficient (nondimensional) } \\
& \rho_{\mathrm{G}}=\text { gas density based upon the temperature and pressure upstream of the } \\
& \text { venturi }\left(\mathrm{kg} / \mathrm{m}^{3}\right) \\
& \mathrm{DP}=\text { differential pressure between the venturi throat and the upstream } \\
& \text { pressure } \operatorname{tap}\left(\mathrm{N} / \mathrm{m}^{2}=\mathrm{kg} / \mathrm{m} \cdot \mathrm{s}^{2}=\mathrm{Pa}\right) \\
& \mathrm{Y}=\text { compressibility correction factor (nondimensional) }
\end{aligned}
$$


For this analysis Equation (B-4) can be rewritten as

$\dot{m}_{G}=K A \sqrt{\rho_{G} D P}$

where $\mathrm{K}=\mathrm{a}$ constant obtained from combining all of the constants in Equation (B-4).

Combining Equation (B-5) and Equation (B-1) the uncertainty in the gas mass flow rate is given by

$$
\delta \dot{m}_{G}=\frac{\Delta \dot{m}_{G}}{\dot{m}_{G}}=\sqrt{\left(\frac{\Delta K}{K}\right)^{2}+\left(\frac{\Delta A}{A}\right)^{2}+\frac{1}{4}\left(\frac{\Delta \rho_{G}}{\rho_{G}}\right)^{2}+\frac{1}{4}\left(\frac{\Delta D P}{D P}\right)^{2}} .
$$

The gas density, $\rho_{\mathrm{G}}$, is obtained using the ideal gas law

$\rho_{G}=\Re_{G} \frac{P}{T}$

where

$\mathfrak{R}_{\mathrm{G}}=$ constant for the gas in question, air, and the units for the pressure and temperature $\left(=3.483 \mathrm{~kg} / \mathrm{m}^{3} \cdot \mathrm{K} / \mathrm{kPa}\right)$

$\mathrm{P} \quad=$ gas pressure $(\mathrm{kPa})$

$\mathrm{T}=$ gas temperature $(\mathrm{K})$.

The uncertainty in the gas density is obtained by substituting Equation (B-7) in Equation (B-1) resulting in

$$
\delta \rho_{G}=\frac{\Delta \rho_{G}}{\rho_{r}}=\sqrt{\left(\frac{\Delta \mathfrak{R}_{G}}{\mathfrak{R}_{G}}\right)^{2}+\left(\frac{\Delta P}{P}\right)^{2}+\left(\frac{\Delta T}{T}\right)^{2}} .
$$

\section{Uncertainty in Nondimensional Mass Fluxes}

The root of the liquid nondimensional mass flux, $\sqrt{j_{F}}$, is given by

$$
\sqrt{j_{F}^{*}}=\frac{\left(\dot{m}_{F} / A\right)^{1 / 2}}{\left[g w \rho_{F}\left(\rho_{F}-\rho_{G}\right)\right]^{1 / 4}}
$$

where

$$
\begin{aligned}
& A=\text { minimum flow are in the test vessel }\left(\mathrm{m}^{2}\right) \\
& \mathrm{g}=\text { gravitational acceleration }\left(9.78 \mathrm{~m} / \mathrm{s}^{2}\right) \\
& \mathrm{w}=\text { characteristic dimension, hydraulic diameter }(\mathrm{m})
\end{aligned}
$$


Combining Equations (B-1) and (B-9), the expression for uncertainty results in,

$$
\frac{\Delta \sqrt{j_{F}^{*}}}{\sqrt{j_{F}^{*}}}=\frac{1}{2} \sqrt{\left(\frac{\Delta \dot{m}_{F}}{\dot{m}_{F}}\right)^{2}+\left(\frac{\Delta A}{A}\right)^{2}+\left(\frac{1}{2} \frac{\Delta g}{g}\right)^{2}+\left(\frac{1}{2} \frac{\Delta w}{w}\right)^{2}+\left(\frac{1}{2} \frac{\left(2 \rho_{F}-\rho_{G}\right)}{\left(\rho_{F}-\rho_{G}\right)} \frac{\Delta \rho_{F}}{\rho_{F}}\right)^{2}+\left(\frac{1}{2} \frac{\rho_{G}}{\rho_{F}-\rho_{G}} \frac{\Delta \rho_{G}}{\rho_{G}}\right)^{2}} .
$$

The root of the gas nondimensional mass flux, $\sqrt{j_{G}{ }^{\circ}}$, is given by

$$
\sqrt{j_{G}^{*}}=\frac{\left(\dot{m}_{G} / A\right)^{1 / 2}}{\left[g w \rho_{G}\left(\rho_{F}-\rho_{G}\right)\right]^{1 / 4}}
$$

When Equation (B-11) is substituted into Equation (B-1), the expression for the uncertainty is

$$
\frac{\Delta \sqrt{j_{G}^{*}}}{\sqrt{j_{G}{ }^{*}}}=\frac{1}{2} \sqrt{\left(\frac{\Delta \dot{m}_{G}}{\dot{m}_{G}}\right)^{2}+\left(\frac{\Delta A}{A}\right)^{2}+\left(\frac{1}{2} \frac{\Delta g}{g}\right)^{2}+\left(\frac{1}{2} \frac{\Delta w}{w}\right)^{2}+\left(\frac{1}{2} \frac{\rho_{F}}{\left(\rho_{F}-\rho_{G}\right)} \frac{\Delta \rho_{F}}{\rho_{F}}\right)^{2}+\left(\frac{1}{2} \frac{\left(\rho_{F}-2 \rho_{G}\right)}{\rho_{F}-\rho_{G}} \frac{\Delta \rho_{G}}{\rho_{G}}\right)^{2}}
$$

\section{Uncertainties for Representative Test Cases}

A set of 5 tests were selected as being representative of the range of conditions experienced during the Septifoil CCFL experiments. These tests cover the range of air injection rates, and thus liquid draining rates, for which flooding occurred $\left(\mathrm{j}_{\mathrm{G}}>0.5 \mathrm{~m} / \mathrm{s}\right)$. The results for these tests are presented in Table B-1. The parameters preceded by $\Delta$ 's are the absolute uncertainties in the calculated parameters at the $95 \%$ confidence level. The parameters preceded by $\delta$ 's are the relative uncertainties (ratio of absolute uncertainty to the measurement) in the calculated parameters. The uncertainties in the square root of the nondimensional liquid superficial velocity range from $0.4 \%$ of reading, at the high draining rates (52 LPM), to $1.4 \%$ at the low draining rates (1 LPM). The uncertainties in the square root of the nondimensional gas superficial velocity range from $2.7 \%$ of reading, at a relatively low injection rate (128 SLPM), to $1.0 \%$ at the highest air injection rate measured using the thermal flow meter (360 SLPM). 


\section{REFERENCES}

B-1 S. J. Kline and F. A. McClintock, "Describing Uncertainty in SingleSample Experiments," Mechanical Engineering, 75, No. 1, pp. 3-8, January 1953.

B-2 ASME-Journal of Fluids Engineering, Guide on Uncertainty Prediction and Presentation Techniques for Authors, August 1975. 

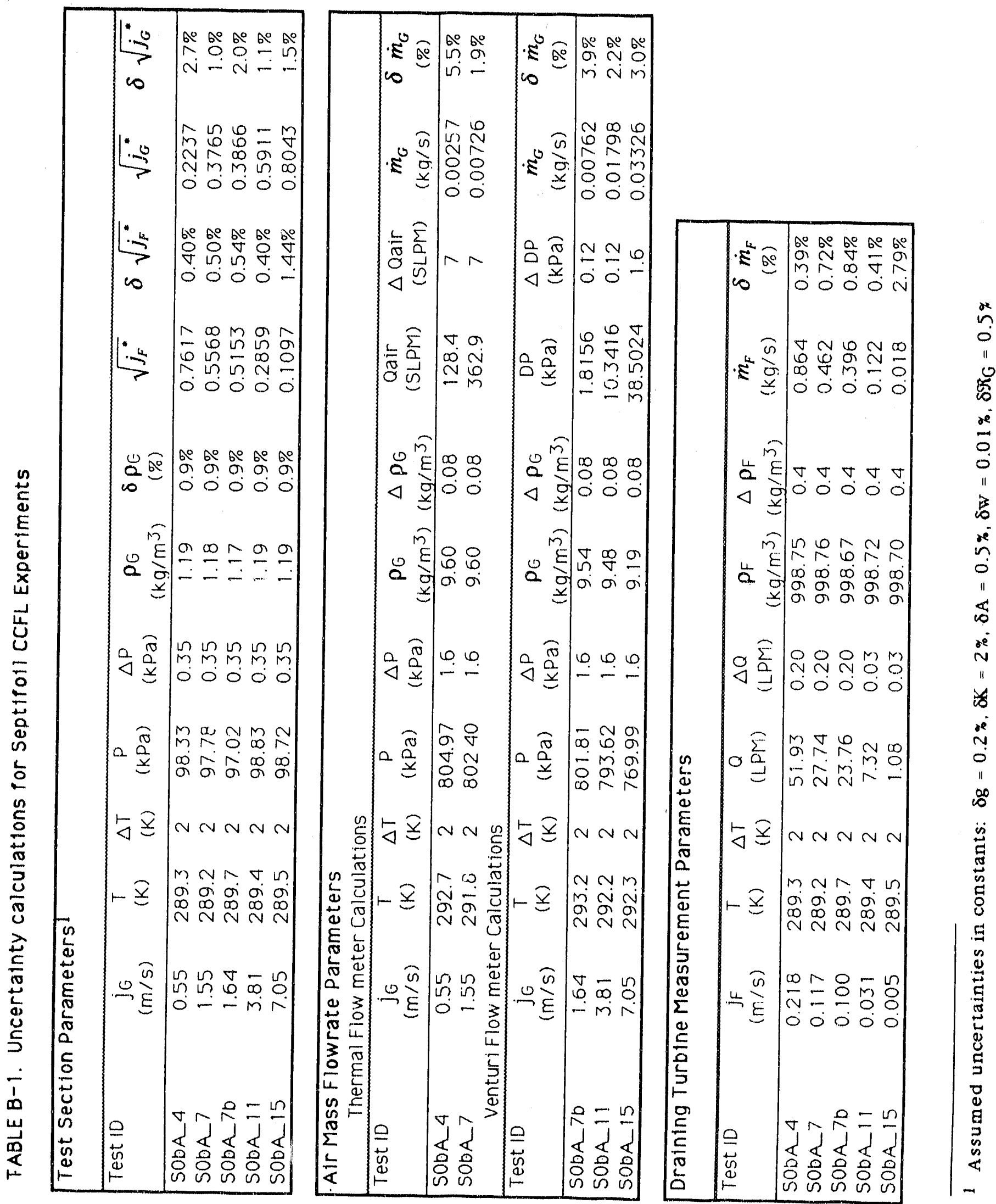


\section{APPENDIX C}

Data Tabulations for Septifoil CCFL.. Experiments 


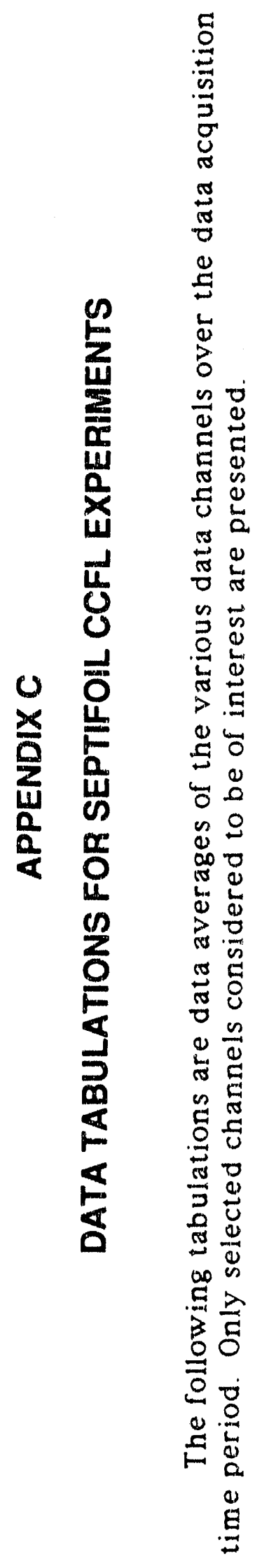

Nm+n6R

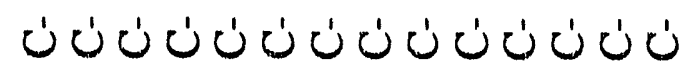

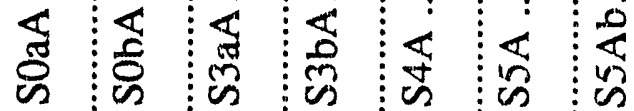

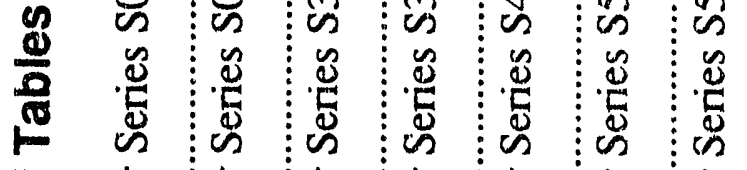

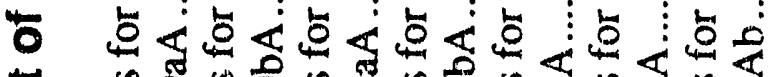

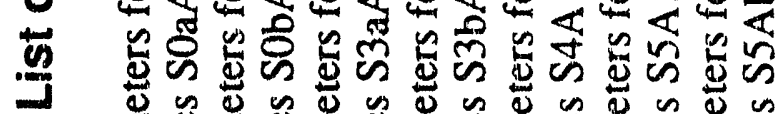

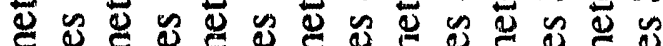

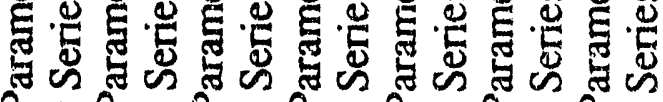
o $A$ a $2,2, \alpha$

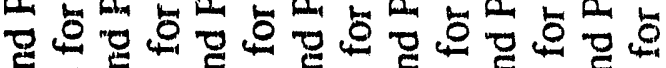

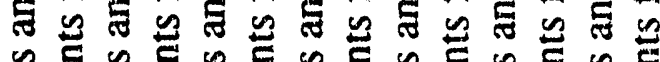

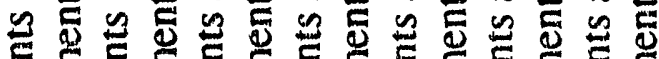
屯 类

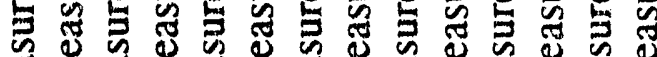

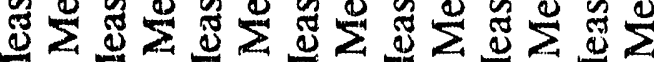

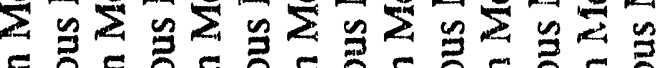

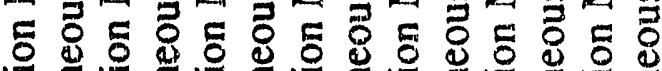

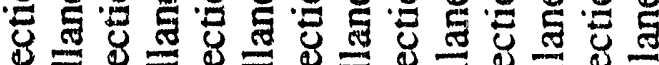

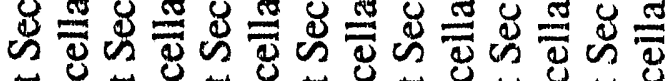

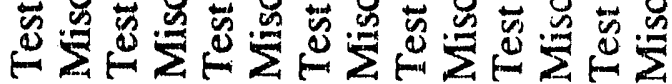

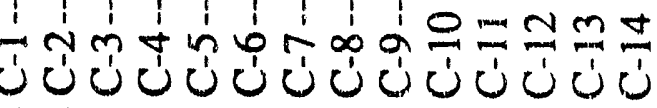

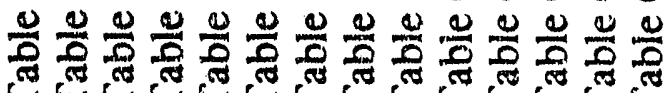




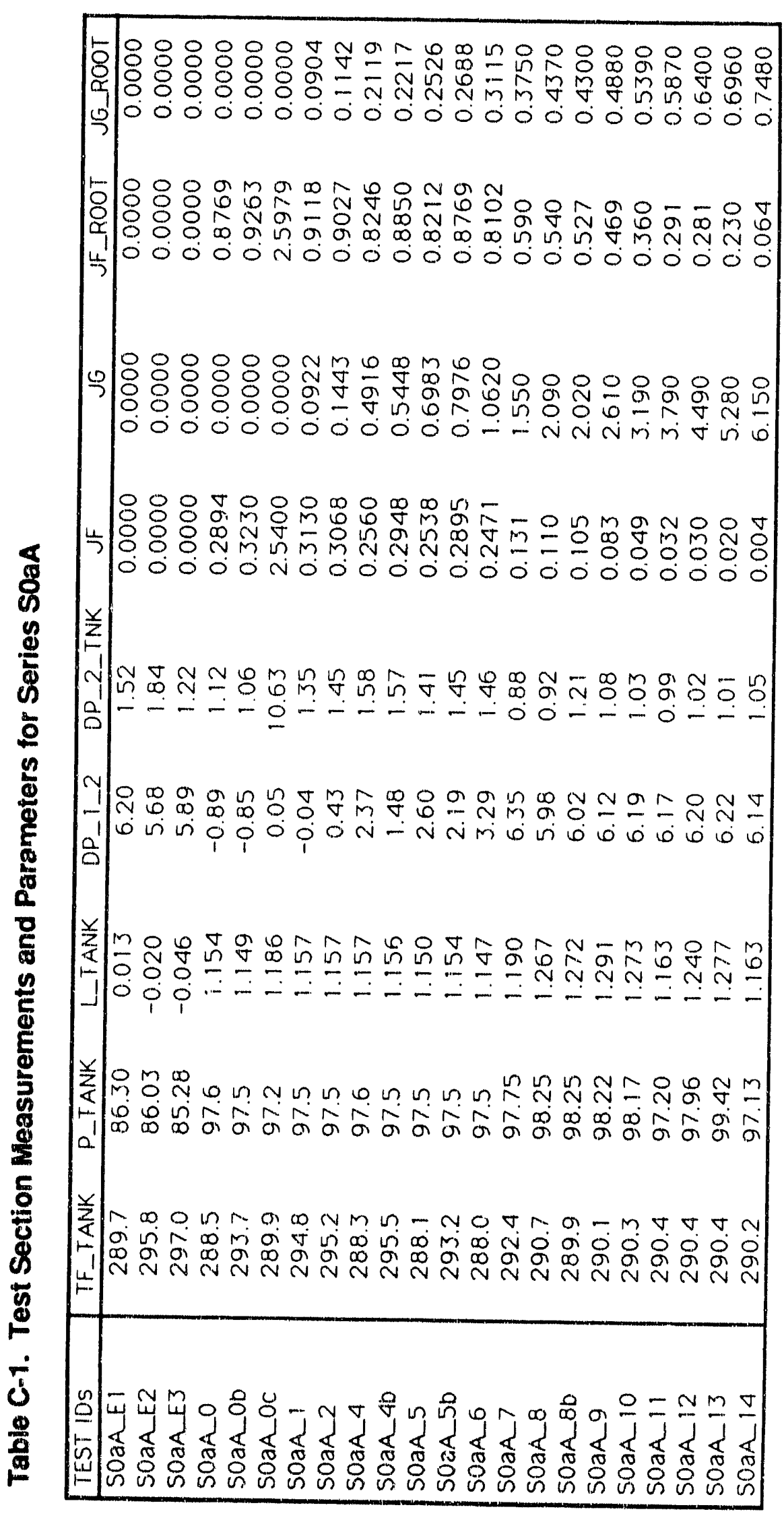




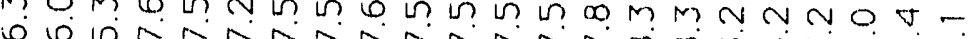
a

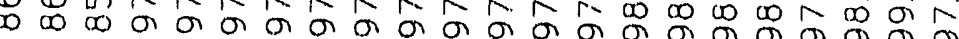

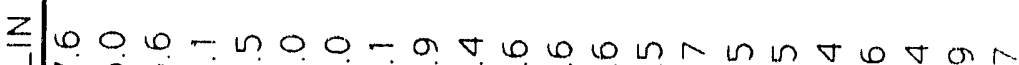
a

F)

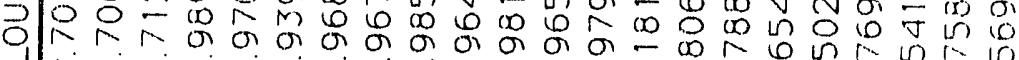

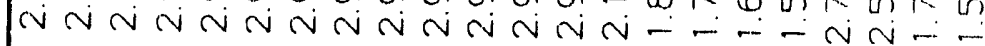

$z$

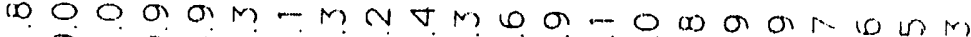

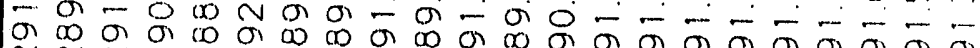

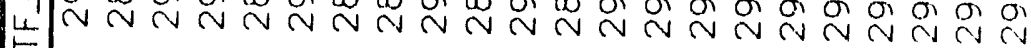

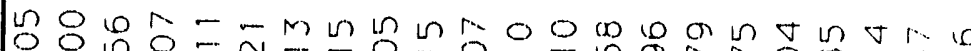

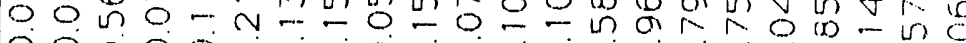
○

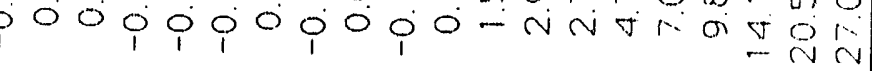

Jan- - 00000 a

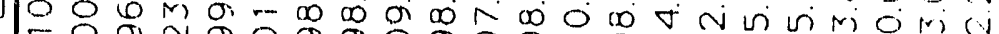

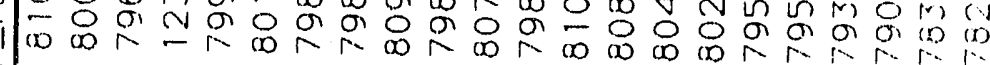

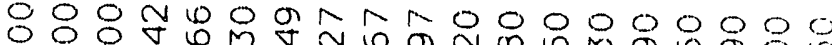
$00000 \mathrm{n} N$ m

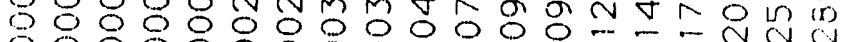

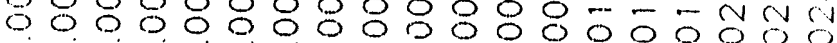

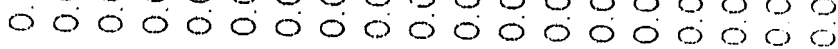

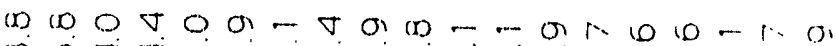

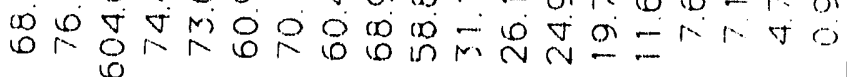

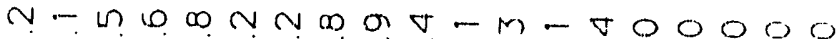
- Nm

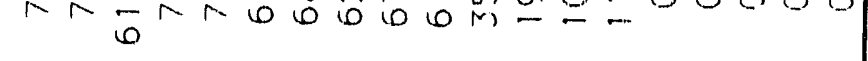

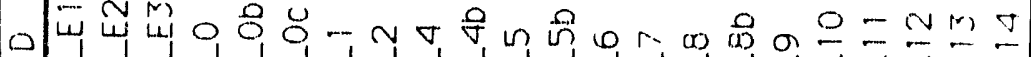




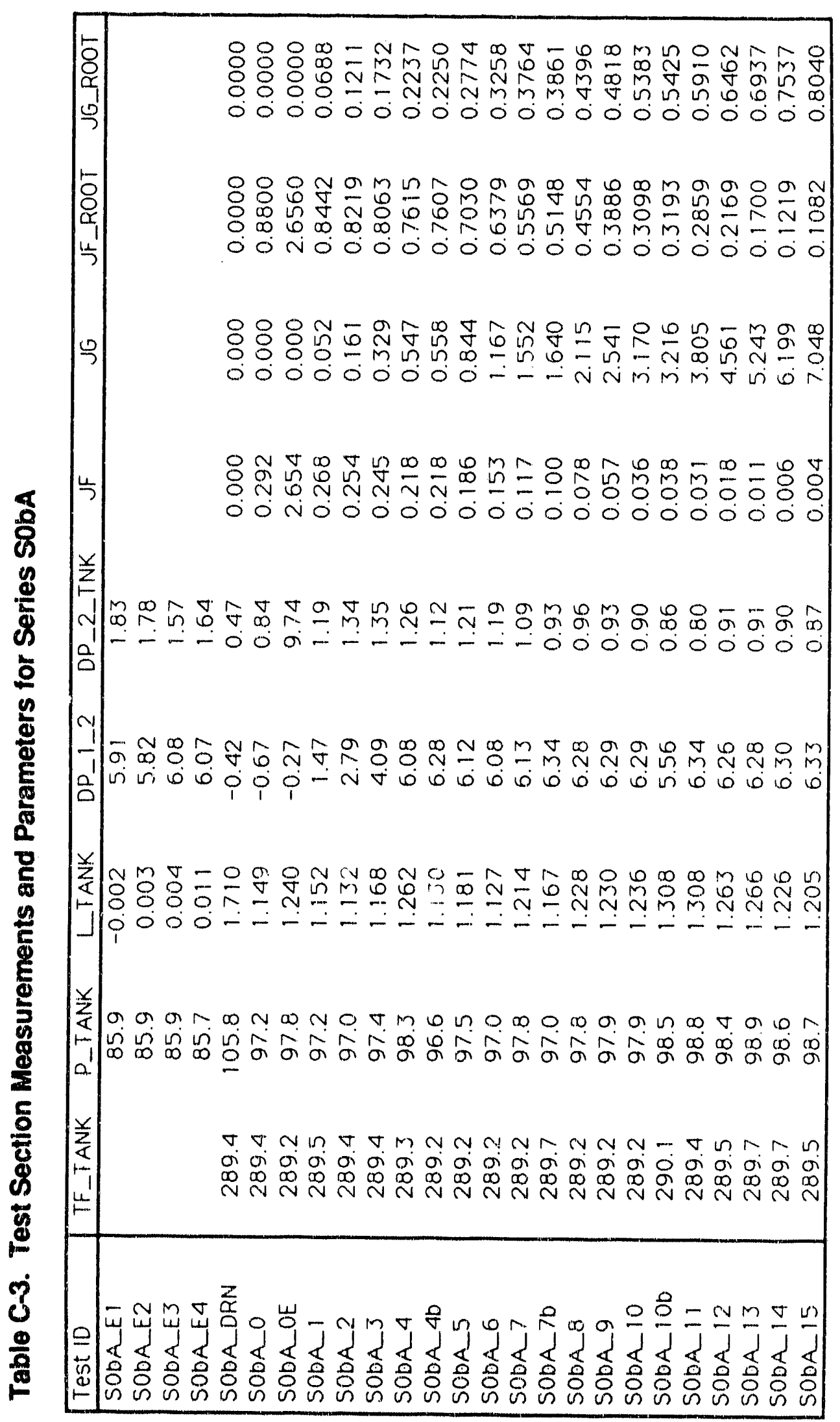




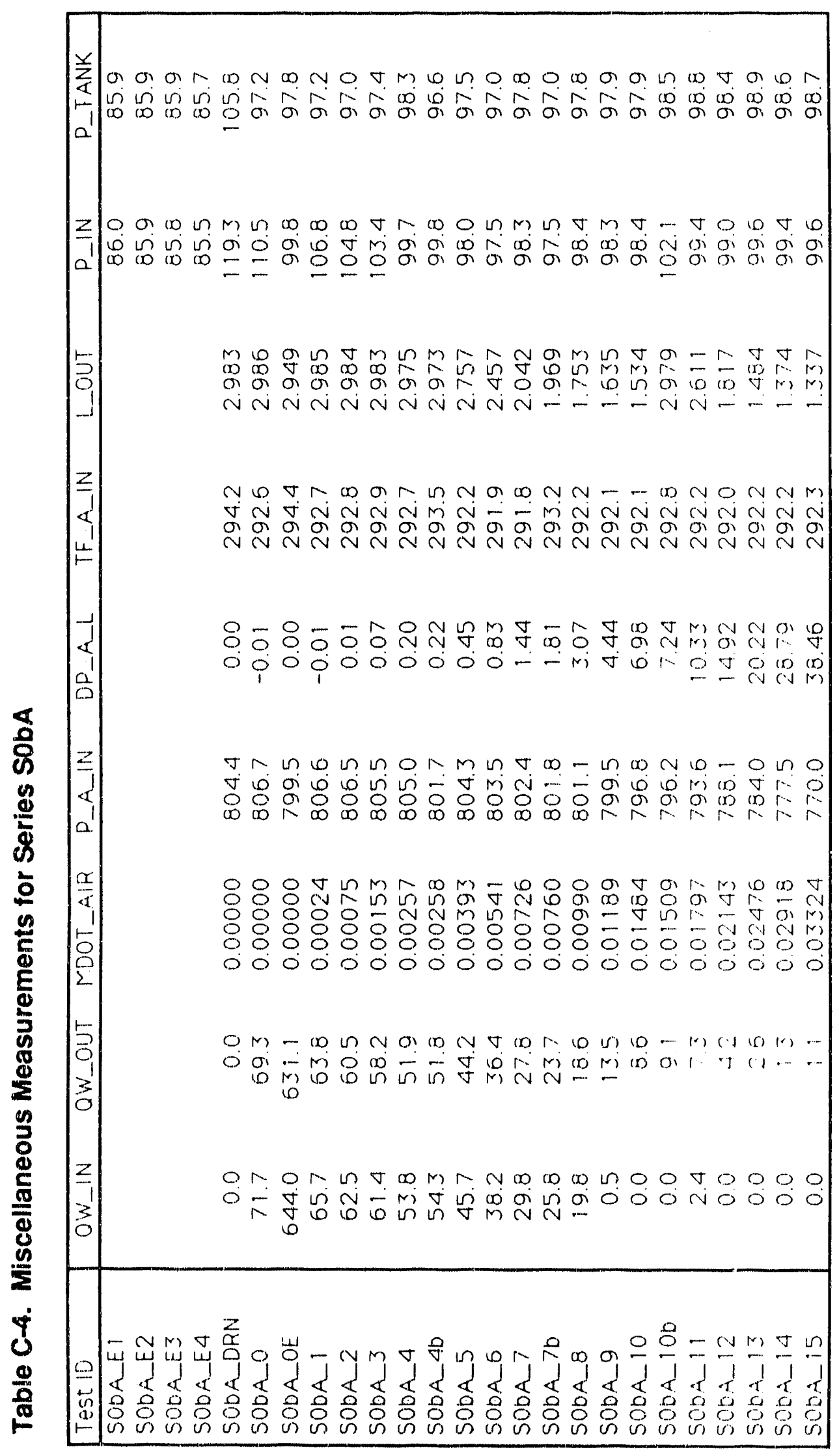




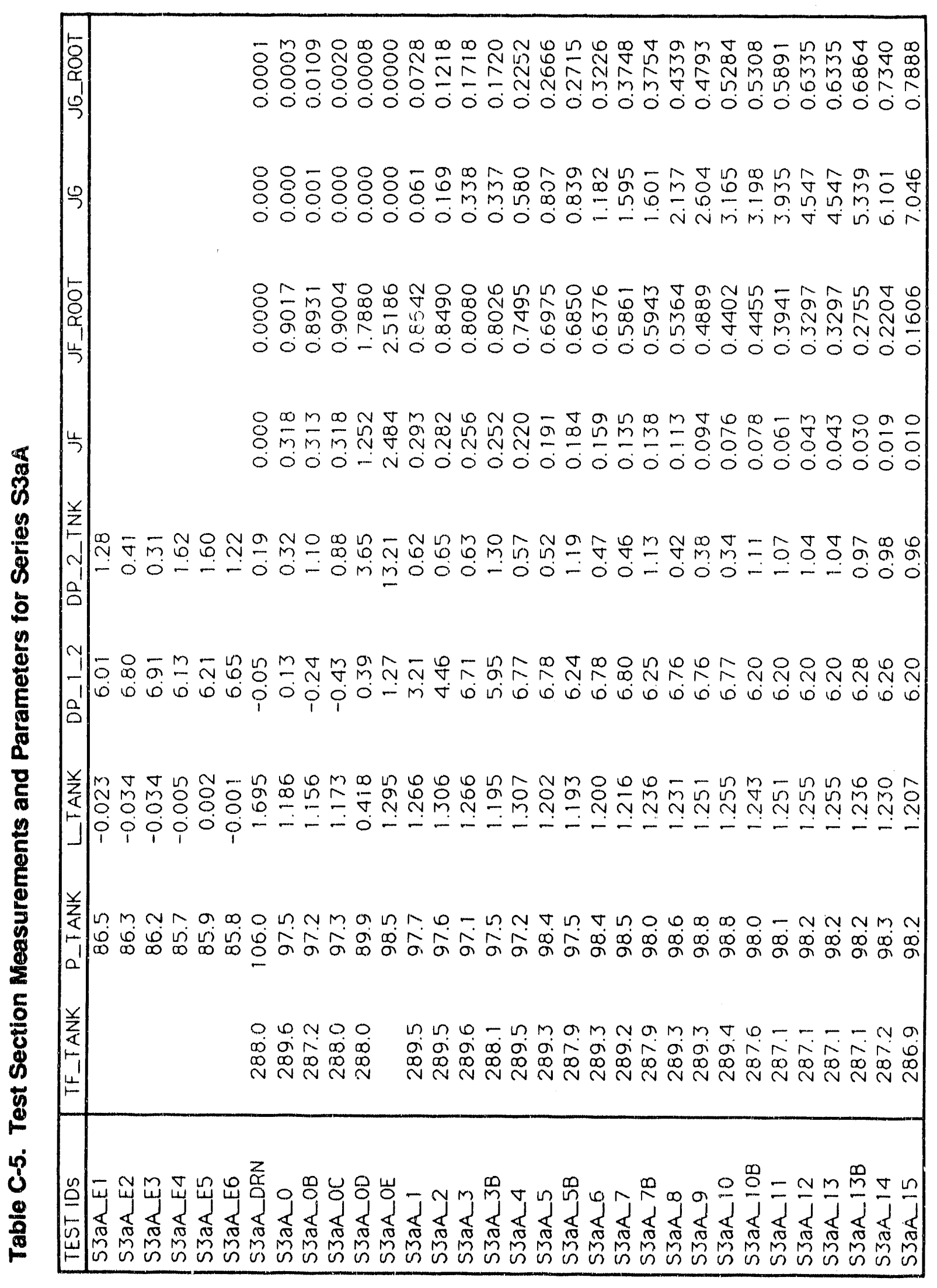




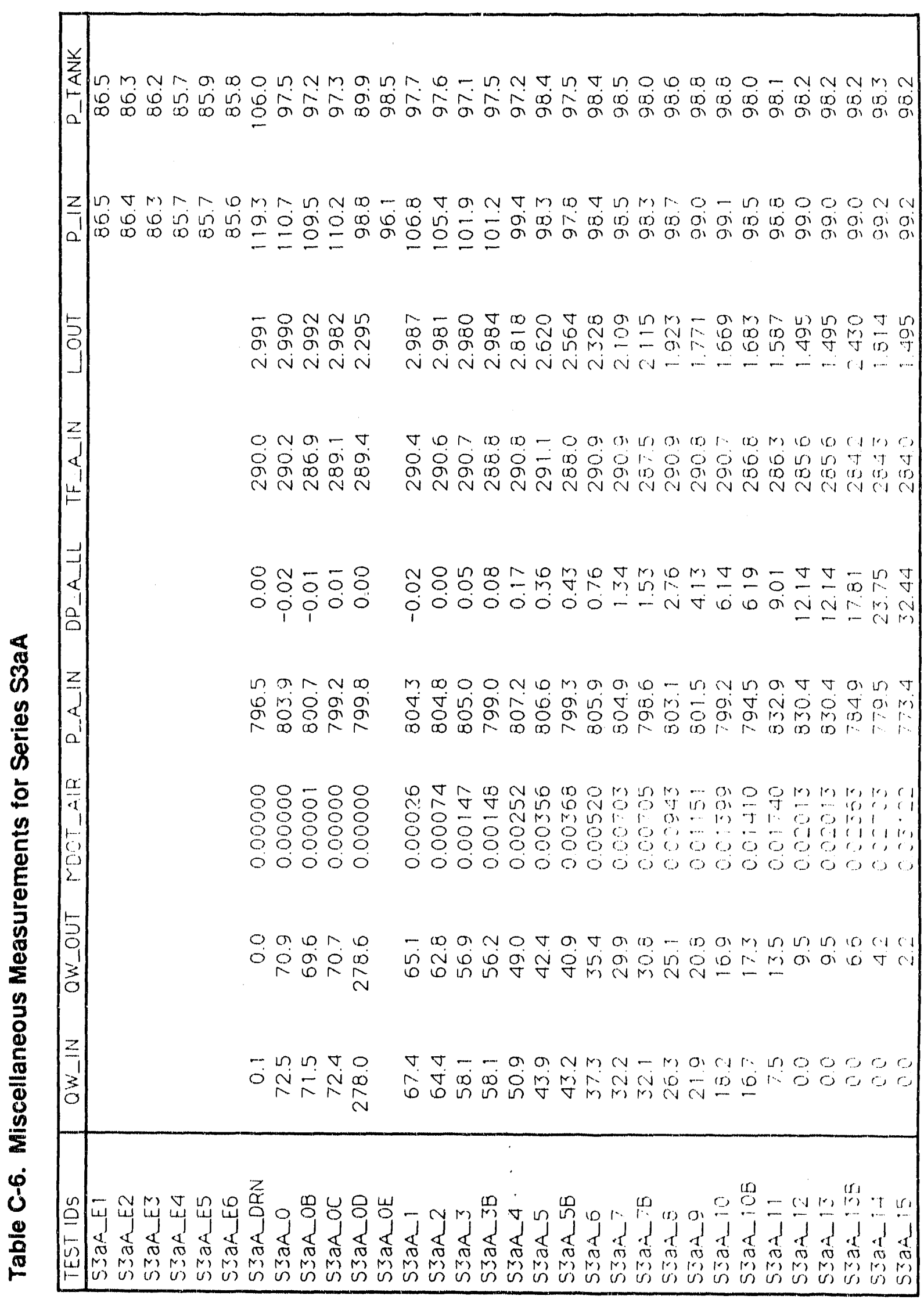




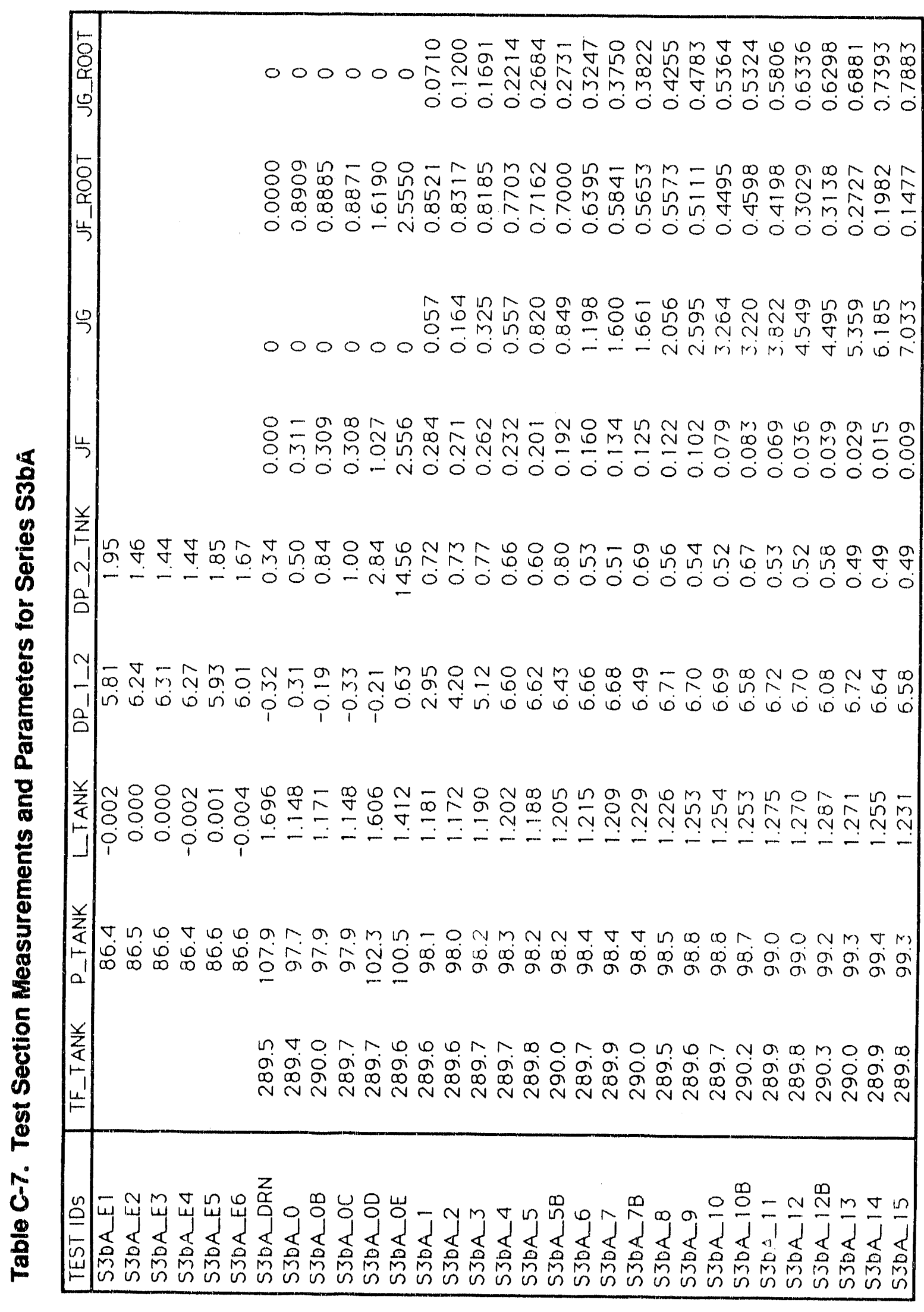




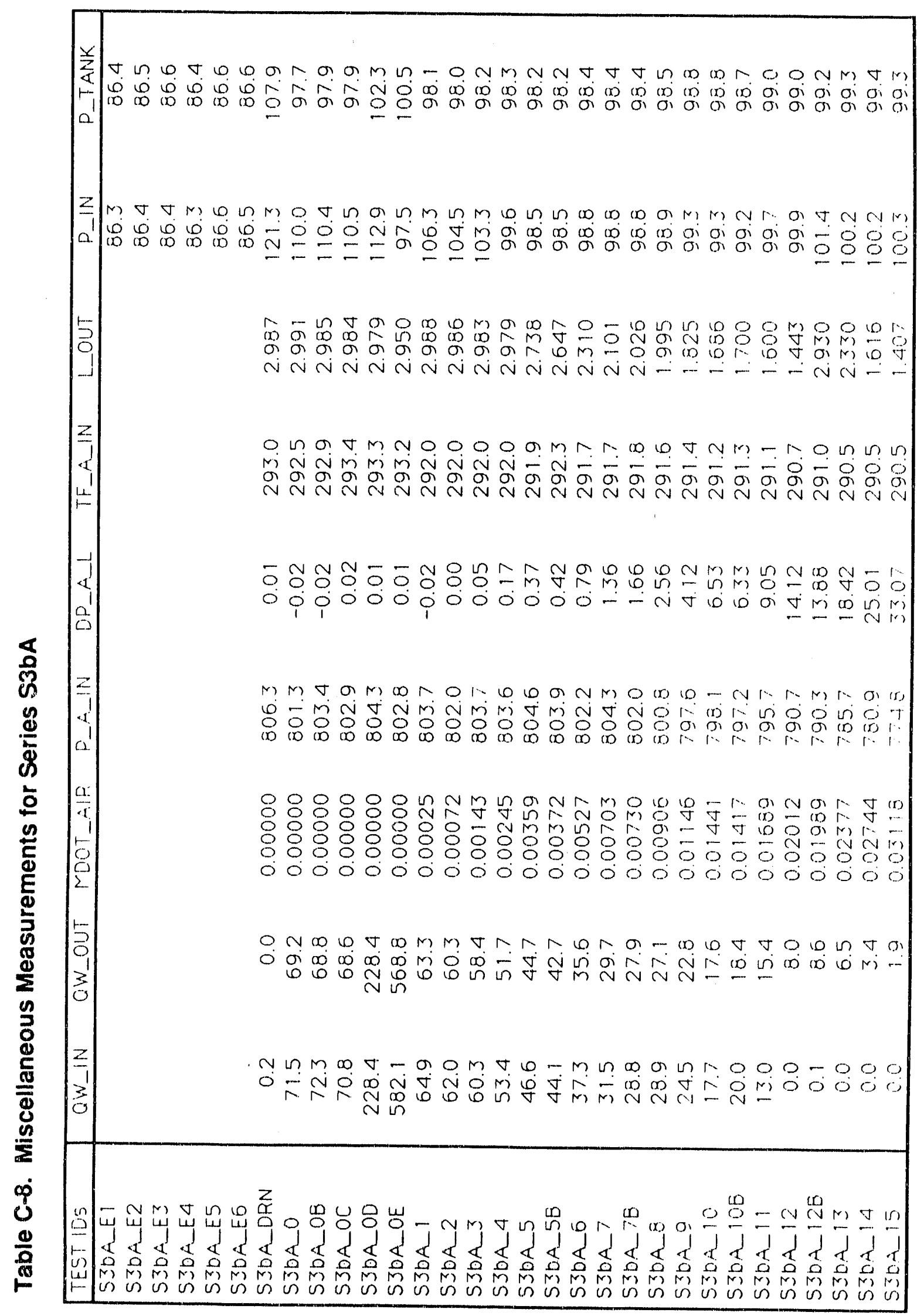




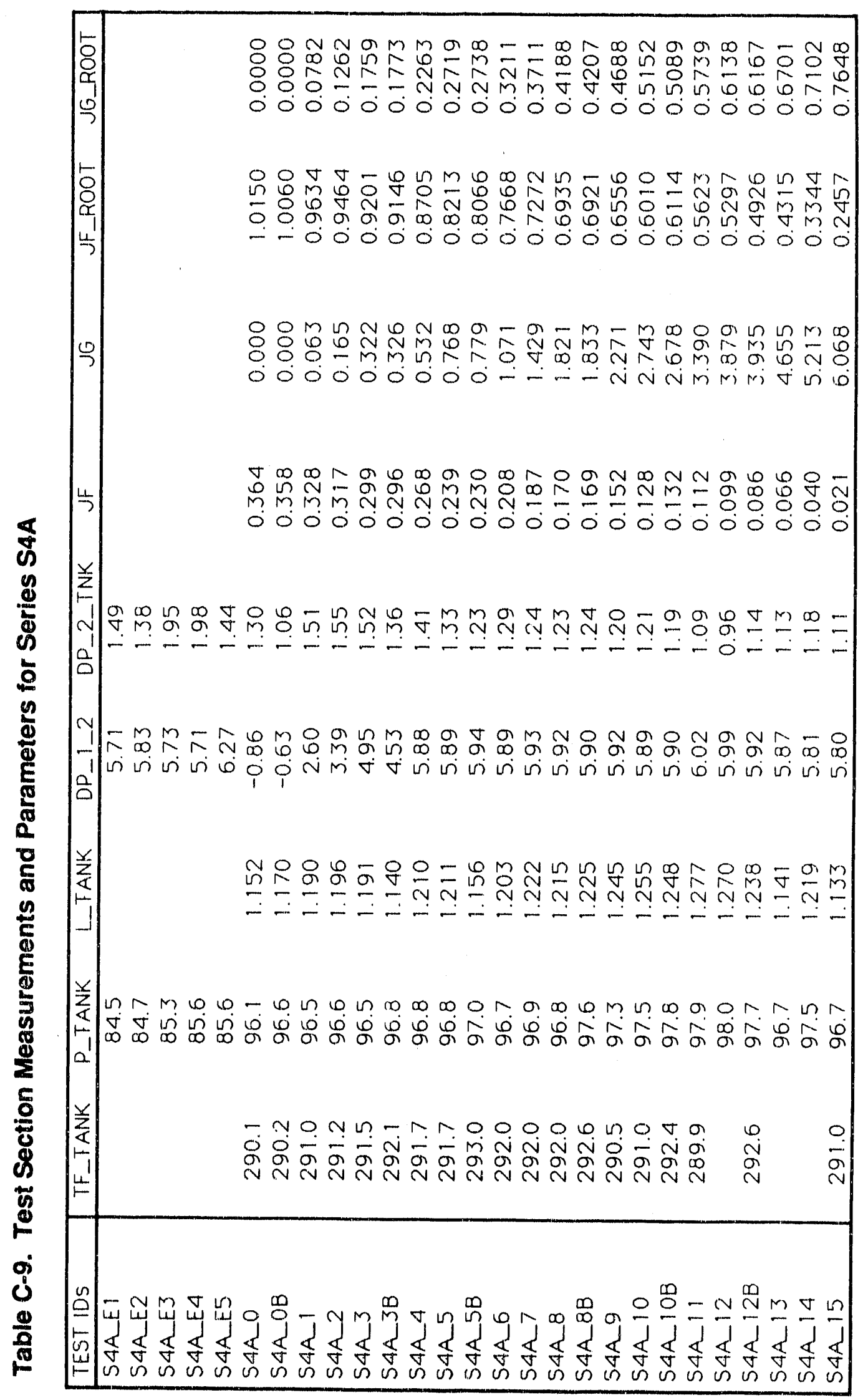




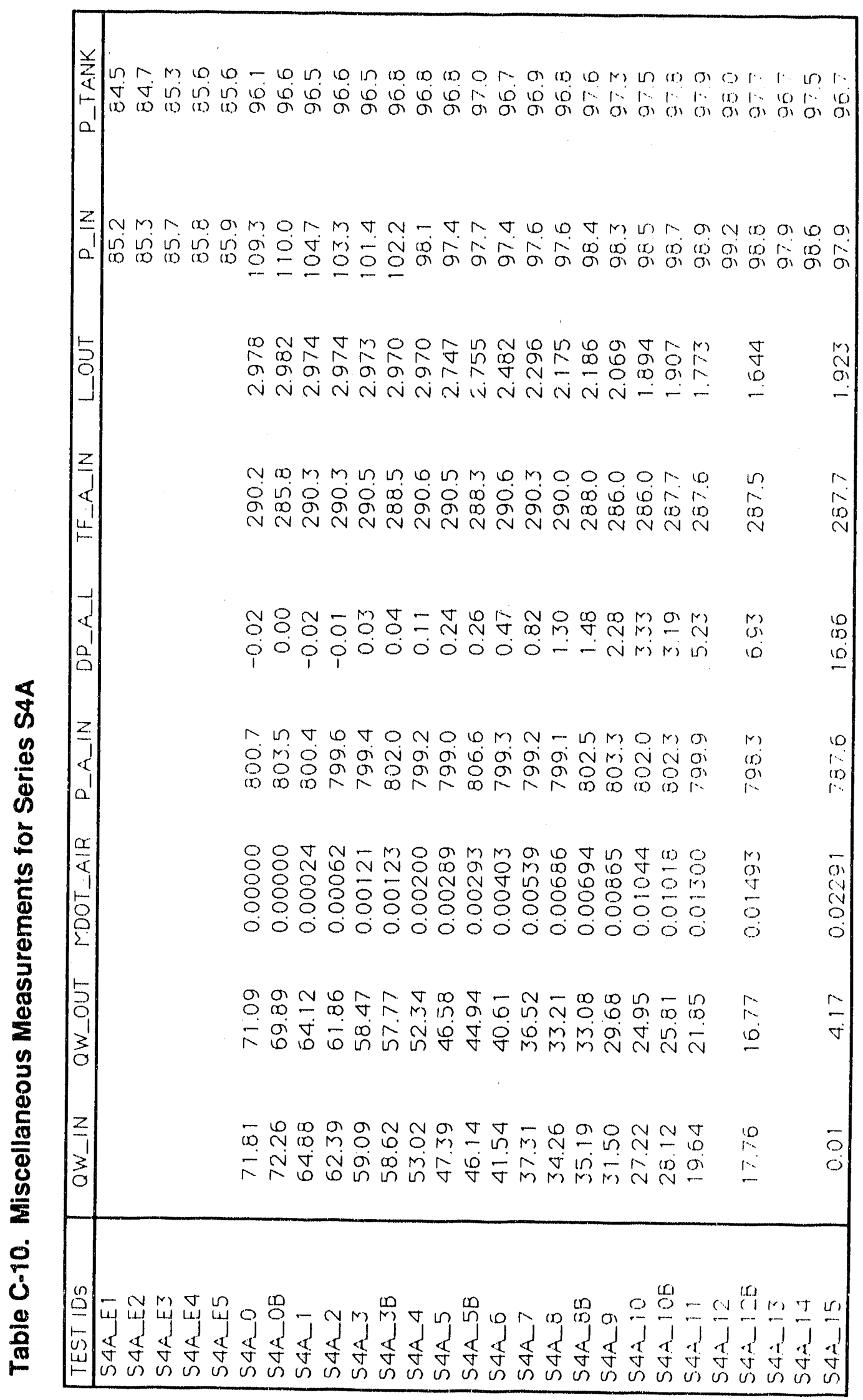




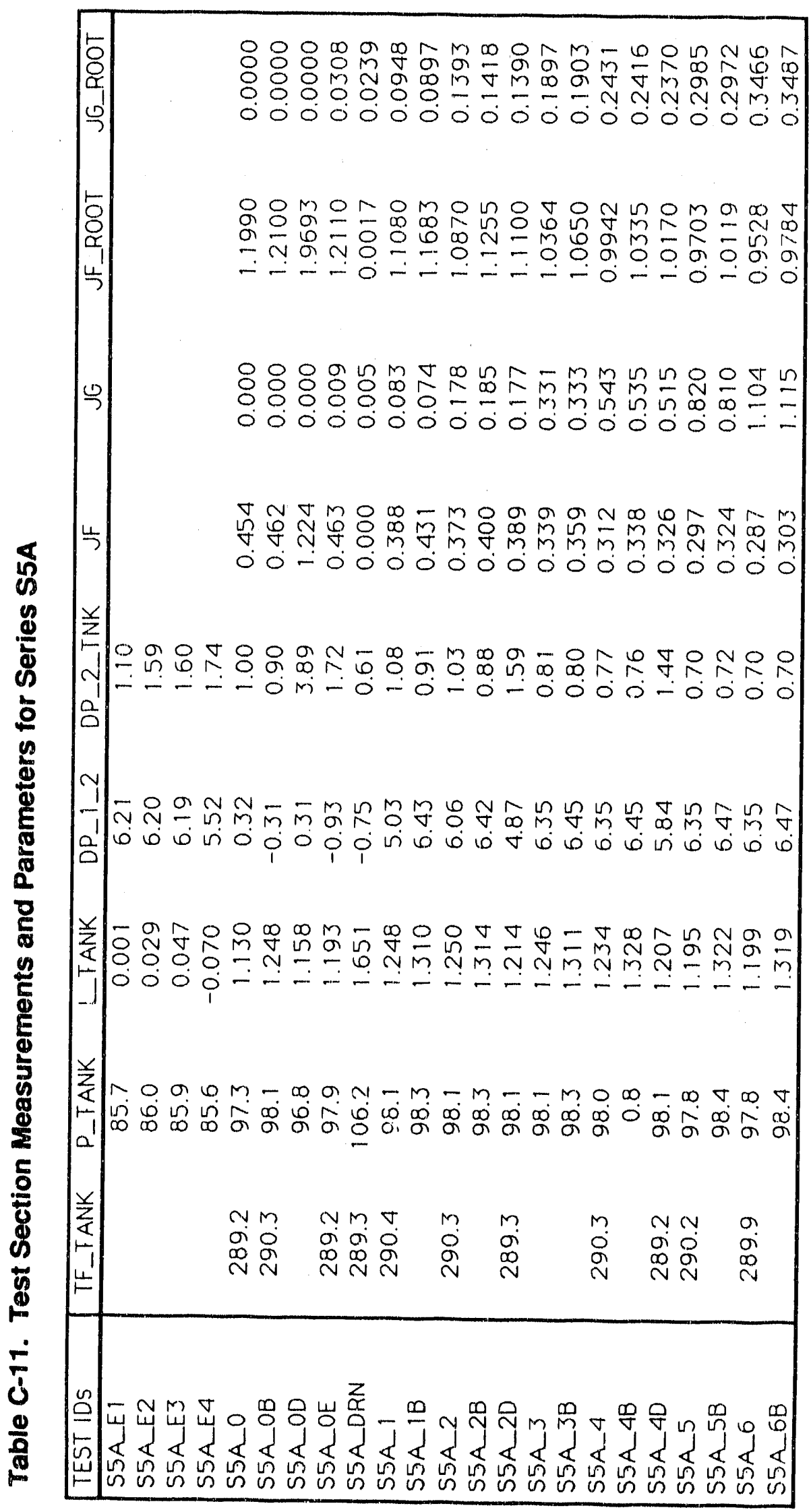




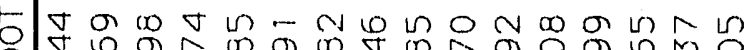

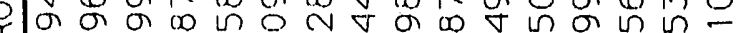
MmM $m$ m

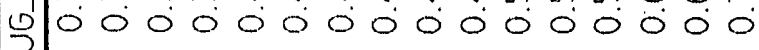

-

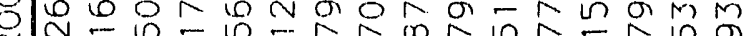

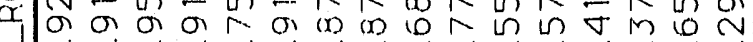
40000000000000000

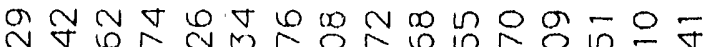

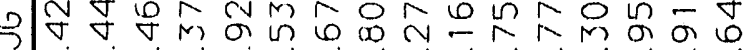

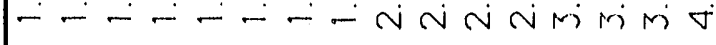

-

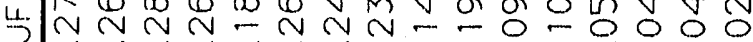
0000000000000000

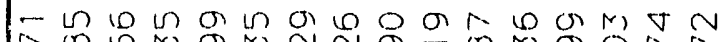
I) $0000-0-0-0-0-00$

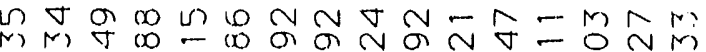
2 ம

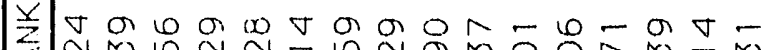

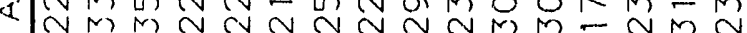
$1-\ldots-\ldots-\ldots-1-\ldots$

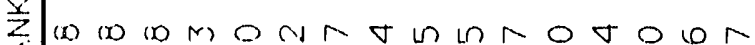

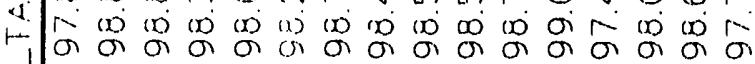

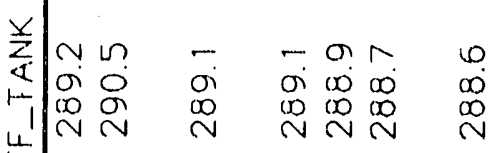

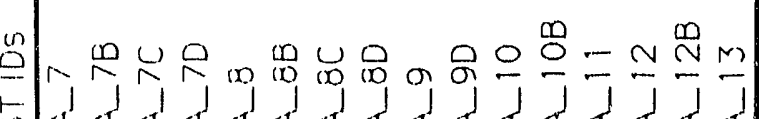

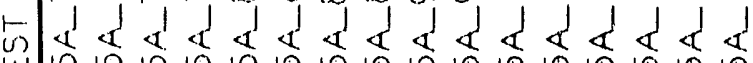

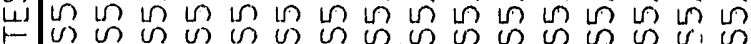




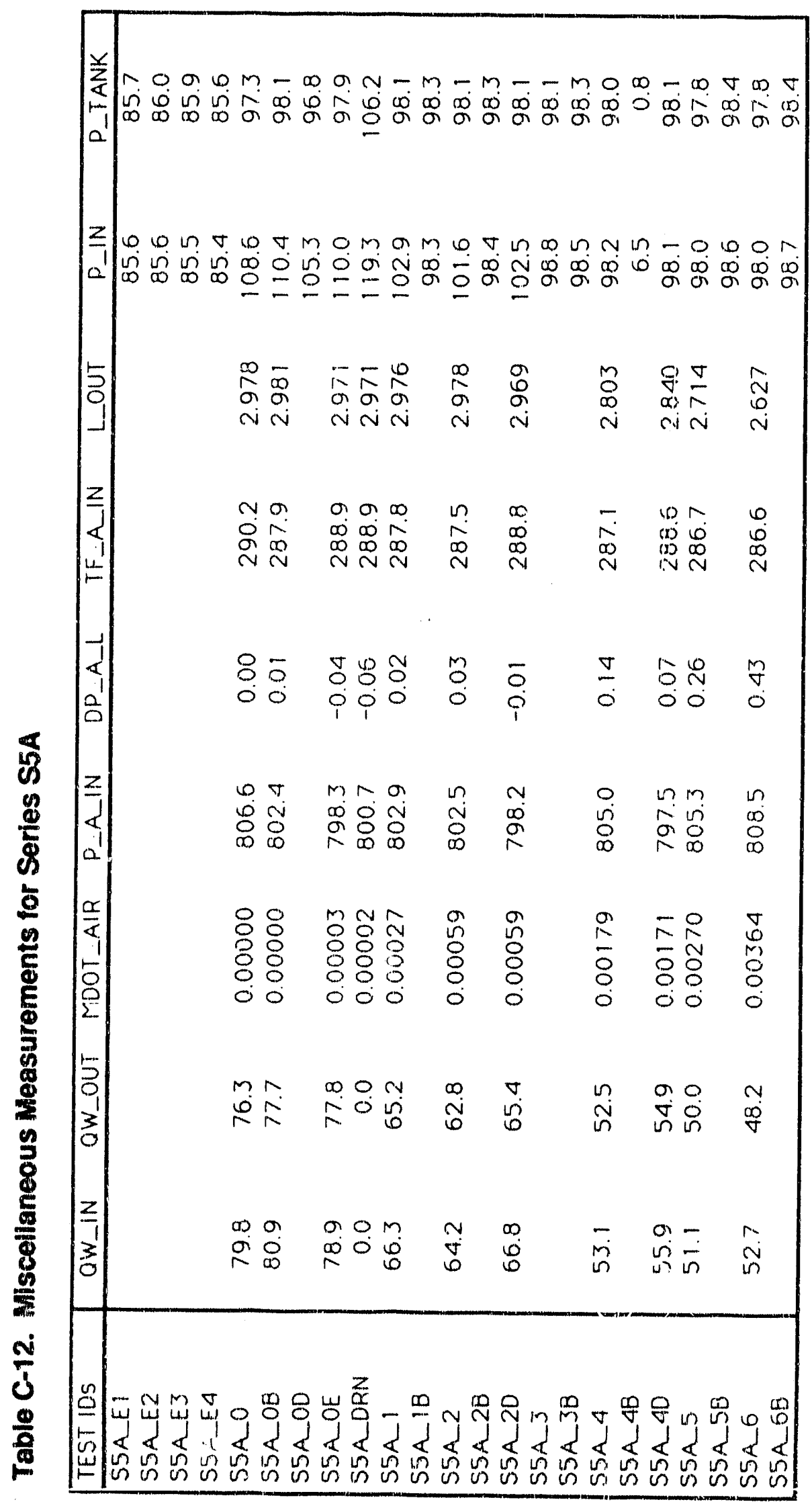


z

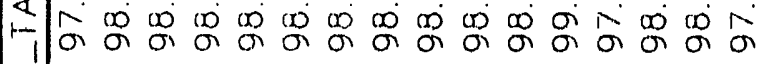

zoo-nnt

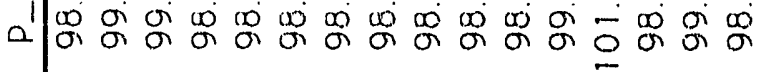

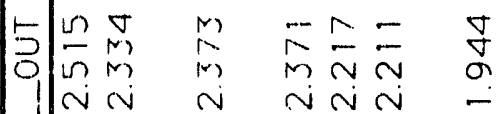

$\underline{2}$

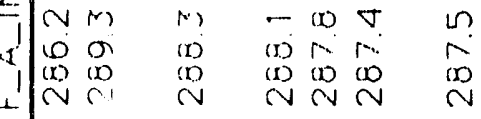

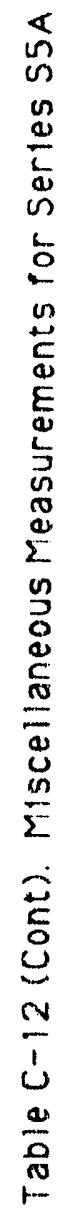

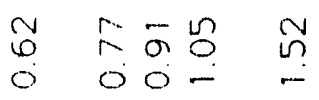

$\begin{array}{llll}m & m & 10 & 1 \\ 0 & 0 & 0\end{array}$

$\alpha$

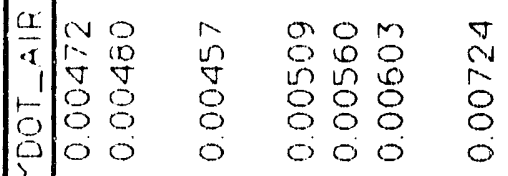

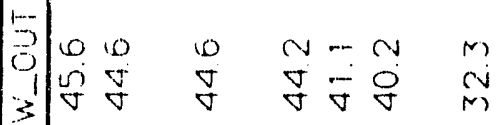

3

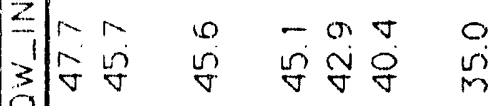

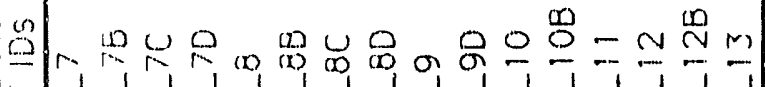

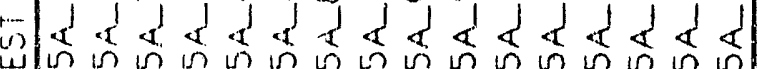

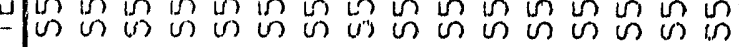




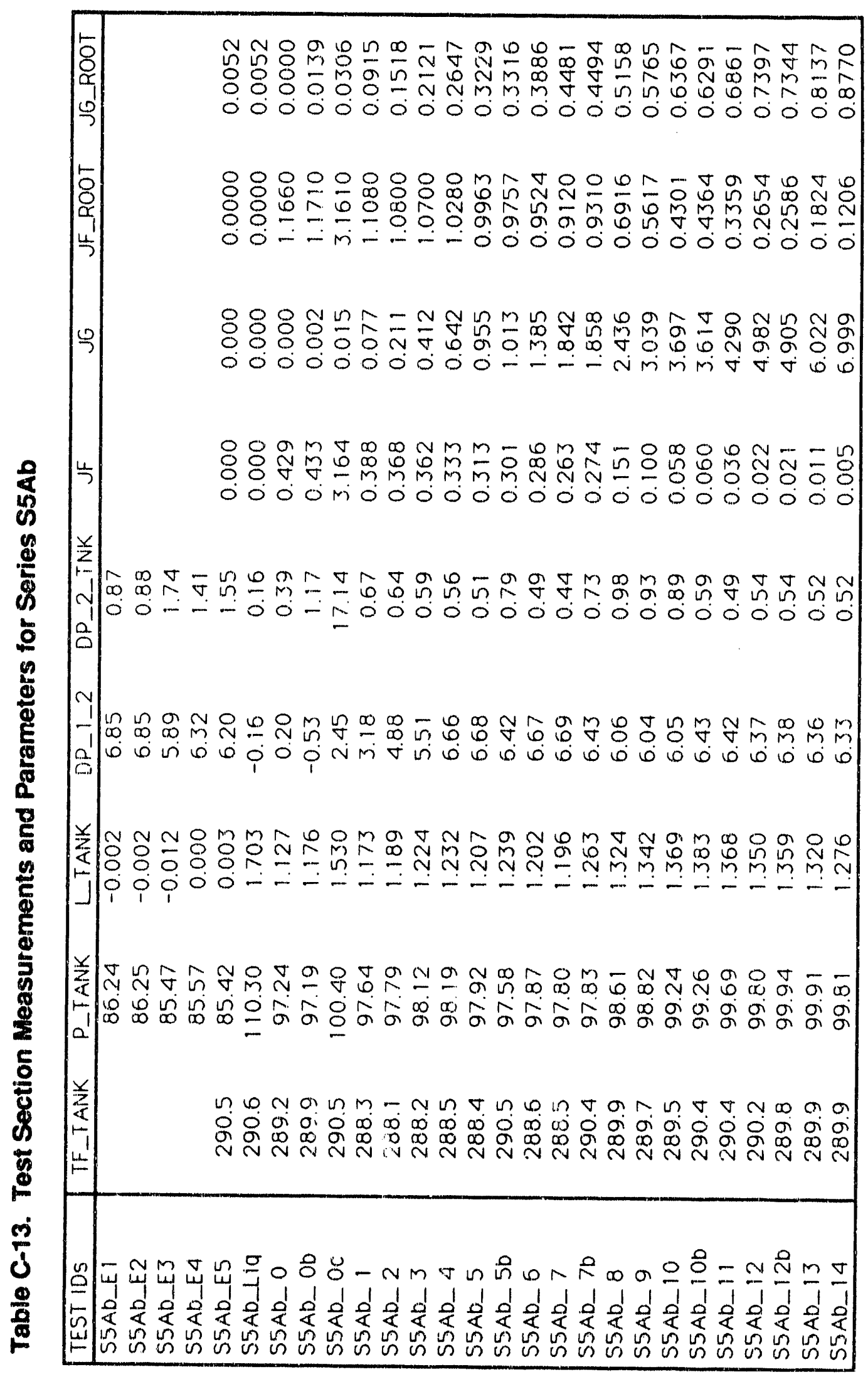




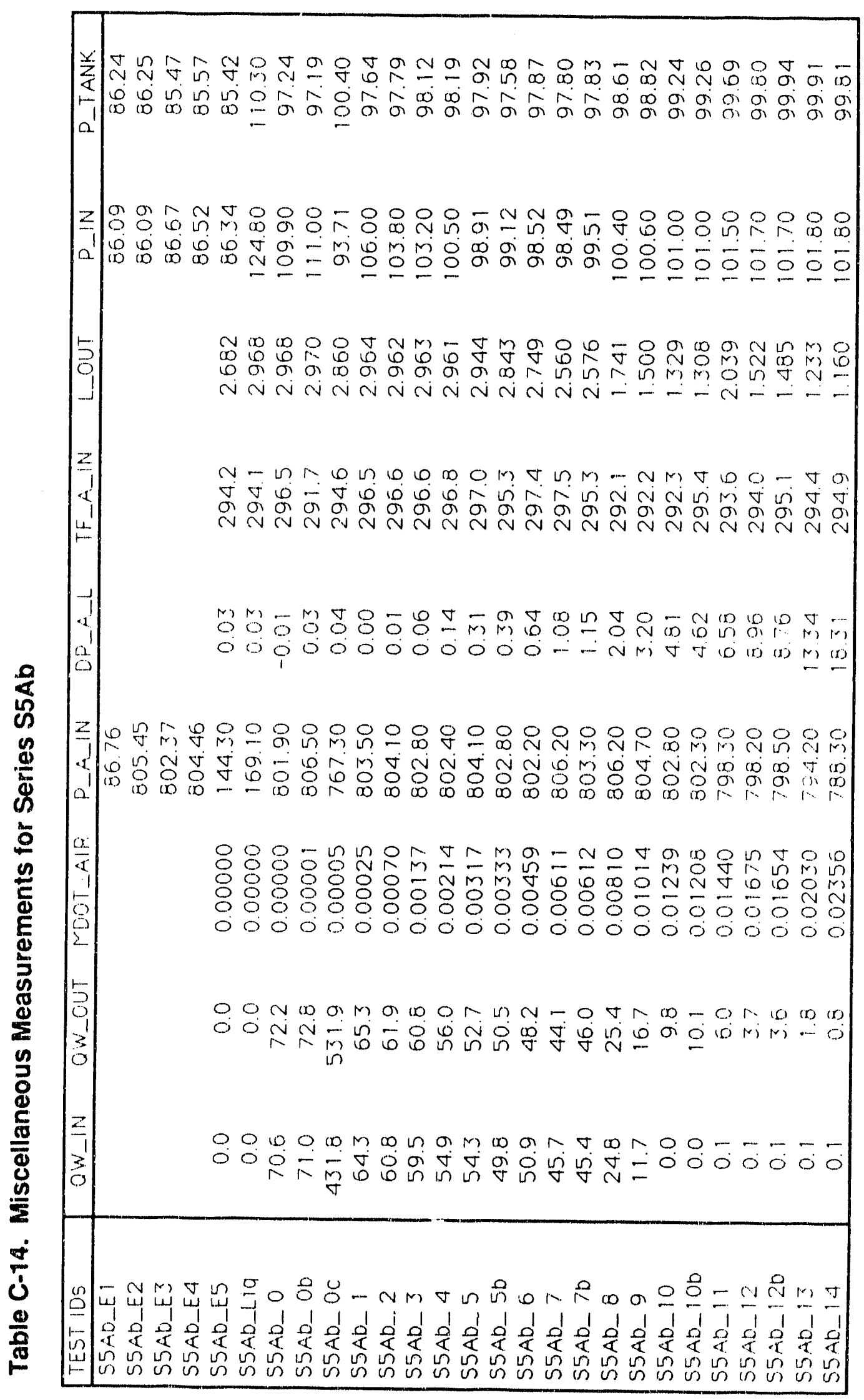




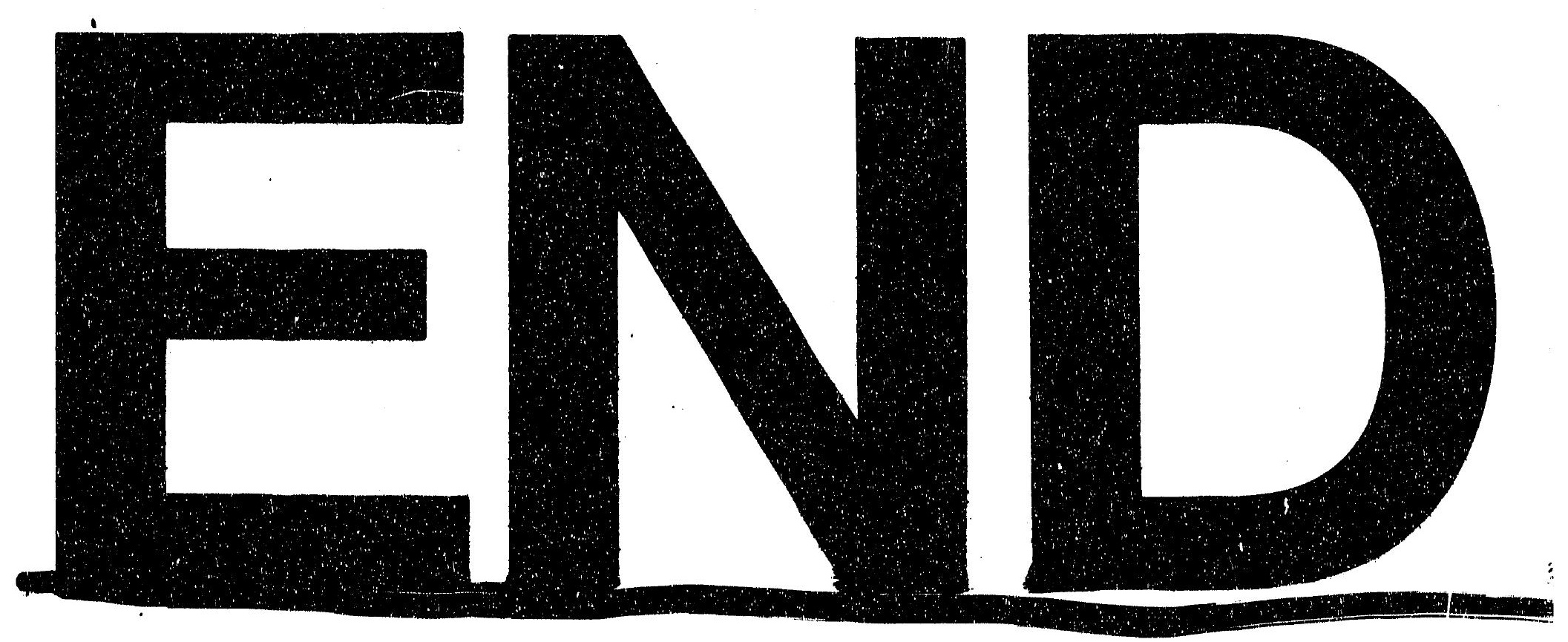

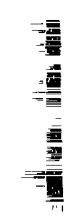
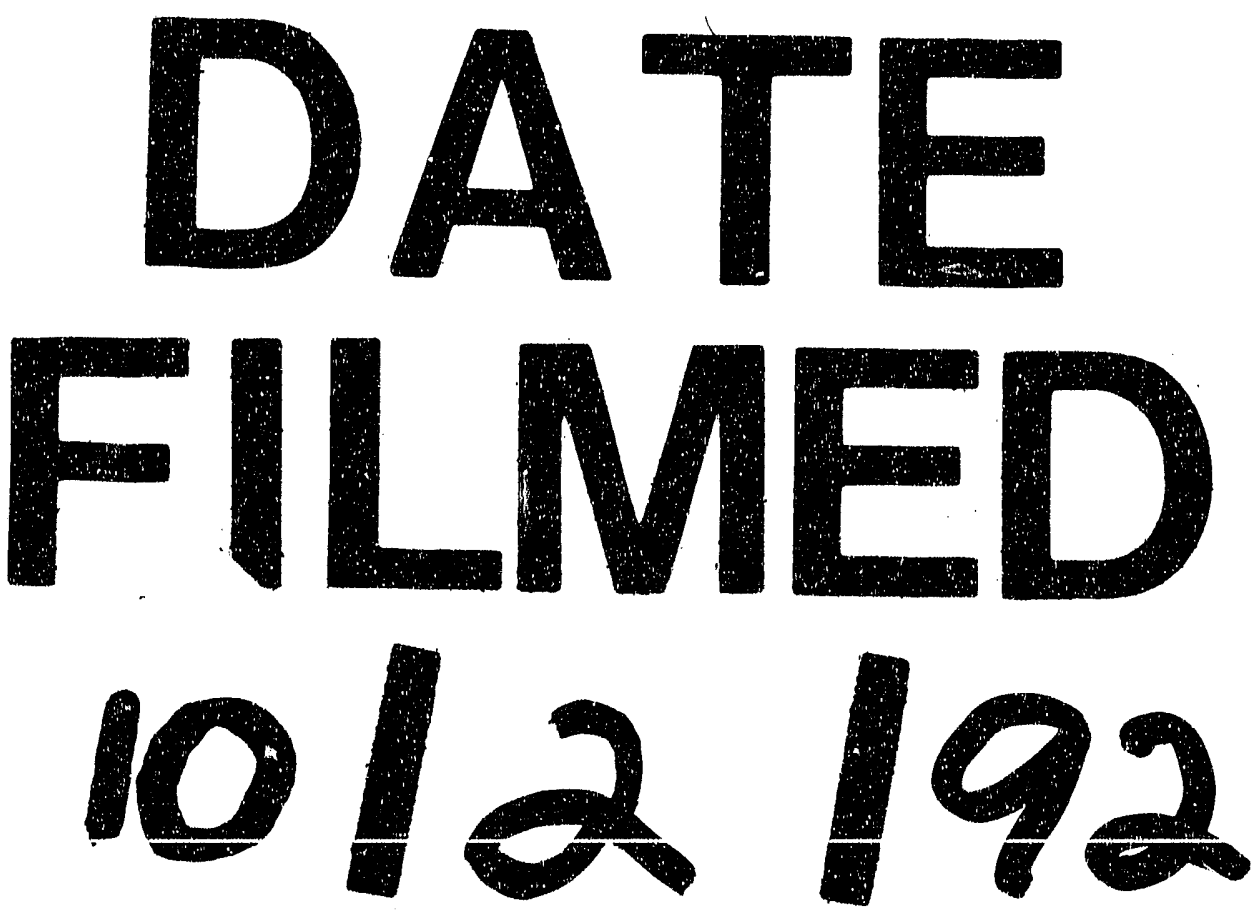


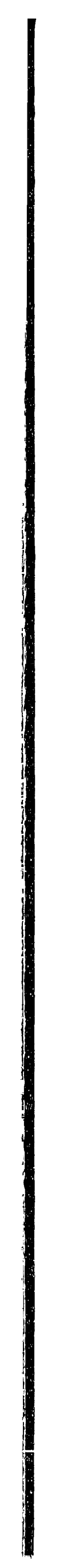

